\title{
SOLUÇÃO NUMÉRICA PARALELA DE EQUAÇÕES ELÍPTICAS DE SEGUNDA ORDEM
}

\author{
Lauro César Galvão
}

Orientador: Prof. Dr. José Alberto Cuminato

Dissertação apresentada ao Instituto de Ciências Matemáticas de São Carlos-USP, como parte dos requisitos necessários para obtenção do título de Mestre em Ciências-Área "Ciências de Computação e Matemática Computacional".

USP - São Carlos

Fevereiro - 1998 


\section{Agradecimentos $^{1}$}

O autor deseja expressar seus sinceros agradecimentos ao Prof. Dr. José Alberto Cuminato pela orientação desse trabalho e assistência fornecida na preparação deste manuscrito. Aos professores Antônio Castelo Filho e Armando Oliveira Fortuna cujas familiaridades com as necessidades dentro do laboratório foram bastante úteis durante a fase de implementação desta tarefa. Aos membros do conselho do ICMSC por suas valiosas informações. As secretárias Beth, Laura, Marília e Andressa pela atenção e aos funcionários de maneira geral. Aos meus amigos do CEFET-PR, departamento de matemática, os quais, me apoiaram e possibilitaram a saída para o mestrado. Aos amigos que conheci em São Carlos, em especial a Luciane Grossi, presente em muitas madrugadas de trabalho e sempre me incentivando nos momentos difíceis; também ao Sadao Massago pela disponibilidade e companheirismo em todos os momentos. Aos amigos José João, Ademir e Altevir pela torcida permanente. A minha amiga Cynthia, que mesmo distante, sempre me deu forças. Aos meus pais, José e Astézia que com muito carinho, me apoiam em tudo que faço. Amo vocês. As minhas irmãs, Terezinha, Lurdinha e Helena. Aos meus cunhados, Paulo, Emerson e Bruno. Aos meus sobrinhos(a), Mariana, Guilherme e Ivan. Aos familiares que citei, obrigado por me acolherem em cada volta a Curitiba. Em especial, ao meu amor, Luciana Taner, pelo apoio, incentivo e principalmente compreensão. Finalmente, agradeço a todos que direta ou indiretamente me ajudaram na execução deste trabalho.

\footnotetext{
'Este trabalho teve suporte financeiro da CAPES.
} 


\begin{abstract}
The aim of this work is to present a parallel algorithm implementing the conjugate gradient method with factorization preconditioning for solving second order elliptic equations in a rectangular domain. The main approach consists of replacing the partial derivatives with finite differences to obtain a sparse linear system. The domain is then decomposed according to the number of available processors, and each one carries out its work on a specific subdomain. The chosen decomposition minimizes the communication traffic between the processors, substantially reducing the solution time.
\end{abstract}




\section{Resumo}

O objetivo deste trabalho é apresentar um algoritmo paralelo que implementa o método do gradiente conjugado com pré condicionamento para resolver equações elípticas de segunda ordem em um domínio retangular. A principal aproximação consiste em substituir as derivadas parciais por diferenças finitas para obter um sistema linear esparso. O domínio é então decomposto de acordo com o número de processadores, e cada um executa o trabalho em um subdomínio específico. A decomposição escolhida minimiza a comunicação entre os processadores, reduzindo substancialmente o tempo de solução. 


\section{Índice Analítico}

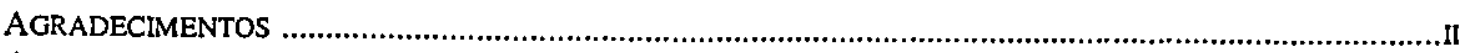

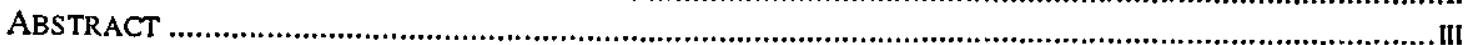

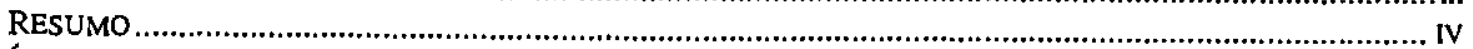

ÍNDICE ANALITICO

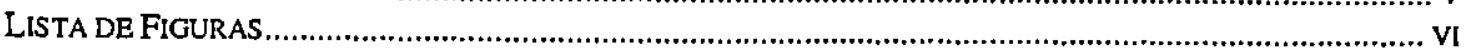

1. INTRODUÇÃ

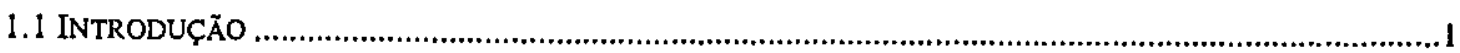

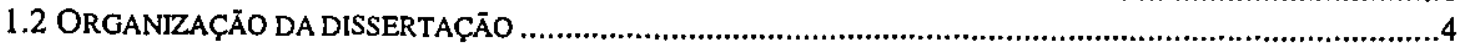

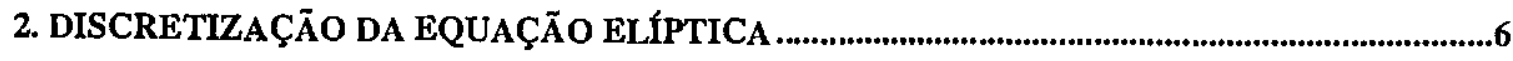

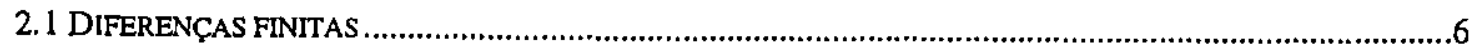

2.2 DISCRETIZAÇÃO DA EQUAÇÃO ELÍPTICA PARA DIMENSĀO DOIS ....................................................

3. ALGORITMO PARA A SOLUÇĀO EM PROCESSAMENTO PARALELO...............................11

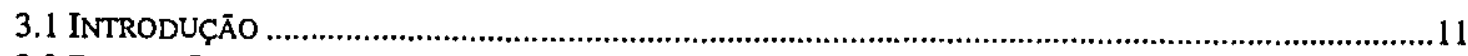

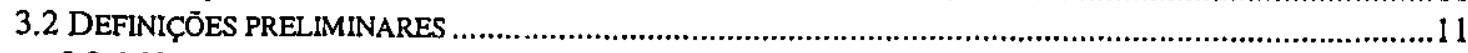

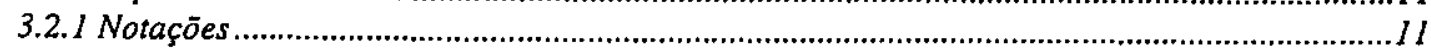

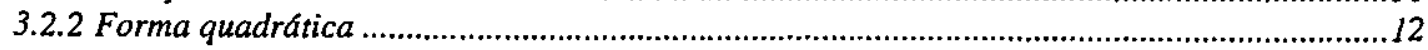

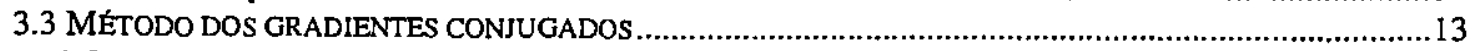

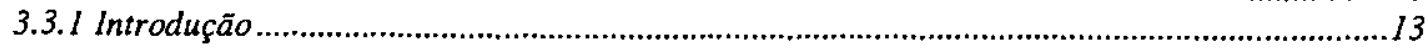

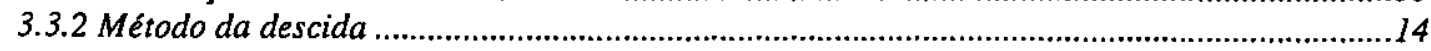

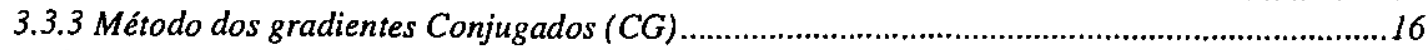

3.4 MÉTODO DOS GRADIENTES CONJUGADOS COM PRÉ CONDICIONAMENTO .........................................18

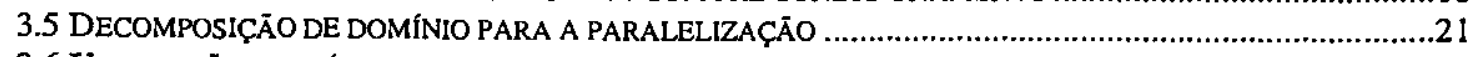

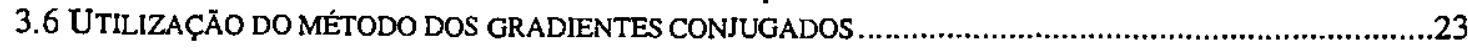

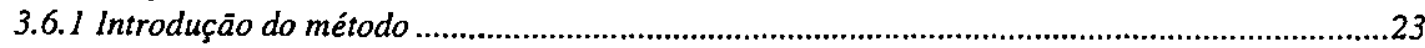

3.6.2 Definiçōes utilizadas no método...................................................................................24

3.6.3 Adaptações das definições para o método ...............................................................................27

3.6.4 Método dos gradientes conjugados com pré condicionamento adaptado à nova divisão de

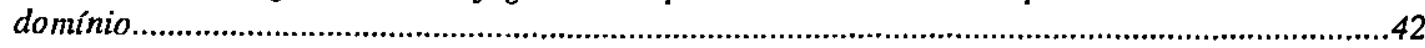

4. PIM 1.1 (MÉTODOS ITERATIVOS PARALELOS PARA SISTEMAS DE EQUAÇŌES

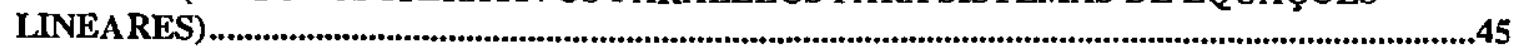

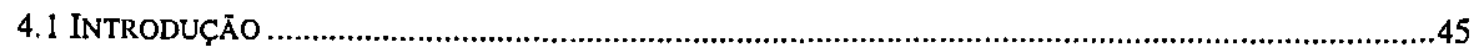

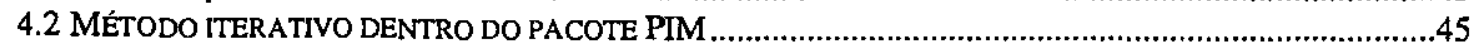

5. EXEMPLOS E COMPARAÇÕES

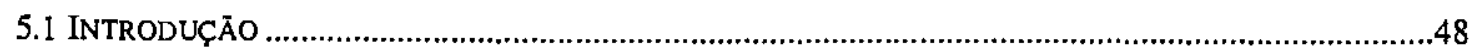

5.2 EXEMPLOS SEQÜENCIAL E PARA VÁRIOS PROCESSADORES ............................................................48

5.2.1 Comparação do desempenho em malhas de tamanhos variados ............................................50

5.2.2 Avaliação do tipo de divisão sobre a malha (bidimensional e unidimensional) ........................53

5.3 COMPARAÇĀO COM O PIM EM UMA MALHA DE 129×129 NÓS .......................................................55

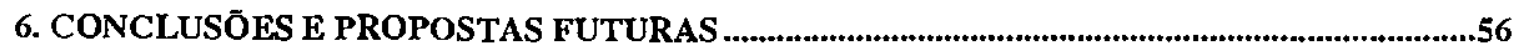

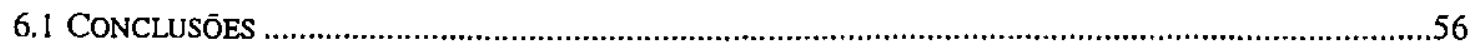

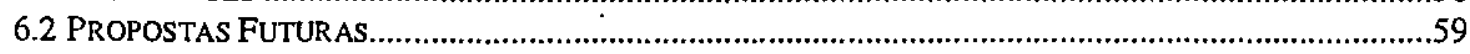

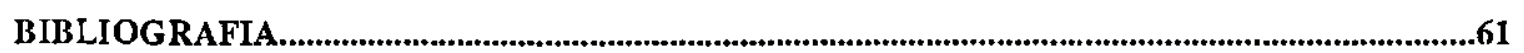




\section{Lista de Figuras}

FIG.1.1 DIVISÃO DO DOMÍNIO $\Omega$ COM $7 \times 5$ NÓS PARA 6 PROCESSADORES.....................................................

FIG.2.1 REPRESENTAÇĀO GERAL DE UM NÓ DE POSIÇÃO $\left(x_{1}, y_{1}\right)$ EM UMA MALHA ........................................8

FIG.3.1 GRAFICO E CURVAS DE NIVEIS DE UMA FUNÇĀO QUADRÁTICA ...................................................12

FIG.3.2 MATRIZ A E UM PRÉ CONDICIONADOR B ${ }^{-1}$ PARA O MÉTODO CG .................................................19

FIG.3.3 DOMINIO $\Omega$ DIVIDIDO EM NOVE SUBDOMÍNIOS PARA NOVE PROCESS ADORES ................................22

FIG.3.4 DOMÍNIO $\Omega$ COM NOVE NÓS PARA QUATRO PROCESS ADORES .....................................................24

FIG.3.5 ORDENAÇĀO DOS NÓS CONFORME A SEQUÊNCIA DOS PROCESSADORES............................................2...2

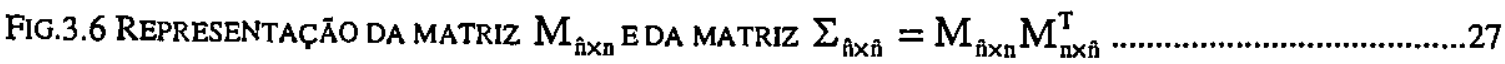

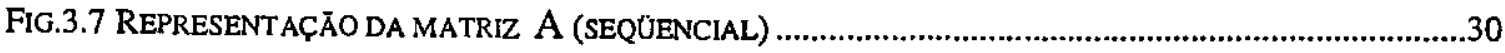

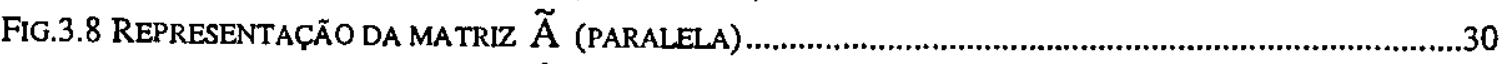

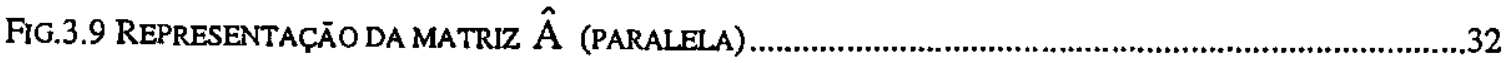

FIG.3.10 REPRESENTAÇĀO DO PRÉ CONDICIONADOR $\hat{B}^{(1)}$ DA MATRIZ $\hat{A}$. ............................................35

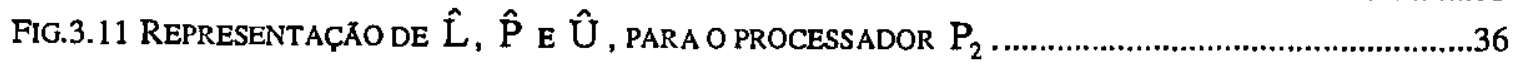

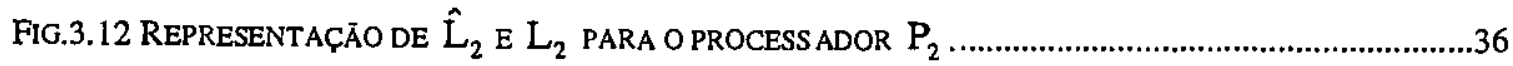

FIG.3.13 REPRESENTAÇÃo de $\mathrm{M}_{2}$ E $\mathrm{L}_{2}$, DE FORMA ORDENADA, PARA O PROCESSADOR $\mathrm{P}_{2} \ldots \ldots . . . . . . . . . .37$

FIG.3.14 DOMÍNIO $\Omega$ COM NOVENTA NÓS PARA NOVE PROCESSADORES E AS FRONTEIRAS 'F' E 'L' ..............41

FIG.4.1 DIAGRAMA PARA SELECIONAR UM MÉTODO ITERATIVO NO PIM ......................................................46

FIG.5.1 DOMÍNIO $\Omega$ COM A REPRESENTAÇÃO DAS FUNÇŌES F DE FRONTEIRA COM $\mathrm{i}=1, \ldots, 4 \ldots \ldots \ldots . . . . . . . .49$

FIG.5.2 GRÁFICO EM 3 DIMENSOES, RELATIVO AOS RESULTADOS DO EXEMPLO APLICADO AO DOMINIO $\Omega . .50$

FIG.5.3 TEMPO DE PROCESSAMENTO DE 1 A 24 PROCESSADORES (MALHA 100×100) .................................51

FIG.5.4 TEMPO DE PROCESSAMENTO DE 1 A 24 PROCESSADORES (MALHA 200×200) …..............................51

FIG.5.5 TEMPO DE PROCESSAMENTO DE 4 A 24 PROCESSADORES (MALHA 400×400) ...................................51

FIG.5.6 TEMPO DE PROCESSAMENTO DE 16 A 24 PROCESSADORES (MALHA 800×790) ...............................52

FIG.5.7 TEMPO DE PROCESSAMENTO DE 20 A 24 PROCESS ADORES (MALHA 890×890) ................................52

FIG.5.8 DESEMPENHO PARA UMA MALHA 100×100, DISTRIBUÍDA PARA 16 PROCESSADORES........................53

FIG.5.9 DESEMPENHO PARA UMA MALHA 700×800, DISTRIBUIDA PARA 16 PROCESSADORES......................54

FIG.5.10 DESEMPENHO PARA UMA MALHA 950×950, DISTRIBUIDA PARA 24 PROCESSADORES...................54

FIG.5.11 TEMPO DE PROCESSAMENTO DE 1 A 24 PROCESSADORES (PIM: 2 A 8 PROC.) (MALHA 129×129) .55

FIG.6.1 CRESCIMENTO DA ORDEM DA MATRIZ NUMA MALHA DE 200×200 ...........................................57

FIG.6.2 FRONTEIRAS EM UMA MALHA, COM DIVISÕES UNI E BIDIMENSIONAIS, PARA NOVE PROCESSADORES.58

FIG.6.3 DOMÍNIO IRREGULAR DIVIDIDO PARA QUATRO PROCESSADORES. .60 


\section{Introdução}

\subsection{Introdução}

Embora as origens da computação paralela tenham surgido antes do final do século, foi somente em 1970 que os computadores paralelos vetoriais tornaram-se disponíveis para a comunidade científica. A primeira dessas máquinas - com 64 processadores Illiac IV, o computador vetorial construído pela Texas Instruments, Control Data Corporation e a CRAY Research Corporation - teve impacto um tanto limitado. Foram colocadas poucas unidades à disposição e direcionadas, geralmente, para os laboratórios governamentais dos Estados Unidos. Porém, uma gota tornou-se uma inundação. Atualmente, eles são muito mais potentes e estão bem difundidos, não somente em laboratórios governamentais mas também nas universidades e industrias. $\mathrm{O}$ principal incentivo à utilização do processamento paralelo é o maior desempenho em aplicações que demandam grande trabalho computacional. As equações diferenciais parciais (EDPs) são aplicaçōes responsáveis por grande avanço no paralelismo, pois são resoluçōes desse tipo que geralmente tomam muito tempo computacional, quando resolvidas em processamento seqüencial. As equações elípticas são EDPs muito utilizadas no meio científico, por isso, é importante pesquisar meios de se obter resoluções eficientes e rápidas dessas equaçōes.

Em aplicações científicas e tecnológicas pode-se citar como exemplos, vários problemas em física, engenharia e ciências aplicadas, tais como, difusão de calor, escoamento de fluídos, que requerem resolução de equações elípticas. Estas equaçōes podern ser representadas da seguinte forma: 


$$
-\left[\frac{\partial}{\partial x} A(x, y) \frac{\partial}{\partial x} U(x, y)+\frac{\partial}{\partial y} B(x, y) \frac{\partial}{\partial y} U(x, y)\right]+C(x, y) U(x, y)=F(x, y)
$$

Existem em geral muitas dificuldades em obter-se uma solução analítica para o problema elíptico acima. Essas dificuldades estão associadas à variedade de condiçōes de fronteira e geometria do domínio que podem ser associadas ao problema elíptico. Daí a necessidade de uma solução numérica. Para a solução numérica da equação (1.1) existem basicamente três técnicas que são diferenças finitas, elementos finitos e volumes finitos. Todas essas técnicas baseiam-se na transformação do problema contínuo em um problema discreto através da substituição das derivadas parciais por aproximações de caráter finito. Nesse processo a tarefa de encontrar uma função que satisfaça a equação e condições de fronteira, reduz-se à solução de um sistema linear, cujas incógnitas são aproximações para valores pontuais da solução contínua. Um método muito utilizado atualmente, e que será o abordado neste trabalho, é o método das diferenças finitas. Nesse método, as derivadas parciais são escritas em função dos valores de pontos discretos na região (domínio) onde se deseja encontrar a solução numérica da equação diferencial parcial. A cada um destes pontos discretos será dado o nome de nó.

O processo de discretização por diferenças finitas gera um sistema linear com características próprias, a saber: um número muito grande de equações e um sistema altamente esparso, isto é, a grande maioria dos elementos da matriz de coeficientes são nulos. Para a resolução desse problema, pode-se utilizar métodos diretos ou indiretos. Os métodos diretos têm a dificuldade de requerer grande espaço para armazenamento, já, os indiretos, requerem menos memória mas podem ter problemas de convergência, por se tratar de métodos iterativos, porém, estes métodos têm maior facilidade para a implementação em paralelo. Os métodos iterativos resolvem sistemas resultantes de discretização de grande porte. Dos métodos iterativos existentes, será utilizado aqui, o método dos gradientes conjugados. 
O método dos gradientes conjugados (CG) pode ser extremamente ineficiente quanto à velocidade de convergência. Uma solução para esse problema é a utilização da técnica de pré condicionamento. Esta técnica permite a redução do número de iteraçōes, mas aumenta o esforço computacional em cada iteração. Mesmo com um número reduzido de iterações, pelo pré condicionamento no método $\mathrm{CG}$, o tempo de execução para o algoritmo em um único processador pode ainda ser grande. Existe também o problema de limite de capacidade de memória em um processador, pois, a resolução do sistema resultante de uma discretização muito grande pode ficar inviável, se limitada a resolução em um único processador, porém, é possível dividir essa tarefa para quantos processadores forem necessários ou disponíveis, de forma a viabilizar a resolução do problema associado em um menor tempo de execução.

Para essa divisão de trabalho, duas filosofias de paralelização podem ser seguidas, qualquer delas implementam métodos que derivam dos algoritmos sequienciais: uma tenta minimizar os efeitos da comunicação, dividindo cargas entre os processadores de forma balanceada, ou seja, de forma que exista uma distribuição das tarefas com tempos de execução próximos; a outra se preocupa em diminuir o número total de operações aritméticas dentro de cada processador. Atualmente, a maioria das técnicas de solução de sistemas lineares dão resultados satisfatórios no caso de algoritmos paralelo com um número moderado de processadores. A solução que será apresentada aqui parece mais adaptada para arquiteturas paralelas que utilizam um número maior de processadores.

Nesta tese, a divisão de trabalho citada anteriormente, em um domínio retangular, será através da técnica de decomposição de domínios ordenados (DDO), o que consiste em dividir o domínio horizontalmente e verticalmente, de forma a se obter subdomínios conforme o número de processadores disponíveis, fazendo com que cada subdomínio corresponda a um único processador. Os subdomínios serão enumerados de tal forma a se obter uma coincidência na ordem da enumeração nas fronteiras para os processadores (Fig.1.1). Para a visualização da enumeração citada, será considerado um domínio $\Omega$ retangular com $7 \times 5$ nós num total de 35 , divididos horizontalmente por duas 
linhas e verticalmente por uma, obtendo-se, dessa maneira, 6 subdomínios com nove nós cada. Cada processador será identificado considerando-se seu posicionamento $\mathrm{P}(\mathrm{i}, \mathrm{j})$, com $\mathrm{i}$ tendo variação na horizontal e j na vertical.

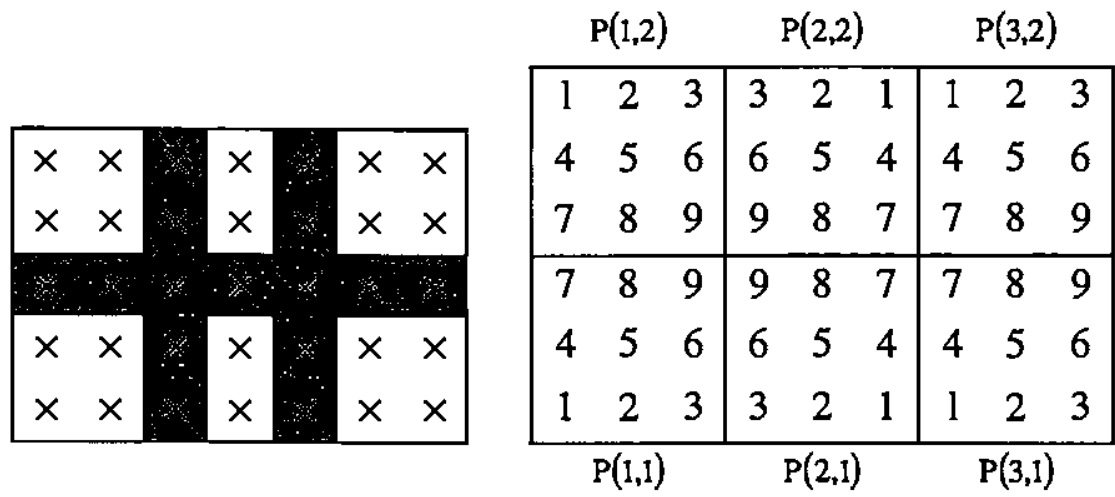

Fig.1.1 Divisão do domínio $\Omega$ com $7 \times 5$ nós para 6 processadores

A técnica DDO facilita a comunicação dos nós localizados nas fronteiras, chamados nós distribuídos. Considerando-se a divisão do domínio $\Omega$ para um número elevado de processadores, é preciso observar que os nós distribuídos iniciais coincidem entre os processadores vizinhos, assim como os nós distribuídos finais e intermediários. Desta maneira, a comunicação entre eles é natural, já que eles têm a mesma representação em todos os processadores.

Qualquer decomposição causa algum prejuízo na convergência, devido ao aumento do número de processadores e das comunicações conseqüentes. Isso não chega a prejudicar a convergência global do método, pois o prejuízo é limitado, comparado ao ganho da paralelização.

\subsection{Organização da dissertação}

Descrição breve dos assuntos em cada capítulo: 
- No Capítulo 1 é apresentada uma introdução geral abordando: o problema a ser resolvido; alguns métodos de discretização e o método a ser utilizado na resolução da equação elíptica; justificativa da utilização da técnica de decomposição de domínios ordenados para a resolução da equação em processamento paralelo.

- No Capítulo 2 é descrita a técnica de discretização por diferenças finitas da equação elíptica apresentada na introdução.

- No Capítulo 3 é descrito um algoritmo para a implementação paralela do método dos gradientes conjugados. A implementação paralela será facilitada por uma nova proposta de enumeração do domínio, citada no começo desse capítulo 1, da qual resulta um sistema linear $\mathrm{Ax}=\mathrm{b}$.

- No Capítulo 4 é dada uma breve apresentação do pacote PIM 1.1 (Métodos Iterativos Paralelos para Sistemas de Equações Lineares), o qual com algumas adaptaçōes, será utilizado na resolução do sistema linear para comparação com os resultados desta dissertação.

- No Capítulo 5 são apresentados alguns exemplos, considerando-se uma malha gerada pela divisão de um domínio retangular. Existem dois testes principais, realizados neste capítulo. $O$ primeiro teste consiste em avaliar o desempenho com execução do programa em seqüencial e para números variados de processadores. $\mathrm{O}$ segundo consiste em avaliar o desempenho do algoritmo aplicado sobre uma malha dividida em duas dimensões, que é a proposta de divisão desse trabalho, em comparação com a divisão unidimensional

- No Capítulo 6 é feito um análise dos resultados do trabalho e também é feito uma proposta para trabalhos futuros. 


\section{Discretização da Equação Elíptica}

\subsection{Diferenças finitas}

Para a discretização da equação em questão pelo método de diferenças finitas são necessários alguns conceitos básicos, os quais serão apresentados abaixo.

Tomando-se a função real $\alpha(\mathrm{x})$ e fazendo-se a expansão pela fórmula de Taylor, têm-se:

T01

$$
\alpha\left(\mathrm{x}+\Delta_{\mathrm{x}}\right)=\alpha(\mathrm{x})+\Delta_{\mathrm{x}} \alpha^{\prime}(\mathrm{x})+\frac{1}{2} \Delta_{\mathrm{x}}^{2} \alpha^{\prime \prime}(\mathrm{x})+\frac{1}{6} \Delta_{\mathrm{x}}^{3} \alpha^{(3)}(\mathrm{x})+\ldots
$$

T02

$$
\alpha\left(\mathrm{x}-\Delta_{\mathrm{x}}\right)=\alpha(\mathrm{x})-\Delta_{\mathrm{x}} \alpha^{\prime}(\mathrm{x})+\frac{1}{2} \Delta_{\mathrm{x}}^{2} \alpha^{\prime \prime}(\mathrm{x})-\frac{1}{6} \Delta_{\mathrm{x}}^{3} \alpha^{(3)}(\mathrm{x})+\ldots
$$

Efetuando-se a soma entre T01 e T02, é obtida a fórmula de diferenças centradas de segunda ordem, que é uma aproximação para a segunda derivada.

$$
\alpha^{\prime \prime}(\mathrm{x}) \equiv \frac{1}{\Delta_{\mathrm{x}}^{2}}\left[\alpha\left(\mathrm{x}+\Delta_{\mathrm{x}}\right)-2 \alpha(\mathrm{x})+\alpha\left(\mathrm{x}-\Delta_{\mathrm{x}}\right)\right]
$$

Efetuando-se a diferença entre T01 e T02, é obtida a fórmula de diferenças centradas de segunda ordem, que é uma aproximação para a primeira derivada.

$$
\alpha^{\prime}(\mathrm{x}) \cong \frac{1}{2 \Delta_{\mathrm{x}}}\left[\alpha\left(\mathrm{x}+\Delta_{\mathrm{x}}\right)-\alpha\left(\mathrm{x}-\Delta_{\mathrm{x}}\right)\right]
$$


Truncando-se a expansão T01 no termo de primeira ordem, obtém-se a fórmula de diferenças avançadas de primeira ordem, que representa uma aproximação para a primeira derivada:

$$
\alpha^{\prime}(\mathrm{x}) \cong \frac{1}{\Delta_{\mathrm{x}}}\left[\alpha\left(\mathrm{x}+\Delta_{\mathrm{x}}\right)-\alpha(\mathrm{x})\right]
$$

Truncando-se a expansão T02 no termo de primeira ordem, obtém-se a fórmula de diferenças atrasadas de primeira ordem, que representa outra aproximação para a primeira derivada:

$$
\alpha^{\prime}(\mathrm{x}) \cong \frac{1}{\Delta_{\mathrm{x}}}\left[\alpha(\mathrm{x})-\alpha\left(\mathrm{x}-\Delta_{\mathrm{x}}\right)\right]
$$

\subsection{Discretização da equação elíptica para dimensão dois}

A equação (2.2) acima pode ser adaptada para dimensão dois, da seguinte maneira:

- Para o eixo $\mathrm{x}$ :

$$
\frac{\partial}{\partial x} \alpha(x, y) \cong \frac{1}{2 \Delta_{x}}\left[\alpha\left(x+\Delta_{x}, y\right)-\alpha\left(x-\Delta_{x}, y\right)\right]
$$

- Para o eixo y:

$$
\frac{\partial}{\partial x} \alpha(x, y) \cong \frac{1}{2 \Delta_{y}}\left[\alpha\left(x, y+\Delta_{y}\right)-\alpha\left(x, y-\Delta_{y}\right)\right]
$$

Empregando uma malha para o domínio $\Omega$, temos a representação de $r \times s$ nós (Fig.2.1) onde cada nó têm sua representação através das coordenadas $\left(x_{i}, y_{j}\right)$ que, para simplificar a notação, será considerada coordenadas ij. A distância entre cada nó é constante. O espaçamento no eixo $x$ será denotado por $h$, i.é., $h=x_{i}-x_{i-1}$ e no eixo y 
será denotado por $\mathrm{k}$, i.é, $\mathrm{k}=\mathrm{y}_{\mathrm{j}}-\mathrm{y}_{\mathrm{j}-1}$. Para a discretização será usado um espaçamento que é a metade da distância entre um nó e outro. No eixo $x$, define-se: $\Delta_{x}=\frac{h}{2}$; no eixo y, define-se: $\Delta_{y}=\frac{k}{2}$.
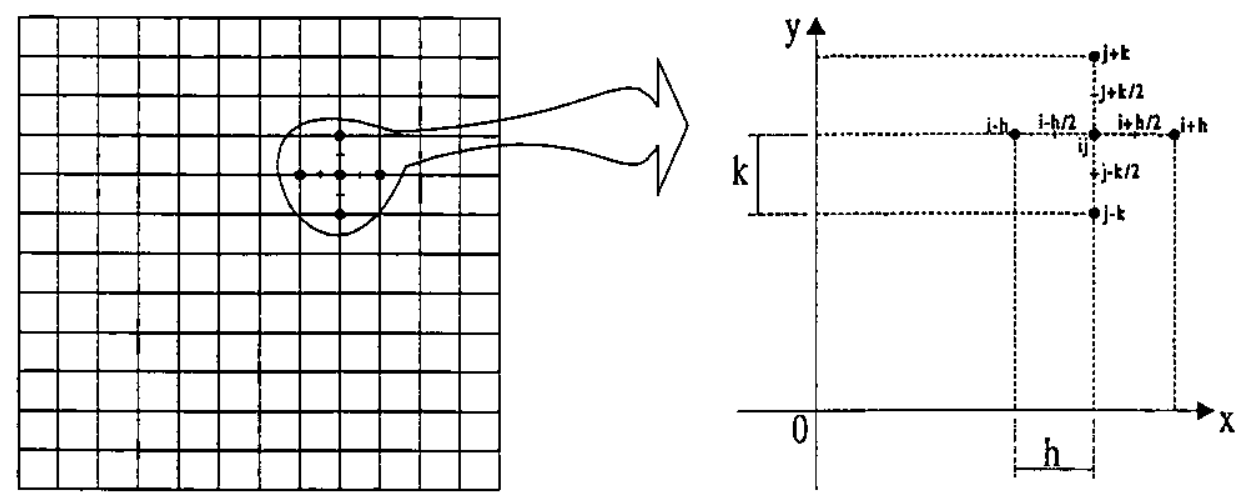

Fig.2.1 Representação geral de um nó de posição $\left(x_{1}, y_{j}\right)$ em uma malha

Para um nó de coordenadas $\left(\mathrm{x}_{\mathrm{i}}, \mathrm{y}_{\mathrm{j}}\right)$ (Fig.2.1), pode-se discretizar a equação (1.1) da seguinte forma:

$$
\underbrace{-\left[\frac{\partial}{\partial x} A\left(x_{i}, y_{j}\right) \frac{\partial}{\partial x} U\left(x_{i}, y_{j}\right)+\frac{\partial}{\partial y} B\left(x_{i}, y_{j}\right) \frac{\partial}{\partial y} U\left(x_{i}, y_{j}\right)\right]}_{\text {PARTE.I }}+\underbrace{C\left(x_{i}, y_{j}\right) U\left(x_{i}, y_{j}\right)=F\left(x_{i}, y_{j}\right)}_{\text {PARTE. } 2}
$$

Para simplificar a notação, será feito primeiramente a PARTE.1, depois a PARTE.2, fazendo-se a junção no final. Sendo $A\left(x_{i}, y_{j}\right), B\left(x_{i}, y_{j}\right), C\left(x_{i}, y_{j}\right)$, e $F\left(x_{i}, y_{j}\right)$ funções conhecidas, é necessário então determinar uma aproximação para $U\left(x_{i}, y_{j}\right)$, usando diferenças centradas de segunda ordem com $\Delta_{x}=\frac{h}{2}$ e $\Delta_{y}=\frac{k}{2}$.

- PARTE.I:

Aplicando-se uma vez diferenças centradas de segunda ordem, obtém-se: 


$$
\begin{aligned}
& -\frac{1}{h}\left[A\left(x_{i}+\frac{h}{2}, y_{j}\right) \frac{\partial}{\partial x} U\left(x_{i}+\frac{h}{2}, y_{j}\right)-A\left(x_{i}-\frac{h}{2}, y_{j}\right) \frac{\partial}{\partial x} U\left(x_{i}-\frac{h}{2}, y_{j}\right)\right] \\
& -\frac{1}{k}\left[B\left(x_{i}, y_{j}+\frac{k}{2}\right) \frac{\partial}{\partial x} U\left(x_{i}, y_{j}+\frac{k}{2}\right)-B\left(x_{i}, y_{j}-\frac{k}{2}\right) \frac{\partial}{\partial x} U\left(x_{i}, y_{j}-\frac{k}{2}\right)\right]
\end{aligned}
$$

Aplicando-se novamente diferenças centradas de segunda ordem, obtém-se:

$$
\begin{aligned}
& -\frac{1}{h^{2}}\left\{A\left(x_{i}+\frac{h}{2}, y_{j}\right)\left[U\left(x_{i}+h, y_{j}\right)-U\left(x_{i}, y_{j}\right)\right]-A\left(x_{i}-\frac{h}{2}, y_{j}\right)\left[U\left(x_{i}, y_{j}\right)-U\left(x_{i}-h, y_{j}\right)\right]\right\} \\
& -\frac{1}{k^{2}}\left\{B\left(x_{i}, y_{j}+\frac{k}{2}\right)\left[U\left(x_{i}, y_{j}+k\right)-U\left(x_{i}, y_{j}\right)\right]-B\left(x_{i}, y_{j}-\frac{k}{2}\right)\left[U\left(x_{i}, y_{j}\right)-U\left(x_{i}, y_{j}-k\right)\right]\right\}
\end{aligned}
$$

Agrupando-se os termos semelhantes em U, obtém-se:

$$
\begin{aligned}
& -\frac{1}{k^{2}} B\left(x_{i}, y_{j}-\frac{k}{2}\right) U\left(x_{i}, y_{j}-k\right)-\frac{1}{h^{2}} A\left(x_{i}-\frac{h}{2}, y_{j}\right) U\left(x_{i}-h, y_{j}\right) \\
& +\left\{\frac{1}{h^{2}}\left[A\left(x_{i}+\frac{h}{2}, y_{j}\right)+A\left(x_{i}-\frac{h}{2}, y_{j}\right)\right]+\frac{1}{k^{2}}\left[B\left(x_{i}, y_{j}+\frac{k}{2}\right)+B\left(x_{i}, y_{j}-\frac{k}{2}\right)\right]\right\} U\left(x_{i}, y_{j}\right) \\
& -\frac{l}{h^{2}} A\left(x_{i}+\frac{h}{2}, y_{j}\right) U\left(x_{i}+h, y_{j}\right)-\frac{1}{k^{2}} B\left(x_{i}, y_{j}+\frac{k}{2}\right) U\left(x_{i}, y_{j}+k\right)
\end{aligned}
$$

Agrupando-se a PARTE.1 com a PARTE.2, obtém-se a discretização de cinco pontos,

$$
\begin{aligned}
& A 1 \times U\left(x_{i}, y_{j}-k\right)+A 2 \times U\left(x_{i}-h, y_{j}\right)+A 3 \times U\left(x_{i}, y_{j}\right) \\
& +A 4 \times U\left(x_{i}+h, y_{j}\right)+A 5 \times U\left(x_{i}, y_{j}+k\right)=F\left(x_{i}, y_{j}\right)
\end{aligned}
$$

onde

$$
\begin{aligned}
& A 1=-B\left(x_{i}, y_{j}-\frac{k}{2}\right) / k^{2} \\
& A 2=-A\left(x_{i}-\frac{h}{2}, y_{j}\right) / h^{2} \\
& A 3=\left[A\left(x_{i}+\frac{h}{2}, y_{j}\right)+A\left(x_{i}-\frac{h}{2}, y_{j}\right)\right] / h^{2}+\left[B\left(x_{i}, y_{j}+\frac{k}{2}\right)+B\left(x_{i}, y_{j}-\frac{k}{2}\right)\right] / k^{2}+C\left(x_{i}, y_{j}\right) \\
& A 4=-A\left(x_{i}+\frac{h}{2}, y_{j}\right) / h^{2}
\end{aligned}
$$


$A 5=-B\left(x_{i}, y_{j}+\frac{k}{2}\right) / k^{2}$

ou seja, $A 1, \ldots, A 5$ são coeficientes da variável $U$, sendo que a enumeração dos cinco pontos na malha, respeita a ordenação da esquerda para a direita e de baixo para cimà (Fig.1.2 e Fig.2.1). 


\section{Algoritmo Para a Solução em Processamento Paralelo}

\subsection{Introdução}

O método dos gradientes conjugados (CG), é um método iterativo muito utilizado para resolver sistemas lineares de grande porte resultantes da discretização de equações à derivadas parciais. CG é utilizado para resolver sistemas lineares,

$$
\mathrm{Ax}=\mathrm{b}
$$

onde $A \in R^{\mathrm{n} \times \mathrm{n}}$ é uma matriz simétrica definida positiva, $b \in R^{\mathrm{n}}$ um vetor dado $e$ $\mathrm{x} \in \mathrm{R}^{\mathrm{n}}$ o vetor à ser calculado. Os métodos iterativos como o CG são apropriados para o uso em matrizes esparsas, portanto, ideal para a resolução do sistema resultante da discretização utilizada neste trabalho. Será descrito, neste capítulo, um algoritmo para a implementação paralela do método CG. A implementação paralela será facilitada por uma nova proposta de enumeração do domínio, citada no capítulo 1 , da qual resulta um sistema linear como em (3.1).

\subsection{Definições preliminares}

\subsubsection{Notações}

Com poucas exceções, serão utilizadas letras maiúsculas para denotar matrizes, letras minúsculas para denotar vetores e letras gregas para denotar escalares. 
$\mathrm{O}$ produto interno entre dois vetores é denotado por $\mathrm{x}^{\mathrm{T}} \mathrm{y}$ e representado pela soma escalar $\sum_{\mathrm{i}=1}^{\mathrm{n}} \mathrm{x}_{\mathrm{i}} \mathrm{y}_{\mathrm{i}}$. Como a matriz A é definida positiva, para todo vetor $\mathrm{x}$ diferente de zero têm-se, $x^{T} A x>0$. Considerando-se duas matrizes de ordem $n$ têm-se, $(A B)^{T}=B^{T} A^{T}$ e $(A B)^{-1}=B^{-1} A^{-1}$, se $A$ e $B$ forem inversíveis.

\subsubsection{Forma quadrática}

A forma quadrática derivada de uma matriz A definida positiva é definida por:

$$
f(x)=\frac{1}{2} x^{T} A x-b^{T} x+c
$$

A superfície definida por $\mathrm{f}(\mathrm{x})$ é uma superfície parabolóide (Fig.3.1) [14]. As figuras abaixo mostram o gráfico e curvas de níveis de uma função $f(x)$ no caso em que $n=2$.
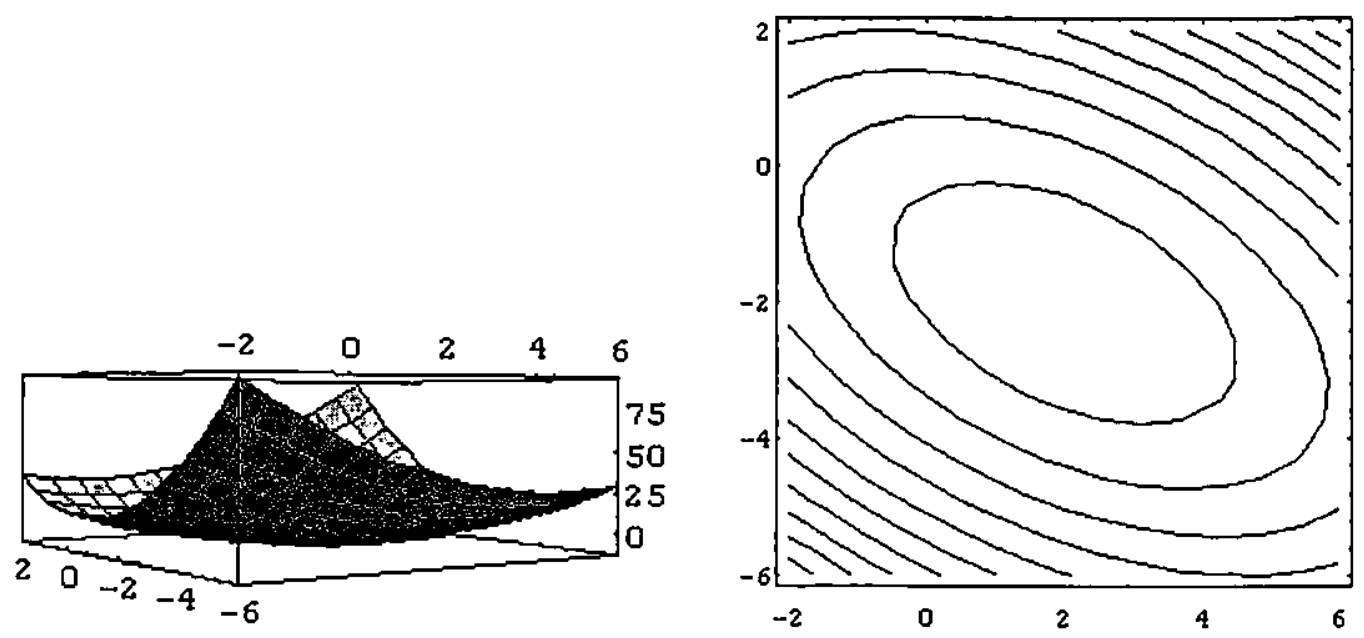

Fig.3.1 Gráfico e curvas de níveis de uma funçāo quadrática

O gradiente da formá quadrática é dado por 


$$
f^{\prime}(x)=\left[\begin{array}{c}
\frac{\partial}{\partial x_{1}} f(x) \\
\frac{\partial}{\partial x_{2}} f(x) \\
\vdots \\
\frac{\partial}{\partial x_{n}} f(x)
\end{array}\right]
$$

e constitui um campo vetorial que, para um ponto $\mathrm{x}$ dado, aponta na direção de maior crescimento da função $f(x)$. O único ponto crítico (gradiente igual a zero) da função é um ponto de mínimo de $f(x)$, ou seja, minimizar $f(x)$ significa calcular o ponto $x$ onde $\mathrm{f}^{\prime}(\mathrm{x})=0$.

Calculando o vetor gradiente de $\mathrm{f}(\mathrm{x})$, obtém-se

$$
f^{\prime}(x)=\frac{1}{2} A^{T} x+\frac{1}{2} A x-b
$$

Se A é uma matriz simétrica, esta equação reduz-se a

$$
f^{\prime}(x)=A x-b
$$

Fazendo-se com que o gradiente seja igual a zero, será obtida a equação (3.1), o sistema linear que se deseja resolver. Portanto, a solução de $\mathrm{Ax}=\mathrm{b}$ é o ponto crítico da função $\mathrm{f}(\mathrm{x})$. Se A é simétrica definida positiva, então esta solução é um mínimo de $\mathrm{f}(\mathrm{x})$, portanto, $A x=b$ pode ser resolvido achando-se um vetor $x$ que minimize $f(x)$.

\subsection{Método dos gradientes conjugados}

\subsubsection{Introdução}

Para a utilização do método dos gradientes conjugados (CG), é necessário que o usuário forneça um ponto inicial arbitrário $x_{(0)}$ e, a partir daí, inicia-se uma marcha em 
direção à parte inferior do parabolóide formado pela equação (3.2). É então gerada uma série de vetores $x_{(1)}, x_{(2)}, \cdots$, à partir de $x_{(0)}$, que seria, em geral, uma seqüuencia infinita e portanto, para efeitos práticos, um membro $x_{(n)}$ dessa seqüência será tomado como aproximação para a solução x. Para gerar a seqüência acima é escolhida uma direção de marcha ao longo da qual a função é minimizada. Essas direções de marcha são determinadas seqüencialmente em cada iteração do método. Na iteração $\mathrm{k}$, avalia-se o gradiente atual e adiciona-se a ele uma combinação linear das direções anteriores, para se obter uma nova direção conjugada ao longo da qual o método prossegue [05].

\subsubsection{Método da descida}

Esse método utiliza a estratégia de escolher a direção de marcha como sendo aquela em que a função $f(x)$ decresça o mais rapidamente possível. Essa direção é a oposta ao gradiente $\mathrm{f}^{\prime}\left(\mathrm{x}_{(\mathrm{i})}\right)$. De (3.5), uma direção é $-\mathrm{f}^{\prime}\left(\mathrm{x}_{(\mathrm{i})}\right)=\mathrm{b}-\mathrm{Ax}(\mathrm{i})$. Definindo agora $e_{(i)}=x_{(i)}-x$ e $r_{(i)}=b-A x_{(i)}$, vem facilmente que $r_{(i)}=-A e_{(i)}$. Portanto, $r_{(i)}=-f^{\prime}\left(x_{(i)}\right)$ é a direção de marcha para a solução $x$. Calculadas as derivadas para a direção de marcha, falta ainda determinar quanto devemos caminhar nessa direção para encontrar o menor valor da função. Deve-se portanto determinar $\alpha$ tal que o novo ponto $x_{(i+1)}=x_{(i)}+\alpha r_{(i)}$ seja um mínimo na direção $r_{(i)}$.

Como $f\left(x_{(i+1)}\right)=\frac{1}{2}\left(x_{(i)}+\alpha r_{(i)}\right)^{T} A\left(x_{(i)}+\alpha r_{(i)}\right)-\left(x_{(i)}+\alpha r_{(i)}\right)^{T} b$, o valor de $\alpha$ que minimiza $f$ na direção $r_{(i)}$ é obtido quando a derivada direcional $\frac{\partial}{\partial \alpha} f\left(x_{(i+1)}\right)$ é igual a zero. Diferenciando-se então $f\left(x_{(i+1)}\right)$ em relação a $\alpha$, obtém-se, $\frac{\partial}{\partial \alpha} f\left(x_{(i+1)}\right)=r_{(i)}{ }^{\top} A r_{(i)} \alpha-r_{(i)}{ }^{\top} r_{(i)}$. Impondo $\frac{\partial}{\partial \alpha} f\left(x_{(i+1)}\right)=0$, é encontrado o valor de $\alpha$ que satisfaz as condições de mínimo local. Assim, $0=r_{(i)}{ }^{T} A r_{(i)} \alpha-r_{(i)}{ }^{T} r_{(i)}$ de onde vem: 


$$
\alpha=\frac{r_{(i)}{ }^{\top} r_{(i)}}{r_{(i)}{ }^{\top}{ }^{T} r_{(i)}}
$$

Condensando as fórmulas obtidas para o escalar $\alpha$ e a direção de marcha $\mathbf{r}_{(\mathrm{i})}$, juntamente com a repetição desses passos para várias iterações, pode-se escrever o seguinte algoritmo para minimização da função $f$, ou equivalentemente para resolver o sistema linear $\mathrm{Ax}=\mathrm{b}$ [01]. A partir de agora, o símbolo ' $\Leftrightarrow$ ' significa que o escalar ou vetor a esquerda recebe o valor que está à direita, $\mathrm{k}_{\max }$ é o número máximo de iterações, um dos critérios de parada para o método e $\varepsilon$ é o erro tolerado na convergência, outro critério de parada.

$$
\begin{aligned}
& \mathrm{k} \Leftarrow 0 \\
& r \Leftarrow b-A x \\
& \delta_{\text {novo }} \Leftarrow r^{\top} r \\
& \delta_{0} \Leftarrow \delta_{\text {novo }}
\end{aligned}
$$$$
\text { algoritmo (01) }
$$

Enquanto $\mathrm{k}<\mathrm{k}_{\max }$ ou $\delta_{\text {novo }}>\varepsilon^{2} \delta_{0}$ faça

$$
\begin{aligned}
& \mathrm{d} \Leftarrow \mathrm{Ar} \\
& \alpha \Leftarrow \frac{\delta_{\text {novo }}}{\mathrm{d}^{\mathrm{T}} \mathrm{r}} \\
& \mathrm{x} \Leftarrow \mathrm{x}+\alpha \mathrm{r} \\
& \mathrm{r} \Leftarrow \mathrm{b}-\mathrm{Ax} \\
& \delta_{\text {velho }} \Leftarrow \delta_{\text {novo }} \\
& \delta_{\text {novo }} \Leftarrow \mathrm{r}^{\mathrm{T}} \mathrm{r} \\
& \mathrm{k} \Leftarrow \mathrm{k}+1
\end{aligned}
$$

Fim enquanto

A convergência global e a velocidade de convergência do algoritmo (01) são dadas pelo teorema:

Teorema 3.1 Se A é definida positiva, então o algoritmo (01) produz uma sequiência $x_{(k+1)}$, satisfazendo:

$$
f\left(x_{(k+1)}\right)+\frac{1}{2} b^{T} A^{-1} b \leq\left(1-\frac{\lambda_{n}(A)}{\lambda_{1}(A)}\right)\left(f\left(x_{(k)}\right)+\frac{1}{2} b^{T} A^{-1} b\right),
$$


onde $\lambda_{i}(\mathrm{~A})$ são os autovalores de $\mathrm{A}$ ordenados em ordem decrescente.

A demonstração desse resultado pode ser encontrada em Luenberger [10] nas páginas 218-219.

\subsubsection{Método dos gradientes Conjugados (CG)}

De (3.7), pode-se observar que se a razão $\lambda_{n}(\mathrm{~A}) / \lambda_{1}(\mathrm{~A})$ for pequena, a taxa de convergência do algoritmo (01) é ruim, visto que, as curvas de nível da função $\mathrm{f}(\mathrm{x})$ são elipsoides (Fig.3.1) muito alongados e para se encontrar o mínimo, que está localizado no fundo de uma concavidade parabólica com paredes laterais íngremes e fundo relativamente plano, o método da descida oscila e o processo de convergência, para esse mínimo, é lento. Essas oscilações é que fazem o processo de convergência ser lento. Porém, este processo pode ser acelerado se for escolhida uma direção de descida diferente daquela da direção oposta do gradiente. Isso é o que faz o método dos gradientes conjugados [01]. Como foi dito na introdução 3.3.1, na iteração $\mathrm{k}$, avalia-se o gradiente atual e adiciona-se a ele uma combinação linear das direções anteriores, para obter-se uma nova direção conjugada de tal forma que esta seja ortogonal às que a precede. A nova direção $d_{(k)}$ é então ortogonal às direções $d_{(0)}, d_{(1)}, \cdots, d_{(k-1)}[07]$. Segue agora o algoritmo do método CG para resolver o sistema linear $\mathrm{Ax}=\mathrm{b}$.

algoritmo (02)

$$
\begin{aligned}
& \mathrm{k} \Leftarrow 0 \\
& \mathrm{r} \Leftarrow \mathrm{b}-\mathrm{Ax} \\
& \mathrm{d} \Leftarrow \mathrm{r} \\
& \delta_{\text {novo }} \Leftarrow \mathrm{r}^{\mathrm{T}} \mathrm{r} \\
& \delta_{0} \Leftarrow \delta_{\text {novo }} \\
& \text { Enquanto } \mathrm{k}<\mathrm{k}_{\max } \text { e } \delta_{\text {novo }}>\varepsilon^{2} \delta_{0} \text { faça } \\
& \quad \mathrm{t} \Leftarrow \mathrm{Ad} \\
& \quad \alpha \Leftarrow \frac{\delta_{\text {novo }}}{\mathrm{d}^{\mathrm{T}} \mathrm{t}} \\
& \quad \mathrm{x} \Leftarrow \mathrm{x}+\alpha \text { d } \\
& \quad \text { Se k é divisível por } \mathrm{n}
\end{aligned}
$$




$$
\mathrm{r} \Leftarrow \mathrm{b}-\mathrm{Ax}
$$

Caso contrário

$$
\mathrm{r} \Leftarrow \mathrm{r}-\alpha \mathrm{t}
$$

Fim se

$$
\begin{aligned}
& \delta_{\text {velho }} \Leftarrow \delta_{\text {novo }} \\
& \delta_{\text {novo }} \Leftarrow \mathrm{r}^{\mathrm{T}} \mathrm{r} \\
& \beta \Leftarrow \frac{\delta_{\text {novo }}}{\delta_{\text {velho }}} \\
& \mathrm{d} \Leftarrow \mathrm{r}+\beta \mathrm{d} \\
& \mathrm{k} \Leftarrow \mathrm{k}+1
\end{aligned}
$$

Fim enquanto

O algoritmo do método CG produz sempre uma solução se a matriz $A$ for simétrica definida positiva, como já foi dito. No entanto a convergência desse método pode deixar muito a desejar, como mostra o seguinte resultado.

Teorema 3.2 Seja A simétrica definida positiva, então o algoritmo dos gradientes conjugados produz uma seqüência de vetores $\mathrm{x}_{(0)}, \mathrm{x}_{(1)}, \cdots$, com a seguinte propriedade na k-ésima iteração:

$$
\left\|x-x_{(k)}\right\|_{A} \leq 2\left(\frac{\sqrt{\kappa}-1}{\sqrt{\kappa}+1}\right)^{k}\left\|x-x_{(0)}\right\|_{A},
$$

onde $\|\mathrm{m}\|_{\mathrm{A}}=\sqrt{\mathrm{m}^{\mathrm{T}} \mathrm{Am}}$ é a norma de um vetor $\mathrm{m}$ em relação a uma matriz $\mathrm{A} \mathrm{e}$ $\kappa=\lambda_{n}(\mathrm{~A}) / \lambda_{1}(\mathrm{~A})$ é a razão entre o menor e o maior autovalor de $\mathrm{A}$, como já foi apresentado no teorema anterior.

A demonstração desse resultado pode ser encontrada em Luenberger [10] página 248. 


\subsection{Método dos gradientes conjugados com pré condicionamento}

De (3.8) é observado que o método dos gradientes conjugados terá sua convergência tanto mais rápida quanto mais próximo de 1 estiver $\kappa=\lambda_{n}(A) / \lambda_{1}(A)$, de tal forma que se $\kappa=1$ o método converge em uma iteração. Visando melhorar a convergência do método $\mathrm{CG}$, é possível resolver um outro sistema linear $\mathrm{BAx}=\mathrm{Bb}$ de tal forma que $\kappa=\lambda_{n}(\mathrm{BA}) / \lambda_{1}(\mathrm{BA})$ seja mais próximo de 1. Para que isso seja possível, a matriz $B$ têm que ser próxima da inversa da matriz $A$, ou seja, $B \approx A^{-1}$. $O$ método dos gradientes conjugados aplicado ao sistema $(B A) x=(B b)$ vai convergir muito mais rapidamente do que o método aplicado ao sistema $\mathrm{Ax}=\mathrm{b}$. Esta é a base teórica que é conhecida como pré condicionamento.

Existem várias técnicas para a escolha da matriz B. Uma delas chamada "fatorização LPU incompleta" consiste em calcular uma aproximação da forma LPU com L sendo matriz triangular inferior, P matriz diagonal e $\mathrm{U}$ matriz triangular superior de forma que $A \approx L P U$ e toma-se então $B^{-1} \approx L P U$, ou seja, $B \approx U^{-1} P^{-1} L^{-1}$.A matriz A, resultante da discretização por diferenças finitas, é pentadiagonal sendo duas delas agrupadas à diagonal principal e as outras duas espaçadas da principal (Fig.3.2). Esta característica facilita a obtenção do pré condicionador usado nesse trabalho, apenas considerando as três diagonais que estão agrupadas, descartando as duas que estão separadas, obtendo-se assim uma matriz $\mathrm{B}^{-1}$ que é uma aproximação para $\mathrm{A}$.

Para a figura abaixo, considere um domínio $\Omega$ dividido em $4 \times 3$ nós. Obtém-se então a matriz A pelo processo de discretização por diferenças finitas e em conseqüência a matriz $\mathrm{B}^{-1}$, derivada de $\mathrm{A}$. 

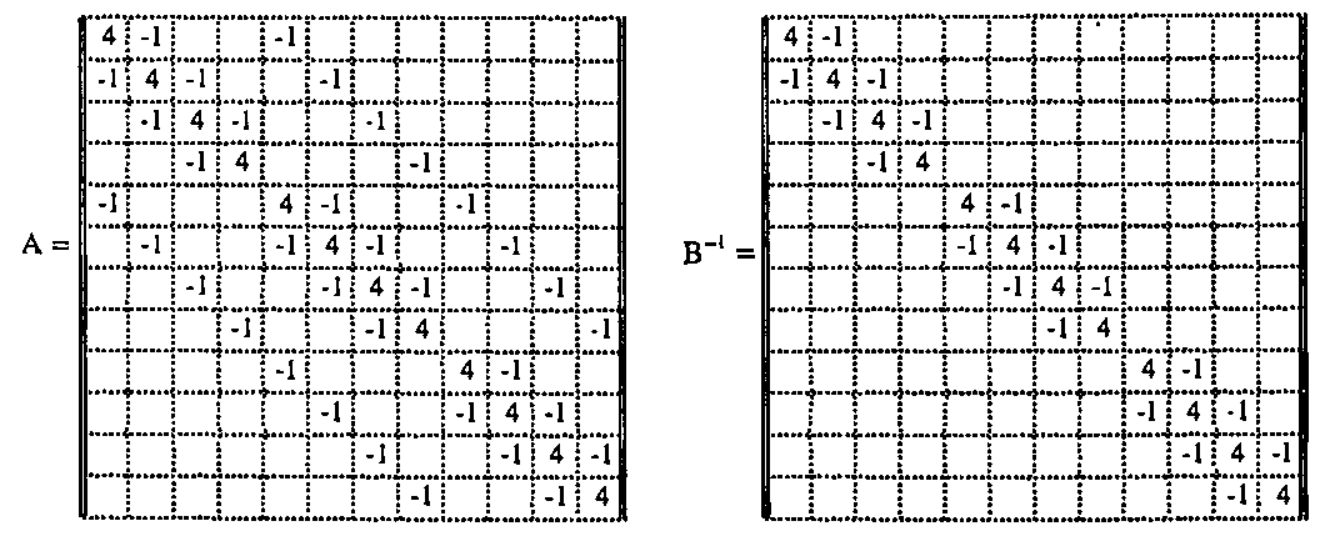

Fig.3.2 Matriz A e um pré condicionador $\mathrm{B}^{-1}$ para o método CG

Para que seja possível explicar as modificações necessárias no algoritmo CG com a aplicação do pré condicionador é preciso observar que, $B^{-1}$ é uma matriz simétrica definida positiva, o problema é que nem sempre o produto BA é uma matriz

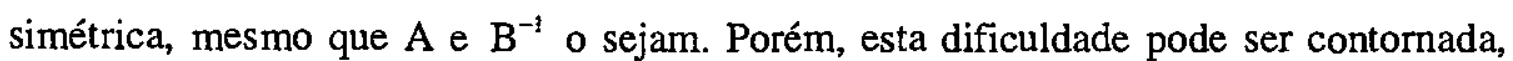
pois, para toda matriz $B^{-1}$ definida positiva, existe $E$ tal que $E^{T}=B^{-1}$. As matrizes $\mathrm{BA} \mathrm{e} \mathrm{E}^{-1} \mathrm{AE}^{-\mathrm{T}}$ têm os mesmos autovalores.

O sistema $\mathrm{Ax}=\mathrm{b}$ pode ser transformado para o problema

$$
E^{-1} A E^{-T} \hat{x}=E^{-1} b, \text { com } \hat{x}=E^{\top} x,
$$

o qual é resolvido primeiro para $\hat{x}$, depois para $x$ [14]. Como $E^{-1} \mathrm{AE}^{-\mathrm{T}}$ é simétrica definida positiva, $\hat{x}$ pode ser encontrado pelo método da descida ou CG. O processo para resolver este sistema usando CG é chamado método do gradiente conjugado com pré condicionamento transformado:

$$
\begin{aligned}
& \hat{\mathrm{d}}_{(0)}=\hat{\mathrm{r}}_{(0)}=\mathrm{E}^{-1} \mathrm{~b}-\mathrm{E}^{-1} \mathrm{AE} \mathrm{E}^{-\mathrm{T}} \hat{\mathrm{x}}_{(0)} \text {, } \\
& \alpha_{(\mathrm{i})}=\frac{\hat{\mathrm{r}}_{(\mathrm{i})}^{\mathrm{T}} \hat{\mathrm{r}}_{(\mathrm{i})}}{\hat{\mathrm{d}}_{(\mathrm{i})}^{\mathrm{T}} \mathrm{E}^{-1} A E^{-\mathrm{T}} \hat{\mathrm{d}}_{(\mathrm{i})}}, \\
& \hat{x}_{(i+1)}=\hat{x}_{(i)}+\alpha_{(i)} \hat{d}_{(i)} \text {, } \\
& \hat{\mathrm{r}}_{(i+1)}=\hat{\mathrm{r}}_{(\mathrm{i})}-\alpha_{(\mathrm{i})} \mathrm{E}^{-1} A \mathrm{E}^{-\mathrm{T}} \hat{\mathrm{d}}_{(\mathrm{i})} \text {, } \\
& \beta_{(i+1)}=\frac{\hat{\mathrm{r}}_{(i+1)}^{\mathrm{T}} \hat{\hat{\mathrm{r}}}_{(i+1)}}{\hat{\mathrm{r}}_{(\mathrm{i})}^{\mathrm{T}} \hat{\mathrm{r}}_{(\mathrm{i})}},
\end{aligned}
$$




$$
\hat{\mathrm{d}}_{(\mathrm{i}+1)}=\hat{\mathrm{r}}_{(\mathrm{i}+1)}+\beta_{(\mathrm{i}+1)} \hat{\mathrm{d}}_{(\mathrm{i})} \text {. }
$$

Este método têm a característica indesejável de ter que calcular a matriz E. No entanto, com um pouco de cuidado pode-se eliminar $\mathrm{E}$ através de uma substituição de variáveis. Colocando $\hat{r}_{(i)}=E^{-1} r_{(i)}$ e $\hat{d}_{(i)}=E^{T} d_{(i)}$, e usando as identidades $\hat{x}_{(i)}=E^{T} x_{(i)}$ e $\mathrm{E}^{-\mathrm{T}} \mathrm{E}^{-1}=\mathrm{B}$, pode-se obter o método do gradiente conjugado com pré condicionamento:

$$
\begin{gathered}
r_{(0)}=b-A x_{(0)}, \\
d_{(0)}=B r_{(0)}, \\
\alpha_{(i)}=\frac{r_{(i)}^{T} B r_{(i)}}{d_{(i)}^{T} A_{(i)}}, \\
x_{(i+1)}=x_{(i)}+\alpha_{(i)} d_{(i)}, \\
r_{(i+1)}=r_{(i)}-\alpha_{(i)} A_{(i)}, \\
\beta_{(i+1)}=\frac{r_{(i+1)}^{T} B r_{(i+1)}}{r_{(i)}^{T} \operatorname{Br}_{(i)}}, \\
d_{(i+1)}=B r_{(i+1)}+\beta_{(i+1)} d_{(i)} .
\end{gathered}
$$

A matriz E não aparece nessas equações, somente a matriz B é necessária.

Agora, o algoritmo do método dos gradientes conjugados com pré condicionamento à esquerda $\mathrm{B}$, para resolver o sistema linear $\mathrm{Ax}=\mathrm{b}$, pode ser escrito da seguinte forma:

$$
\begin{aligned}
& \mathrm{k} \Leftarrow 0 \\
& \mathrm{r} \Leftarrow \mathrm{b}-\mathrm{Ax} \\
& \mathrm{d} \Leftarrow \mathrm{Br} \\
& \delta_{\text {novo }} \Leftarrow \mathrm{r}^{\mathrm{T}} \mathrm{d} \\
& \delta_{0} \Leftarrow \delta_{\text {novo }}
\end{aligned}
$$$$
\text { algoritmo (03) }
$$

Enquanto $\mathrm{k}<\mathrm{k}_{\max }$ e $\delta_{\text {novo }}>\varepsilon^{2} \delta_{0}$ faça

$$
\begin{aligned}
& \mathrm{t} \Leftarrow \mathrm{Ad} \\
& \alpha \Leftarrow \frac{\delta \text { novo }}{\mathrm{d}^{\mathrm{T}} \mathrm{t}} \\
& \mathrm{x} \Leftarrow \mathrm{x}+\alpha \mathrm{d}
\end{aligned}
$$

Se k é divisível por $\mathrm{n}$

$$
\mathrm{r} \Leftarrow \mathrm{b}-\mathrm{Ax}
$$




\section{Caso contrário}

Fim se

$$
r \Leftarrow r-\alpha t
$$

$$
\begin{aligned}
& \mathrm{g} \Leftarrow \mathrm{Br} \\
& \delta_{\text {velho }} \Leftarrow \delta_{\text {novo }} \\
& \delta_{\text {novo }} \Leftarrow \mathrm{r}^{\mathrm{T}} \mathrm{g} \\
& \beta \Leftarrow \frac{\delta_{\text {novo }}}{\delta_{\text {velho }}} \\
& \mathrm{d} \Leftarrow \mathrm{g}+\beta \mathrm{d} \\
& \mathrm{k} \Leftarrow \mathrm{k}+1
\end{aligned}
$$

Fim enquanto

\subsection{Decomposição de domínio para a paralelização}

Considere no domínio $\Omega$ uma malha de $r \times s$ nós (Fig.3.3). Divida esta malha em $\mathrm{p}_{\mathrm{x}} \times \mathrm{p}_{\mathrm{y}}$ subdomínios com $\left(\mathrm{p}_{\mathrm{x}}-1\right)$ linhas verticais $\mathrm{e}\left(\mathrm{p}_{\mathrm{y}}-1\right)$ linhas horizontais. Estas linhas passam pelos nós que definirão as fronteiras nos subdomínios. Os nós nas fronteiras internas, os hachurados na figura a seguir, serão considerados em cada processador separadamente. Define-se assim, a malha local como sendo a malha delimitada por estas linhas, isto é, os nós pertencentes ao subdomínio considerado e também, a malha global como sendo a malha inicial de $r \times s$ nós. Para cada subdomínio, atribui-se um processador que identifica os nós pertencentes à malha local. Cada processador trabalha com estes nós como um único trabalhando na malha global.

Na figura abaixo, é considerada uma malha em um domínio $\Omega$ de $9 \times 10$ nós. Fazendo-se a divisão desta malha para nove processadores e fazendo-se a ordenação dos nós em cada um, têm-se: 

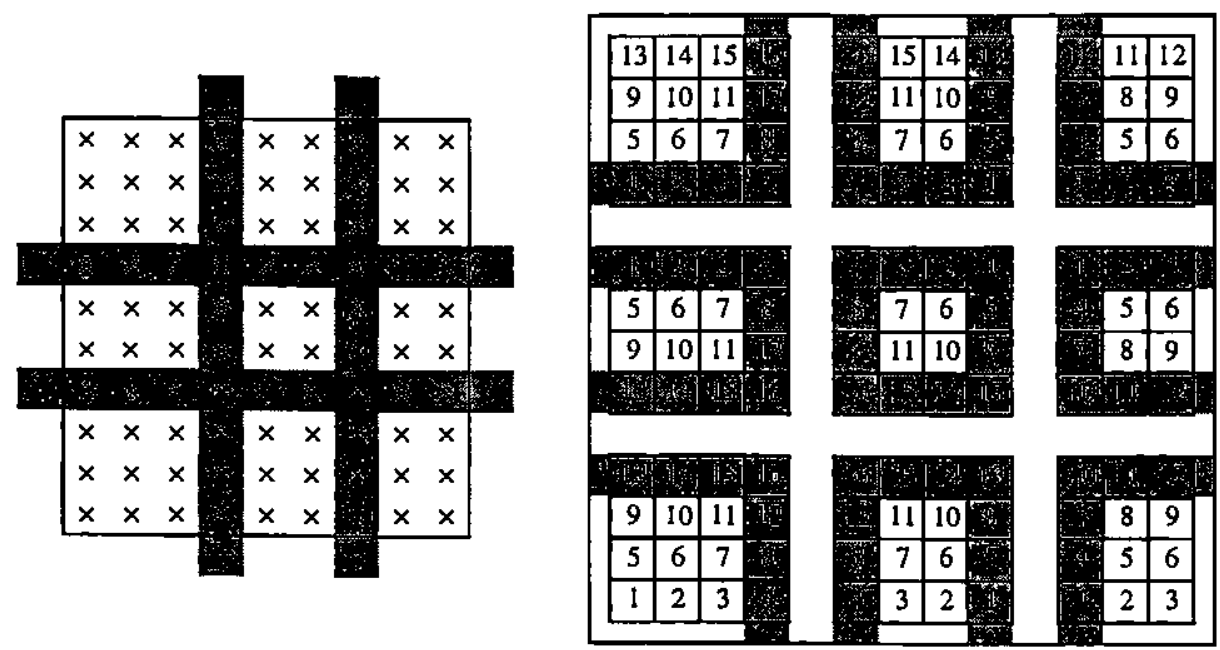

Fig.3.3 Domínio $\Omega$ dividido em nove subdomínios para nove processadores

Desta forma, os nós das fronteiras internas são distribuídos sobre os diferentes processadores adjacentes, sendo que, a soma dos conjuntos de nós locais é maior que o número de nós do conjunto inicial. $O$ algoritmo que será proposto neste trabalho aplica diretamente o processo iterativo neste conjunto de variáveis aumentadas, de forma a haver uma equivalência com o algoritmo seqüencial aplicado ao verdadeiro conjunto de variáveis.

É preciso agora, considerar algumas relações entre um vetor definido na malha global e as representações locais nos diferentes processadores. Aqui, dois tipos de representações serão consideradas. Um vetor será dito distribuído sempre que o valor verdadeiro em algum nó é recuperado pela soma dos valores nos diferentes locais de representações do nó, enquanto que um vetor será dito replicado sempre que o valor, em qualquer representação local de um nó, é uma cópia do valor verdadeiro para este nó (sequiência da Fig.3.7). Com essa técnica, nós distribuídos não sāo atribuídos para um processador em particular. No entanto, cada vetor envolvido no processo iterativo aplicado ao sistema original, pode ter uma representação distribuída ou replicada no sistema aumentado.

Para recuperar um vetor distribuído, soma-se os valores em cada nó das malhas locais onde esse vetor estiver representado. Para recuperar um vetor replicado, basta 
copiar o valor desse vetor na malha local onde ele estiver representado (seqüuencia da Fig.3.7). Note que a troca da representação de um vetor distribuído para replicado requer comunicação, o que pode ser observado na fórmula a seguir onde $x_{p}$ denota a representação local do vetor $\mathrm{x}$ no processador $\mathrm{p}$ :

$$
\forall p \text { e } \forall \mathrm{i}:\left(\mathrm{x}_{\mathrm{p}}\right)_{\mathrm{i}} \leftarrow\left(\mathrm{x}_{\mathrm{p}}\right)_{\mathrm{i}}+\sum_{\mathrm{q} \neq \mathrm{p}} \sum_{\substack{\mathrm{j} \\ \text { i c j corresponde ao } \\ \text { mesmo ponto da malha }}}\left(\mathrm{x}_{\mathrm{q}}\right)_{\mathrm{j}}
$$

Esta fórmula significa: para todo processador $\mathrm{p}$, o vetor distribuído $\mathrm{x}_{\mathrm{p}}$ desse processador é transformado em sua forma replicada, somando-se cada elemento deste vetor com sua representação em outros processadores $\mathrm{q}$, onde este nó, em suas várias representações, corresponde a um mesmo ponto da malha.

\subsection{Utilização do método dos gradientes conjugados}

\subsubsection{Introdução do método}

Considere então o algoritmo (03), método dos gradientes conjugados com pré condicionamento. $O$ processo abordado a seguir aplica-se a esse método, no entanto, um processo similar pode ser feito para outros métodos iterativos, incluindo métodos para sistemas não simétricos ou indefinidos.

Neste processo, o objetivo é distribuir as incógnitas nos vários processadores, de tal forma que algumas variáveis podem estar representadas em mais de um processador (Fig.3.3). Os nós associados a essas variáveis, distribuídos em mais de um processador, serão chamados de nós de interface. O ponto inicial para a paralelização do algoritmo em questão é permitir que b, r, t sejam vetores distribuídos e g, u, d sejam replicados. Essa escolha é consistente visto que no método dos gradientes conjugados as operações de soma e subtração envolvem somente vetores do mesmo tipo, enquanto que as operações de produto interno envolvem um vetor de cada tipo, o que diminui a 
comunicação entre os processadores. Isto ocorre porque antes da operação de produto interno não é necessária a comunicação, ela é executada somente quando for feita a soma dos escalares resultantes dos produtos internos realizados em cada processador. Com esta escolha, os produtos internos $r^{T} g$ e $d^{T} t$, ambos envolvendo um vetor distribuído e um replicado, são recuperados por soma em todos os processadores. Outra característica desejada é que a aproximação do vetor solução x seja replicada, i.e., x está acessível em cada processador com a solução calculada igualmente em qualquer nó representado em processadores vizinhos.

\subsubsection{Definições utilizadas no método}

Serão introduzidas algumas notações e definições adicionais para que se possa desenvolver essa idéia de forma mais completa. Para facilitar o entendimento das definições básicas utilizadas no método, será considerado um exemplo de tamanho o menor possível para que se possa ter quatro processadores (Fig.3.4). Este exemplo será introduzido e desenvolvido, no decorrer da exposição.

Tome uma malha em um domínio $\Omega$ de $3 \times 3$ nós. Fazendo-se a divisão desta malha para quatro processadores, da forma descrita acima, obtêm-se:
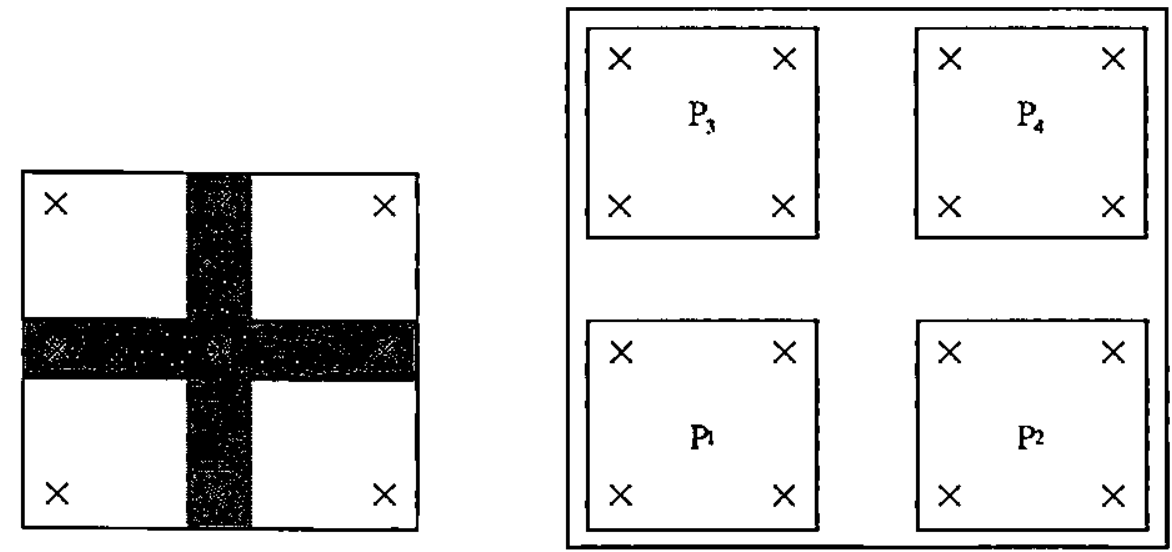

Fig.3.4 Domínio $\Omega$ com nove nós para quatro processadores 
Será assumido que existem $\mathrm{N}$ processadores (ou tarefas independentes). Denote por $\mathrm{P}_{\mathrm{p}}$ o conjunto de nós representados no processador $\mathrm{p}$. Cada $\left(\mathrm{P}_{\mathrm{p}}\right)_{\mathrm{p}=l_{1}, \mathrm{~N}}$ é deste modo um subconjunto de $[1, \mathrm{n}]$, sendo $\mathrm{n}$ o número total de nós do domínio $\Omega$. Seja $\mathrm{n}_{\mathrm{p}}$ o número de nós representados no processador $p$ (Fig.3.5). Têm-se, para $p=1, \ldots, N$ :

$$
n_{p}=\# P_{p} \text { e } P_{p} \subset[1, n] \operatorname{com}[1, n]=\bigcup_{p=1}^{N} P_{p}
$$

Ao conjunto de nós locais $P_{p}$ com $n_{p}$ elementos, associa-se um conjunto de nós estendidos $[1, \hat{\mathrm{n}}]$ onde $\hat{n}$ é a soma do número de nós existentes em cada processador. Daí, obtêm-se uma partição natural $\left(\hat{\mathrm{P}}_{\mathrm{p}}\right)_{\mathrm{p}=\iota_{,}, \mathrm{N}}$ para este conjunto estendido, sendo $\mathrm{P}_{\mathrm{p}} \circ$ conjunto dos nós locais (ou malha local) para o processador p (Fig.3.5). Desta forma obtêm-se:

$$
\hat{\mathrm{n}}=\sum_{\mathrm{p}=1}^{\mathrm{N}} \mathrm{n}_{\mathrm{p}} \text { e } \hat{\mathrm{P}}_{\mathrm{p}}=\left[\sum_{\mathrm{q}=1}^{\mathrm{p}-1} \mathrm{n}_{\mathrm{q}}+1, \sum_{\mathrm{q}=1}^{\mathrm{p}} \mathrm{n}_{\mathrm{q}}\right] .
$$

Para a figura seguinte (Fig.3.5), será feita uma numeração conforme a seqüência dos processadores, de forma a haver uma equivalência entre o algoritmo seqüencial e o algoritmo aplicado no conjunto de variáveis aumentadas.

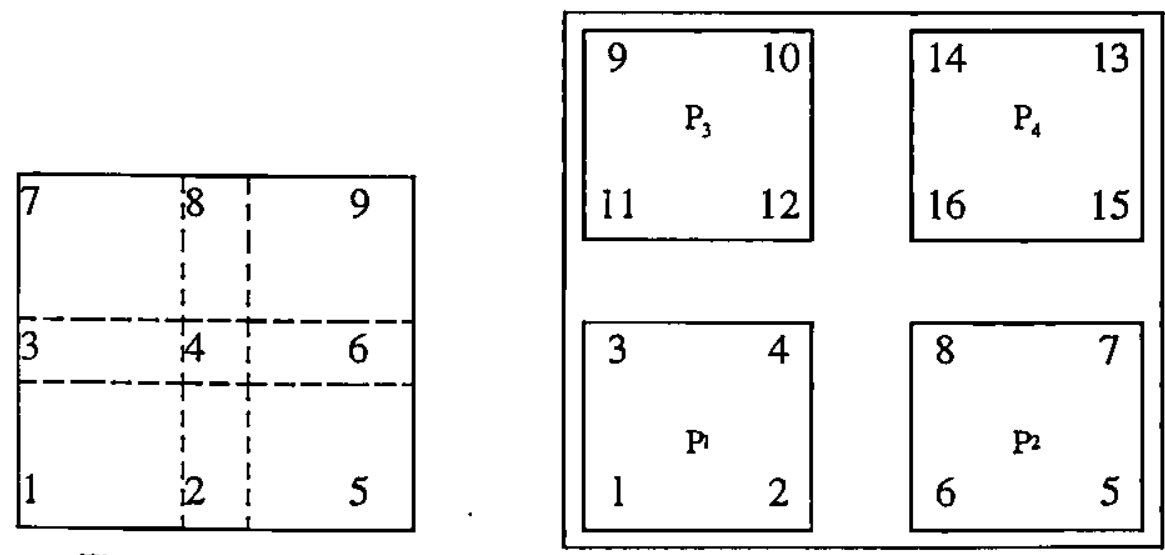

Fig.3.5 Ordenação dos nós conforme a sequência dos processadores 
De acordo com as definições acima, para este exemplo têm-se:

- $N=4, n=9 \Rightarrow[1, n]=\bigcup_{p=1}^{N} P_{p}, \log 0[1,9]=\{1, \ldots, 9\}, n_{1}=\ldots=n_{4}=4$;

- $\hat{\mathrm{n}}=\sum_{\mathrm{p}=1}^{\mathrm{N}} \mathrm{n}_{\mathrm{p}} \Rightarrow \hat{\mathrm{n}}=16, \log \mathrm{o}[1,16]=\{1, \ldots, 16\}$

$\hat{P}_{p}=\left[\sum_{q=1}^{p-1} n_{q}+1, \sum_{q=1}^{p} n_{q}\right], \quad \operatorname{logo} \quad \hat{P}_{1}=[1,4], \quad \hat{P}_{2}=[5,8], \quad \hat{P}_{3}=[9,12]$, $\hat{\mathrm{P}}_{4}=[13,16]$.

Desta forma conclui-se que, cada nó em $[1, n]$ tem uma ou mais correspondência em $[1, \hat{n}]$, por outro lado, cada nó em $[1, \hat{n}]$ tem uma única correspondência em $[1, n] . A$ representação matemática desta relação de correspondência é obtida com a matriz booleana $\mathrm{M}_{\hat{\mathrm{n} \times n}}$ definida por:

$$
M_{\hat{i} \times i}=\left\{\begin{array}{l}
I \text { se } \hat{i} \in \hat{P}_{p} \text { e i é o }\left(\hat{i}-\sum_{q=1}^{p-1} n_{q}\right)^{0} \text { nó em } P_{p} \\
0 \text { nos demais }
\end{array}\right.
$$

A matriz $M$ tem exatamente um elemento diferente de zero por linha e pelo menos um diferente de zero por coluna. Da matriz $M$ pode-se obter a matriz simétrica $\Sigma$ que é o produto de $\mathrm{M}$ por sua transposta (Fig.3.6). $\Sigma$ tem ordem $\hat{n} \times \hat{n}$ onde $\Sigma_{\tilde{\mathrm{ij}}}=1$ se e somente se $\hat{\mathrm{i}}$ e $\hat{\mathrm{j}}$ correspondem ao mesmo nó em $[1, \mathrm{n}]$, com $\Sigma_{\mathrm{ij}}=0$ nos demais.

$$
\Sigma=\mathrm{MM}^{\mathrm{T}}
$$

Considerando o exemplo em questão, com a matriz $\mathrm{M}$ obtém-se a matriz $\Sigma_{\hat{n} \times \hat{n}}=M_{\hat{n} \times n} M_{n \times \hat{n}}^{T}$ que estão representadas abaixo. 

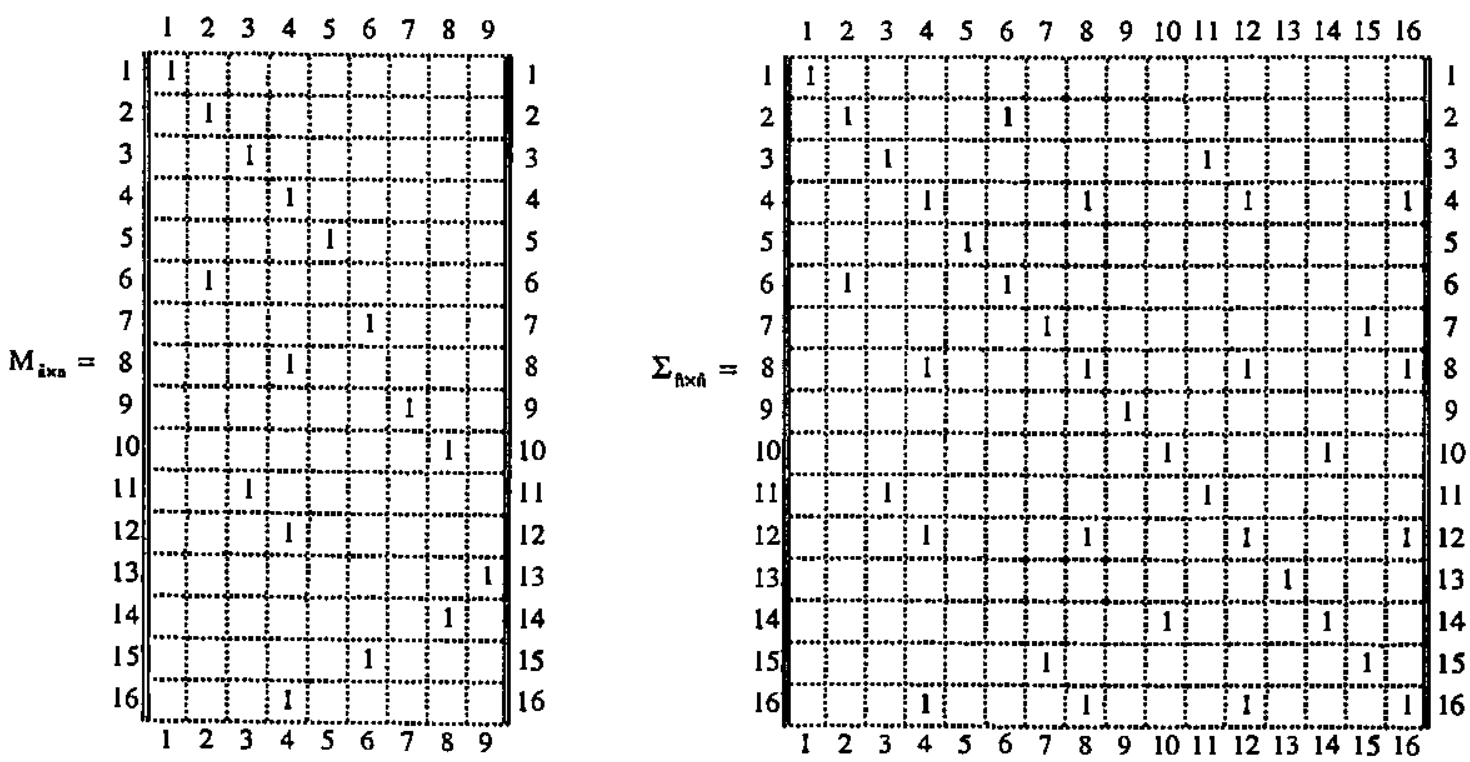

Fig.3.6 Representação da matriz $M_{\hat{n} \times n}$ e da matriz $\Sigma_{\hat{n} \times \hat{n}}=M_{\hat{n} \times n} M_{n \times \hat{n}}^{T}$

Um vetor $\hat{x}$ em $R^{\hat{n}}$ é a representação distribuída de um vetor $x$ em $R^{n}$ se e somente se $x=M^{T} \hat{x}$. Inversamente, $\hat{x}$ em $R^{\dot{n}}$ é a representação replicada de um vetor $\mathrm{x}$ em $\mathrm{R}^{\mathrm{n}}$ se e somente se $\hat{\mathrm{x}}=\mathrm{Mx}$ (seqüûncia da Fig.3.8). Em consequiência a matriz $\Sigma$ transforma a representação distribuída de um vetor para sua representação replicada.

$$
\hat{\mathrm{x}} \text { (vetor distribuído) } \Rightarrow \hat{\mathrm{y}}=\Sigma \hat{\mathrm{x}} \Rightarrow \hat{\mathrm{y}} \text { (vetor replicado) }
$$

\subsubsection{Adaptações das definições para o método}

Para o algoritmo dos gradientes conjugados, a escolha que foi feita para as representações distribuída e replicada de um vetor, implicam em:

$$
\text { Vetores distribuídos: } b=M^{T} \hat{b}, r=M^{T} \hat{r} \text { e } t=M^{\top} \hat{t}
$$

Vetores replicados: $\hat{g}=M g, \hat{u}=M u$ e $\hat{d}=M d$ 
Considerando-se o sistema $\mathrm{Ax}=\mathrm{b}$, define-se $\hat{\mathrm{A}}$ como a matriz do sistema estendido de ordem $\hat{\mathrm{n}} \times \hat{\mathrm{n}}$ e $\hat{\mathrm{B}}^{(1)}$ o pré condicionador ${ }^{2}$.

$$
\begin{aligned}
\mathrm{A} & =\mathrm{M}^{\mathrm{T}} \hat{\mathrm{A} M} \\
\hat{\mathrm{B}}^{(1)} & =\mathrm{MB}^{-1} \mathrm{M}^{\mathrm{T}} .
\end{aligned}
$$

A multiplicação por $\hat{A}$ é a representação algébrica da implementação do produto de uma matriz por vetor o qual admite um vetor replicado como entrada para produzir um vetor distribuído como saída. Logo, se $\hat{x}=M x$, então $A x=M^{T} \hat{A} M x=M^{T}(\hat{A} \hat{x})$.

Reciprocamente, a multiplicação por $\hat{\mathrm{B}}^{(1)}$ é a representação algébrica da implementação do produto de um pré condicionador por vetor o qual admite um vetor distribuído como entrada para produzir um vetor replicado como saída. Logo, se $y=M^{T} \hat{y}$, então $\hat{B}^{(1)} \hat{y}=M B^{-1} M^{T} \hat{y}=M\left(B^{-1} y\right)$.

Segue então, das definições da seção 3.6.2, que em vez de utilizar o algoritmo (03), algumas adaptações podem ser feitas de forma a obter-se um outro algoritmo equivalente, só que este, para o conjunto de variáveis estendidas com a matriz $\hat{A}$ e pré condicionador $\hat{\mathrm{B}}^{(1)}$. O termo independente $\hat{b}$ é tal que $b=M^{\top} b$ e a aproximação inicial $\hat{\mathrm{x}}_{0}$ é $\hat{\mathrm{x}}_{0}=\mathrm{Mx}_{0}$. As sequiências geradas $\{\hat{\mathrm{r}}\},\{\hat{\mathrm{t}}\},\{\hat{\mathrm{g}}\},\{\hat{\mathrm{x}}\},\{\hat{\mathrm{d}}\}$ satisfarão as igualdades (3.16) e (3.17) com respeito à sequiência original.

Para a prova formal destes resultados, é suficiente notar que:

$$
\begin{aligned}
& \hat{\mathrm{r}}_{0} \equiv \hat{\mathrm{b}}-\hat{\mathrm{A}} \hat{\mathrm{x}}_{0}=\mathrm{M}\left(\mathrm{b}-A \mathrm{x}_{0}\right)=M \mathrm{Mr}_{0} \\
& \hat{\mathrm{g}}_{0} \equiv \hat{\mathrm{B}}^{(\mathrm{l})} \hat{\mathrm{r}}_{0}=M\left(\mathrm{~B}^{-1} \mathrm{r}_{0}\right)=\mathrm{Mg}_{0} \\
& \hat{\mathrm{t}}_{0} \equiv \hat{\mathrm{A}} \hat{\mathrm{g}}_{0}=M\left(A \mathrm{~g}_{0}\right)=\mathrm{Mt}_{0} \quad \text { obs.: } \mathrm{d}_{0}=\mathrm{g}_{0}
\end{aligned}
$$

\footnotetext{
${ }^{2}$ Não podemos escrever $\hat{B}^{-1}$ porque $\hat{B}$ pode não ser inversível.
} 
Portanto, as igualdades (3.16) e (3.17) são verdadeiros para $k=0$. Um argumento similar, juntamente com a utilização da indução finita, prova que os enunciados são verdadeiros para todo $\mathrm{k}$ se os valores dos produtos internos, calculados pelas duas técnicas são iguais, isto é;

$$
\begin{aligned}
& \left(\hat{g}_{k}, \hat{r}_{k}\right)=\left(M g_{k}, \hat{r}_{k}\right)=\left(g_{k}, M^{T} \hat{r}_{k}\right)=\left(g_{k}, r_{k}\right) \\
& \left(\hat{t}_{k}, \hat{d}_{k}\right)=\left(\hat{t}_{k}, M d_{k}\right)=\left(M \hat{t}_{k}, d_{k}\right)=\left(t_{k}, d_{k}\right)
\end{aligned}
$$

As igualdades (3.16) e (3.17) justificam o que foi dito sobre a equivalência entre ambos os processos. Qualquer vetor no algoritmo original será unicamente determinado da representação deste, no sistema estendido. Ver sequiência da (Fig.3.7) a seguir.

Agora, pela equação (3.18), será encontrada uma matriz Â equivalente à matriz A, considerando o mesmo domínio do exemplo dado pela (Fig.3.4) e a mesma enumeração feita na (Fig.3.5). Antes, porém, para que se possa fazer a comparação entre as matrizes A e Â pode-se rescrever os elementos da equação (3.18) da seguinte forma:

$$
a_{i j}=\sum_{\substack{i s \in m_{i} \neq 0 \\ j s \in m_{i} \neq 0}} \hat{a}_{i j} \text {, para todo i e } j,
$$

onde " $\hat{\mathrm{i}}$ se $\mathrm{m}_{\hat{\mathrm{i}}} \neq 0$ " e " $\hat{\mathrm{j}}$ se $\mathrm{m}_{\hat{\mathrm{i}}} \neq 0$ " significam que serão somados os elementos $\hat{\mathrm{a}}_{\mathrm{ij}}$ da matriz $\hat{\mathrm{A}}$ cujas posições equivalentes $\hat{\mathrm{i}}$ e $\hat{\mathrm{j}}$ da matriz $\mathrm{M}$ forem diferentes de zero.

Para que se possa gerar a matriz A (Fig.3.7), do algoritmo seqüencial, e a matriz $\hat{A}$ equivalente à aplicada na resolução do algoritmo do sistema aumentado (Fig.3.8), considere as funções $\mathrm{A}(\mathrm{x}, \mathrm{y})=1, \mathrm{~B}(\mathrm{x}, \mathrm{y})=1$ e $\mathrm{C}(\mathrm{x}, \mathrm{y})=0$ na equação elíptica. Considere também os espaçamentos entre os nós, na horizontal e na vertical iguais a um, isto é, $\mathrm{h}=\mathrm{k}=1$, então 


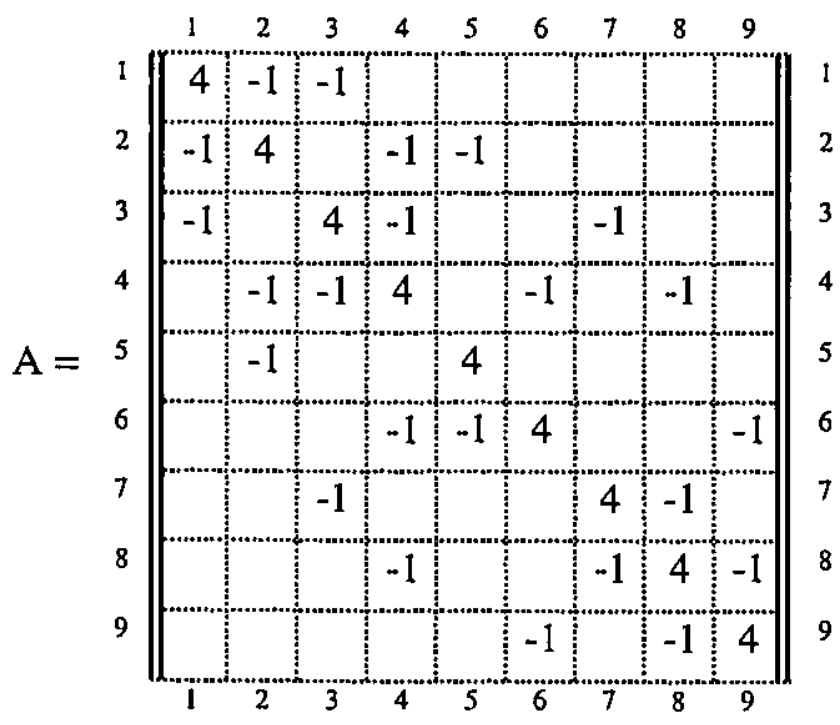

Fig.3.7 Representação da matriz A (seqüencial)

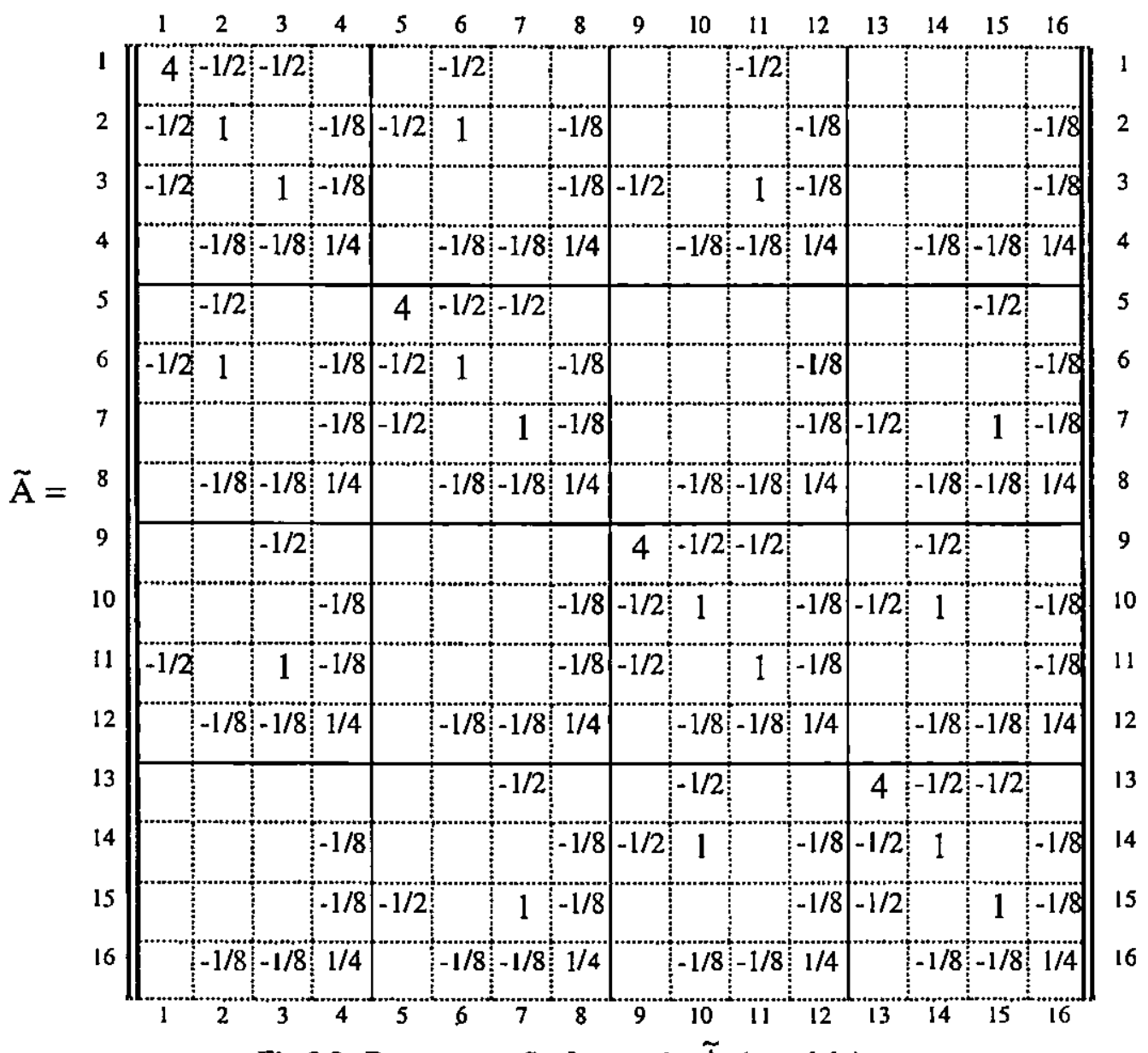

Fig.3.8 Representação da matriz $\tilde{A}$ (paralela) 
Considerando-se um vetor inicial $\mathrm{x}=\left(\begin{array}{lllllllll}1 & 2 & 4 & 5 & 3 & 6 & 7 & 8 & 9\end{array}\right)^{\mathrm{r}}$, o vetor replicado equivalente $\hat{x}$ é obtido pela equação $\hat{x}=M x$ (3.17), que é:

$$
\hat{\mathrm{x}}=\left(\begin{array}{llllllll|llllllll}
1 & 2 & 4 & 5 & 3 & 2 & 6 & 5 & 7 & 8 & 4 & 5 & 9 & 8 & 6 & 5
\end{array}\right)^{\mathrm{T}} .
$$

Fazendo-se os produtos destes vetores pelas matrizes A e $\widetilde{A}$, obtêm-se:

$$
\begin{aligned}
& \mathrm{Ax}=\left(\begin{array}{lllllllll}
-2 & -1 & 3 & 0 & 4 & 7 & 16 & 11 & 22
\end{array}\right)^{\mathrm{T}}=\mathrm{y} \\
& \tilde{\mathrm{A}} \hat{\mathrm{x}}=\left(\begin{array}{llllllllllllllll}
-2 & -\frac{1}{2} & \frac{3}{2} & 0 & 4 & -\frac{1}{2} & \frac{7}{2} & 0 & 16 & \frac{11}{2} & \frac{3}{2} & 0 & 22 & \frac{11}{2} & \frac{7}{2} & 0
\end{array}\right)^{\mathrm{T}}=\bar{y}
\end{aligned}
$$

O vetor y equivalente ao vetor $\widetilde{y}$, é obtido pela equação $y=M^{T} \tilde{y}$ (3.16), que é:

$$
M^{\top} \tilde{y}=\left(\begin{array}{lllllllll}
-2 & -1 & 3 & 0 & 4 & 7 & 16 & 11 & 22
\end{array}\right)^{\mathrm{T}}=\mathrm{y}
$$

$\mathrm{O}$ vetor $\tilde{\mathrm{y}}$ é a representação distribuída do vetor $\mathrm{y}$. Porém, o produto da matriz $\tilde{\mathrm{A}}$ estendida pelo vetor $\hat{\mathrm{x}}$ replicado, exige muita comunicação. Para diminuir este problema, será considerada a geração de uma outra matriz Â que satisfaça igualmente a equação (3.20), tal que, no produto pelo vetor $\hat{x}$ resulta num vetor $\hat{y}$ equivalente a $\tilde{y}$.

Além disso, se todas as entradas $a_{i j}$ diferentes de zero em A são tais que $\mathrm{i}$ e $\mathrm{j}$ pertençam a pelo menos um dos índices do mesmo processador, pode-se satisfazer a equação (3.20) apenas limitando-se a soma do vetor resultante, do produto por $\mathrm{A}$, para os nós $\hat{i}, \hat{j}$ pertencentes a uma mesma malha local. Considerando o bloco particionado associado à partição $\left(\hat{\mathrm{P}}_{\mathrm{p}}\right)_{\mathrm{p}=1, \ldots, \mathrm{N}}$ de $[1, \hat{\mathrm{n}}]$, $\hat{\mathrm{A}}$ é então um bloco diagonal (Fig.3.9). Em consequiência, têm-se uma implementação paralela para os produtos $\hat{A} \hat{x}_{k}$ e $\hat{t}_{k}=\hat{A} d_{k}$ onde a comunicação foi eliminada, visto que, tomando-se o vetor resultante $\hat{t}_{k}, o$ 
cálculo do p-ésimo bloco componente $\hat{\mathrm{t}}_{\mathrm{kp}}$ depende somente do p-ésimo bloco componente $\hat{d}_{k p}$ de $\hat{d}_{k}$.

$$
\hat{t}_{k p}=\hat{A}_{p p} \hat{d}_{k p}, \text { com } P=1, \ldots N
$$

Um exemplo de regra para se determinar $\hat{A}$ é $\hat{a}_{i j}=\frac{a_{i j}}{v_{i j}}$ se $\hat{i}, \hat{j} \in \hat{P}_{p}$ para algum $p$ e $\hat{a}_{i j}=0$ para os demais. Os índices $i, j$ representam os nós em $[1, n]$ que tenham, respectivamente, $m_{\hat{i i}}=1$ e $m_{i j}=1$ da matriz $M$, e onde $v_{i j}=\#\left\{p \in[1, N] / i, j \in P_{p}\right\}$ é o número de processadores que partilham i e j (Fig.3.9).

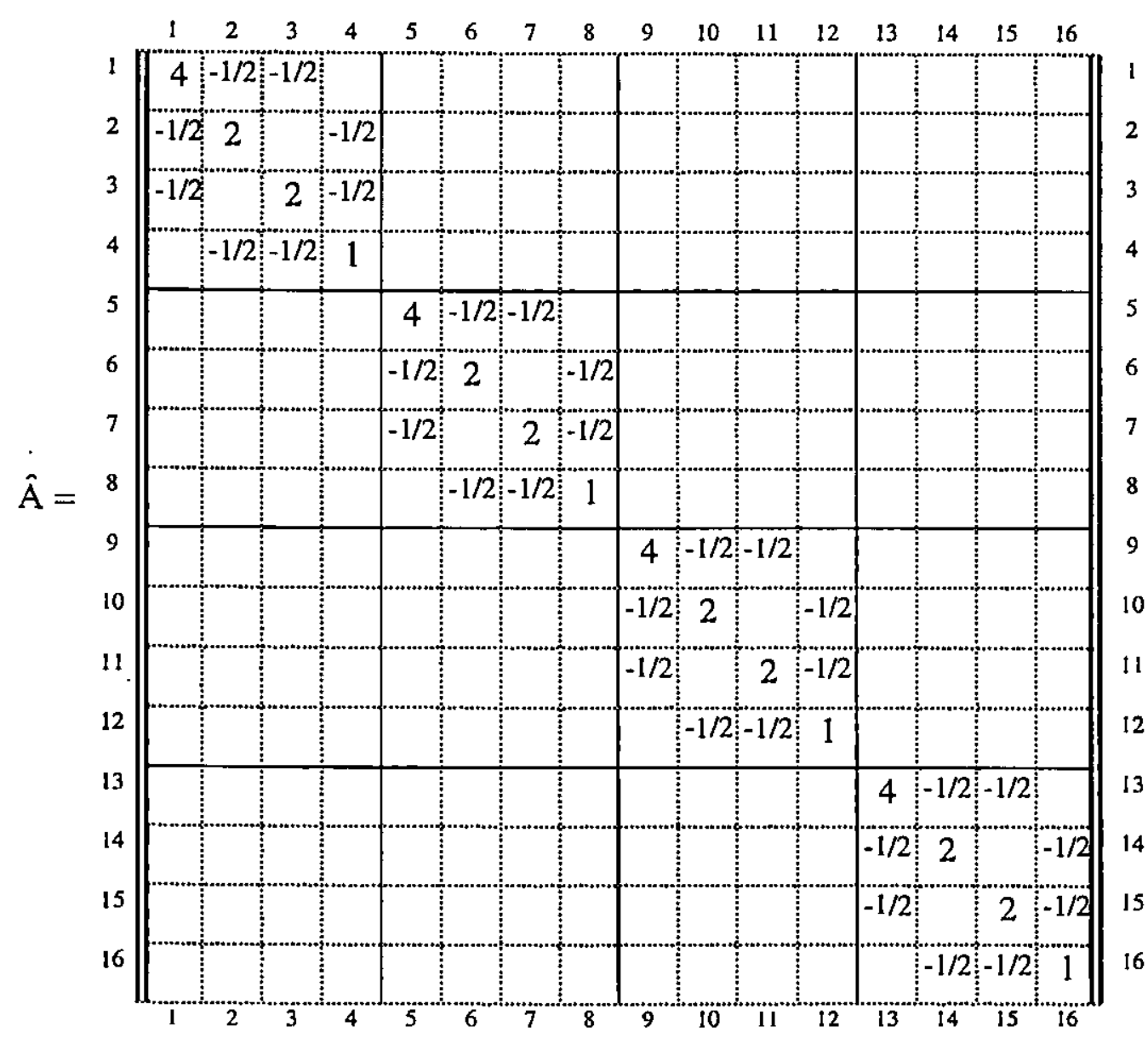

Fig.3.9 Representaçāo da matriz Â (paralela) 
Retomando-se o exemplo e fazendo-se Âû com

$$
\begin{aligned}
& \hat{\mathrm{u}}=\left(\begin{array}{llllllllllllllll}
1 & 2 & 4 & 5 & 3 & 2 & 6 & 5 & 7 & 8 & 4 & 5 & 9 & 8 & 6 & 5
\end{array}\right)^{\mathrm{T}} \text {, têm-se: } \\
& \hat{\mathrm{A}} \hat{\mathrm{u}}=\left(\begin{array}{llll|lllllllllll}
-2 & \frac{1}{2} & \frac{9}{2} & 2 & 4 & -\frac{3}{2} & \frac{13}{2} & 1 & 16 & \frac{13}{2} & -\frac{3}{2} & -1
\end{array} \mid \begin{array}{lllll}
22 & \frac{9}{2} & \frac{1}{2} & -2
\end{array}\right)^{\mathrm{T}}=\hat{\mathrm{y}}
\end{aligned}
$$

$\mathrm{O}$ vetor distribuído equivalente $\hat{y}^{1}$ é obtido pela equação $\hat{y}^{1}=\Sigma \hat{y}$ (3.15), que significa fazer a soma dos valores que estão nas fronteiras:

$$
\hat{\mathrm{y}}^{\mathrm{I}}=\left(\begin{array}{llll|llllllllllll}
-2 & -\frac{2}{2} & \frac{6}{2} & 0 & 4 & -\frac{2}{2} & \frac{14}{2} & 0 & 16 & \frac{22}{2} & \frac{6}{2} & 0 & 22 & \frac{22}{2} & \frac{14}{2} & 0
\end{array}\right)^{\mathrm{T}}
$$

Dividindo-se cada nó da fronteira pelo número de representação em cada processador, têm-se:

$$
\hat{\mathrm{y}}^{\mathrm{II}}=\left(\begin{array}{llllllllllll|llll}
-2 & -\frac{1}{2} & \frac{3}{2} & 0 & 4 & -\frac{1}{2} & \frac{7}{2} & 0 & 16 & \frac{11}{2} & \frac{3}{2} & 0 & 22 & \frac{11}{2} & \frac{7}{2} & 0
\end{array}\right)^{\mathrm{T}}=\tilde{\mathrm{y}} .
$$

É claro, outras regras que conservem a equação (3.21) também podem ser utilizadas. Nas aplicações em EDP, os elementos dos blocos serão freqüentemente obtidos diretamente da discretização executada localmente sobre cada processador.

Se o produto da matriz pelo vetor é agora puramente local, isto não significa que resolve-se um sistema decomposto sem necessidade de comunicação. Na verdade, as comunicações são somente transferidas para o passo de pré condicionamento $\hat{\mathrm{g}}_{\mathrm{k}}=\hat{\mathrm{B}}^{(1)} \hat{\mathrm{r}}_{\mathrm{k}}=\mathrm{MB}^{-1} \mathrm{M}^{\mathrm{T}} \hat{\mathrm{r}}_{\mathrm{k}}$ o qual é à primeira vista seqüencial. Contudo, sem o pré condicionamento, a operação acima reduz-se a $\hat{g}_{k}=M^{T} \hat{r}_{k}=\sum \hat{r}_{k}$ que implica somente em comunicações entre processadores vizinhos, necessária na implementação paralela do algoritmo dos gradientes conjugados sem pré condicionamento. 
O objetivo deste trabalho é investigar como o algoritmo que implementa o método dos gradientes conjugados pré condicionado pode ser implementado usando o mesmo tipo de comunicação. Em particular, é considerado o pré condicionador da forma $\mathrm{B}^{-1}=\mathrm{LPU}$ e é introduzida a representação replicada $\hat{\mathrm{L}}, \hat{\mathrm{P}}$ e $\hat{\mathrm{U}}$ das respectivas matrizes L, P e U as quais são definidas como o bloco diagonal da matriz $\hat{n} \times \hat{n}$ onde cada bloco diagonal é a restrição relacionada ao conjunto de nós locais para a matriz correspondente. No enunciado seguinte, $\operatorname{diag}_{\text {bloco }}(*)$ denota a parte do bloco diagonal relativo às partições $\left(\hat{\mathrm{P}}_{\mathrm{p}}\right)_{\mathrm{p}=1, \ldots, \mathrm{N}}$ de $[1, \hat{\mathrm{n}}]$.

$$
\begin{aligned}
& \hat{\mathrm{L}}=\operatorname{diag}_{\text {bloco }}\left(\mathrm{MLM}^{\mathrm{T}}\right) \\
& \hat{\mathrm{P}}=\operatorname{diag}_{\text {bloco }}\left(\mathrm{MPM}^{\mathrm{T}}\right) \\
& \hat{\mathrm{U}}=\operatorname{diag}_{\text {bloco }}\left(\mathrm{MUM}^{\mathrm{T}}\right)
\end{aligned}
$$

Se L, P e U são inversíveis, então $\hat{\mathrm{L}}, \hat{\mathrm{P}}$ e $\hat{\mathrm{U}}$ também o são, porque o seu determinante é o produto dos menores principais da matriz original.

Dando continuidade ao exemplo, usando-se o mesmo processo para a obtenção do pré condicionador $\mathrm{B}^{-1}$ da seção 3.4 (Fig.3.2), pode-se obter também o pré condicionador $\hat{\mathrm{B}}^{(1)}$ (Fig.3.10) com base na matriz estendida $\hat{\mathrm{A}}$ (Fig.3.9) para se obter $\hat{\mathrm{L}}$, $\hat{\mathrm{P}}$ e $\hat{\mathrm{U}}$ diretamente dos blocos diagonais, que neste caso são quatro. 


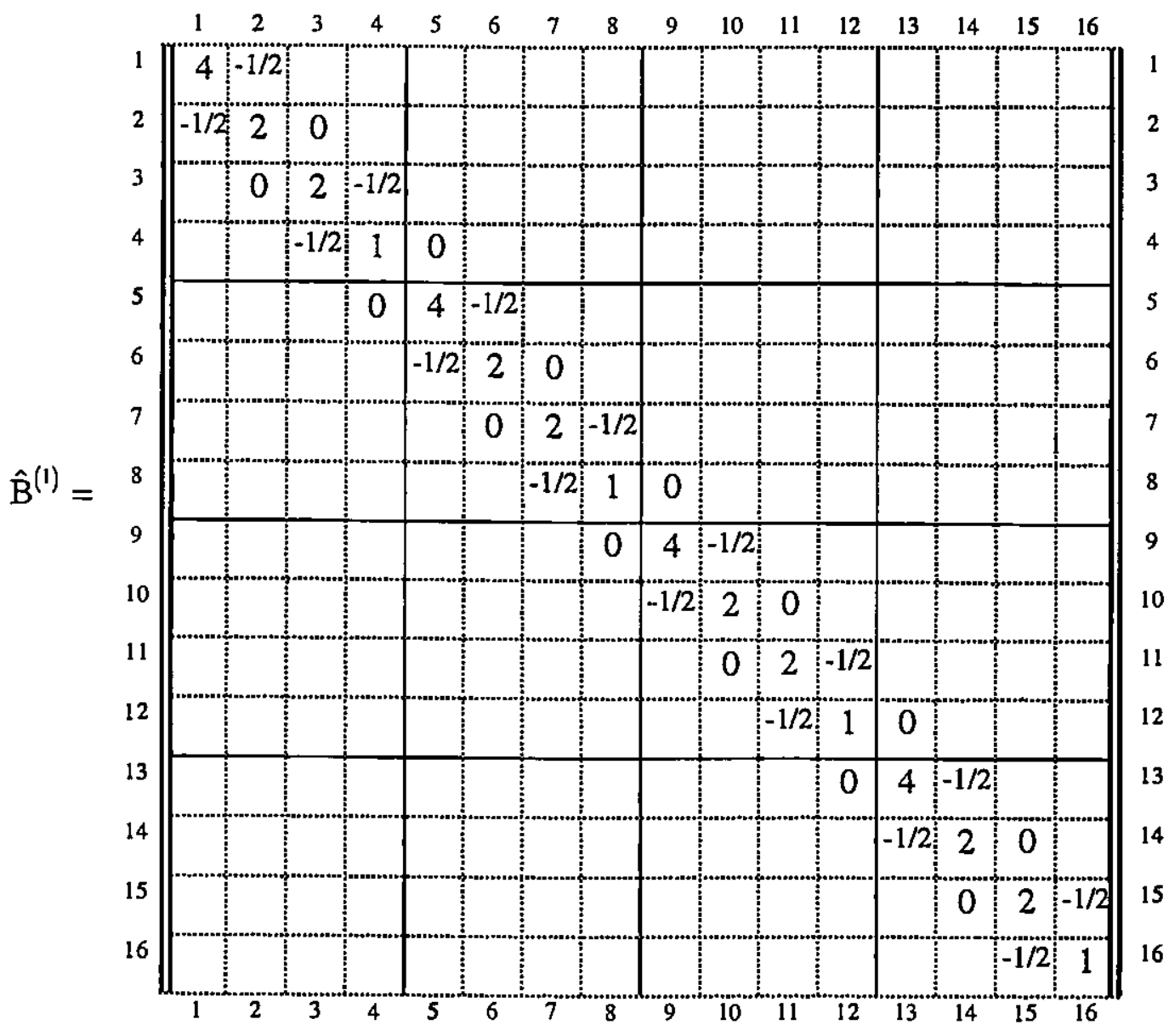

Fig.3.10 Representaçāo do pré condicionador $\hat{B}^{(1)}$ da matriz $\hat{A}$.

Para este pré condicionador, têm-se a seguinte relação, para todo $i, j$, com $i \neq j$ :

$$
\begin{gathered}
\exists p \in[1, N] \text { com } j \in P_{p} \text { e } i \notin P_{p} \text {, tal que } I_{i j}=u_{j i}=p_{i j}=p_{j i}=0 \\
\text { então } \\
\hat{U}^{-1} \hat{P} \Sigma \hat{L}^{-1}=\hat{U}^{-1} \Sigma \hat{P} \hat{L}^{-1}=M^{-1} \mathrm{PL}^{-1} M^{T} .
\end{gathered}
$$

Considerando $p=2$, no processador $P_{2}$, as representaçöes de $\hat{L}, \hat{P}$ e $\hat{U}$ seriam da seguinte forma: 

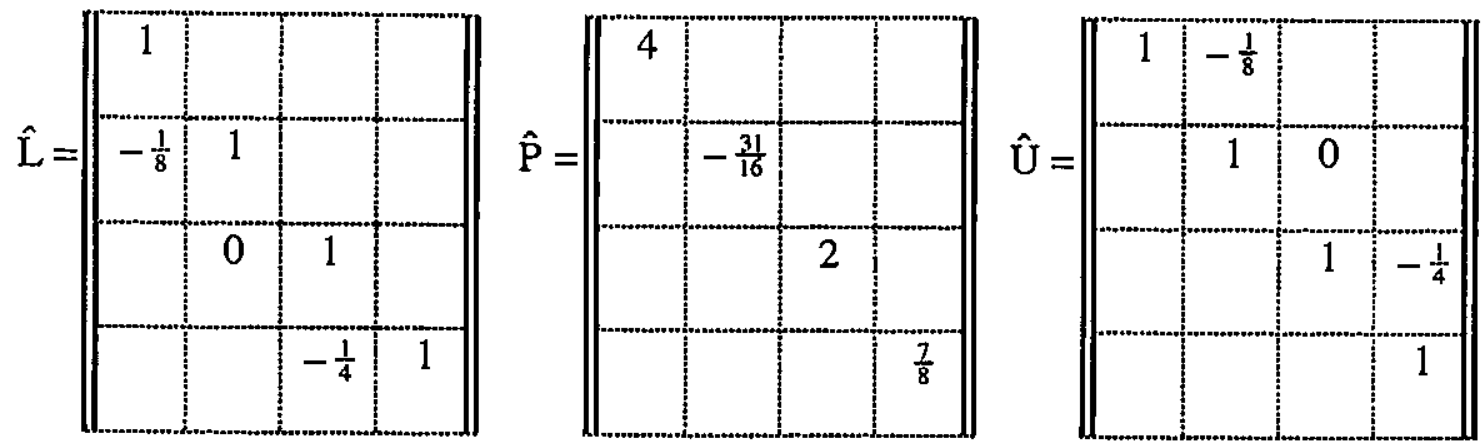

Fig.3.11 Representação de $\hat{\mathrm{L}}, \hat{\mathrm{P}}$ e $\hat{\mathrm{U}}$, para o processador $\mathrm{P}_{2}$.

Para que se possa visualizar as equações (3.22), (3.23) e (3.24), será desenvolvido a equação (3.22) que é $\hat{\mathrm{L}}=\operatorname{diag}_{\text {bloco }}\left(\mathrm{MLM}^{\mathrm{T}}\right)$, considerando o bloco diagonal equivalente ao processador $\mathrm{P}_{2}$ do pré condicionador $\hat{\mathrm{B}}^{(1)}$. Nesse exemplo, considere na equação (3.22) a seguinte equivalência, para o processador $\mathrm{P}_{2}$ :

$$
\hat{\mathrm{L}}_{2}=\mathrm{M}_{2} \mathrm{~L}_{2} \mathrm{M}_{2}^{\mathrm{T}} \text { equivalente a } \hat{\mathrm{L}}=\operatorname{diag}_{\text {bloco }}\left(\mathrm{MLM} \mathrm{M}^{\mathrm{T}}\right)
$$
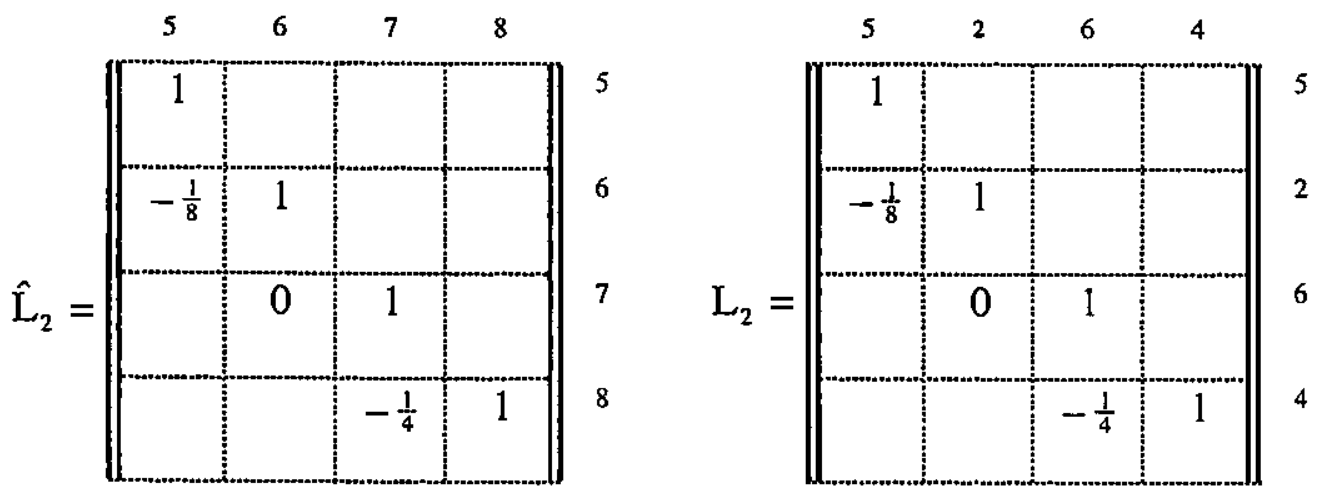

Fig.3.12 Representação de $\hat{L}_{2}$ e $L_{2}$ para o processador $P_{2}$.

Lembrando que $M_{16 \times 9}$ (Fig.3.6) e $L_{9 \times 9}$, para que se possa efetuar o produto $M_{2} L_{2} M_{2}^{T}$, é melhor organizar as matrizes $\mathrm{M}_{2}$ e $\mathrm{L}_{2}$ conforme seus índices, que estão representados na lateral direita (posição da linha) e na parte superior (posição da coluna) das matrizes (Fig.3.13). 


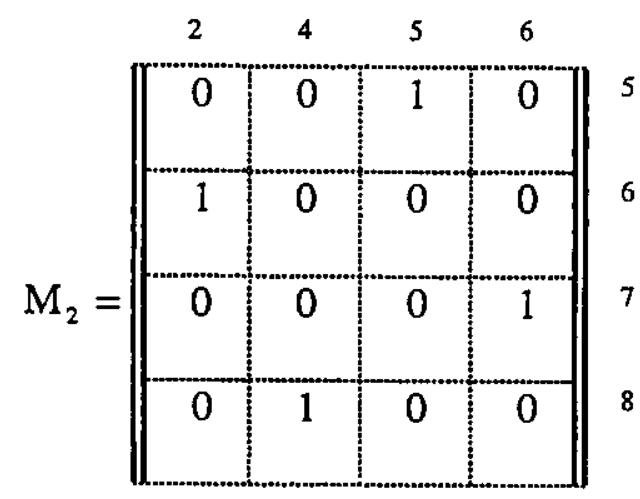

$\mathrm{L}_{2}=\left|\begin{array}{c|c|c|c|c}2 & 4 & 5 & 6 \\
1 & 0 & -\frac{1}{8} & 0 \\
\hdashline 0 & 1 & 0 & -\frac{1}{4} \\
\hdashline 0 & 0 & 1 & 0 \\
\hdashline 0 & 0 & 0 & 1\end{array}\right|$\begin{tabular}{l}
2 \\
\hdashline
\end{tabular}

Fig.3.13 Representação de $M_{2}$ e $L_{2}$, de forma ordenada, para o processador $P_{2}$.

Desta forma, o produto $M_{2} L_{2} M_{2}^{T}$ pode ser facilmente efetuado, produzindo o resultado desejado $\hat{L}_{2}$. As equações (3.23) e (3.24) podem ser desenvolvidas da mesma maneira, assim como para todos os outros processadores (blocos).

Através desses exemplos (Fig.3.10), pode-se perceber que $1_{\mathrm{ji}}$ ou $\mathrm{u}_{\mathrm{ij}}$ serão sempre nulos se estiverem entre um nó de interface i e um nó interior j (Fig.3.12). Contudo, não é permitido uma conexão de i para j em $\mathrm{L}, \mathrm{U}^{\mathrm{T}}, \mathrm{P}$ e $\mathrm{P}^{\mathrm{T}}$ se $\mathrm{j}$ é um nó de interface e i não pertencer a todos os processadores nos quais j está representado. Note entretanto que nenhuma permutação é na verdade requerida e que, alternativamente, pode-se descartar entradas que são proibidas derivadas do pré condicionador. Note também que não é preciso ter $\mathrm{L}$ e $\mathrm{U}$ triangular e $\mathrm{P}$ diagonal. Portanto, estes resultados podem ser úteis para blocos paralelos tal como a fatorização incompleta pré condicionada, por exemplo.

O desenvolvimento acima cobre situações mais gerais, se em vez de (3.25), para todo $\mathrm{i}, \mathrm{j}$, com $\mathrm{i} \neq \mathrm{j}$, pode-se ter:

\section{$\mathrm{Se}$}

$$
\begin{gathered}
\exists p \in[1, N] \text { com } i \in P_{p} \text { e } j \notin P_{p} \text { tal que } 1_{i j}=u_{j i}=p_{i j}=p_{j i}=0 \\
\text { então } \\
\Sigma \hat{U}^{-1} \hat{P} \Delta \hat{L}^{-t} \Sigma=\Sigma \hat{U}^{-1} \Delta \hat{P} \hat{L}^{-1} \Sigma=M U^{-1} P^{-1} M^{\top}
\end{gathered}
$$

onde $\Delta$ é a matriz diagonal $\hat{\mathrm{n}} \times \hat{\mathrm{n}}$ tal que 


$$
\Delta^{-1} \varepsilon=\Sigma \varepsilon \operatorname{com} \varepsilon=(1 \ldots 1)^{\mathrm{T}}
$$

Este resultado é usado quando os nós de interface são ordenados primeiro.

Considerando agora, a ordenação estratégica proposta na introdução deste trabalho, é interessante tratar o caso onde parte dos nós de interface são ordenados primeiro e os remanescentes no final, isto é, uma mistura entre as situaçōes cobertas por (3.26). Isto requer a introdução de mais algumas notaçōes para que se possa distinguir entre ambos os tipos de fronteiras. Se $\mathrm{P}_{\mathrm{p}} \cap \mathrm{P}_{\mathrm{q}} \neq \varnothing$, então os pontos da fronteira serão rotulados com as letras ' $f$ ' ou ' $l$ '. Os pontos marcados com ' $f$ ' serão aqueles ordenados primeiro e os com ' $\mathrm{l}$ ', aqueles ordenados no final (Fig.3.14). Define-se fronteira(p,q) como sendo a fronteira entre os processadores $P_{p}$ e $P_{q}$, logo:

Se $P_{p} \cap P_{q} \neq \varnothing$, então fronteira $(p, q)=$ ' $f^{\prime}$ ou fronteira $(p, q)=$ ' $l^{\prime}$.

As classificações do tipo "fronteira 'o'" são relacionadas com interfaces em 3D, e serão introduzidas por razões técnicas dentro desta conexão porque necessitam satisfazer as seguintes propriedades:

Propriedade 3.1 Para todo $p, q, r \in[1, N]$ tal que $P_{p} \cap P_{q} \cap P_{r} \neq \varnothing$ :

$$
\begin{aligned}
& \left.\begin{array}{l}
\text { fronteira }(p, q)=f^{\prime} \\
\operatorname{fronteira}(q, r)=f^{\prime}
\end{array}\right\}, \text { então fronteira }(p, r)=f^{\prime} \\
& \left.\begin{array}{l}
\text { fronteira }(p, q)=l^{\prime} l^{\prime} \\
\text { fronteira }(q, r)=l^{\prime} l^{\prime}
\end{array}\right\} \text {, então fronteira }(p, r)={ }^{\prime} l^{\prime}
\end{aligned}
$$

Propriedade 3.2 Para todo $\mathrm{p}, \mathrm{q} \in[1, \mathrm{~N}]$ tal que fronteira $(\mathrm{p}, \mathrm{r})=\mathrm{e}^{\mathrm{o}} \mathrm{o}$, e para todo $i \in P_{p} \cap P_{q}$, existem $r, s \in[1, N]$ tal que $i \in P_{r} \cap P_{s}$ com

$$
\text { fronteira }(p, r)=\text { ' } f \text { ', fronteira }(r, q)=\text { 'l' }
$$




$$
\text { fronteira }(p, s)=\text { ' } 1 \text {, fronteira }(s, q)=\text { ' } f \text { '. }
$$

Para que se satisfaçam estas propriedades, será feita a escolha da "fronteira" (qualquer uma, ' $f$ ' ou ' $l$ ') nos pares de processadores que compartilham uma fronteira principal (em 2D têm-se a representação da fronteira por uma linha e em 3D a representação é por um plano), e então deixar as fronteiras que ainda restam serem determinadas, aplicando-se a propriedade 3.1, o que também implica em $\left.\begin{array}{l}\text { fronteira }(p, q)=f^{\prime} \\ \text { fronteira }(q, r)={ }^{\prime} l\end{array}\right\}$, então fronteira $(p, r)={ }^{\prime} o^{\prime}$ para algum $p, q, r$ tal que $\mathrm{P}_{\mathrm{p}} \cap \mathrm{P}_{\mathrm{q}} \cap \mathrm{P}_{\mathrm{r}} \neq \varnothing \quad$ (qualquer outra escolha para fronteira(p,r) implicaria numa contradição da propriedade 3.1. Se não existe contradição, é mantida somente a checagem da propriedade 3.2, a qual não se têm dificuldades para o cálculo regular nas malhas.

Devido às propriedade 3.1 e 3.2 a matriz $\Sigma$ será decomposta em um produto tal que, $\Sigma=\Sigma_{1} \Sigma_{f}$, onde: $\left(\Sigma_{\mathrm{f}}\right)_{\mathrm{ij}}=\Sigma_{\mathrm{ij}}$ se $\hat{\mathrm{i}} \in \mathrm{P}_{\mathrm{p}}, \hat{\mathrm{j}} \in \mathrm{P}_{\mathrm{q}}$ com $\mathrm{p}=\mathrm{q}$ ou $\mathrm{P}_{\mathrm{p}} \cap \mathrm{P}_{\mathrm{q}} \neq \varnothing$ e fronteira $(p, q)=f^{\prime}$ sendo $\left(\Sigma_{f}\right)_{i j}=0$ nos demais; $\left(\Sigma_{1}\right)_{i j}=\Sigma_{i j}$ se $\hat{i} \in P_{p}, \hat{j} \in P_{q}$ com $\mathrm{p}=\mathrm{q}$ ou $\mathrm{P}_{\mathrm{p}} \cap \mathrm{P}_{\mathrm{q}} \neq \varnothing$ e fronteira $(\mathrm{p}, \mathrm{q})=$ ' $\mathrm{l}^{\prime}$ sendo $\left(\Sigma_{1}\right)_{\mathrm{ij}}=0$ nos demais.

Portanto, $\Sigma_{\mathrm{f}}$ e $\Sigma_{\mathrm{l}}$ são matrizes deduzidas de $\Sigma$ por montagem de zeros para os blocos paralelos à diagonal secundária correspondentes aos pares de processadores cuja "fronteira" não é igual para os respectivos 'f' ou ' $l$ '.

Com a utilização destes resultados, pode-se concluir que:

Se, para todo $\mathrm{i}, \mathrm{j}, \mathrm{i} \neq \mathrm{j}$ tal que $\mathrm{l}_{\mathrm{ij}} \neq 0$ ou $\mathrm{u}_{\mathrm{ji}} \neq 0$ ou $\mathrm{p}_{\mathrm{ij}} \neq 0$ ou $\mathrm{p}_{\mathrm{ji}} \neq 0$, têm-se:

a) $i, j \in P_{p}$ para algum $p \in[1, \dot{N}]$; 
b) $j \in P_{p} \cap P_{q}$ para algum $p, q \in[1, N]$ com $p \neq q$ e front $(p, q)=$ 'l' então $i \in P_{p} \cap P_{q}$

c) $i \in P_{p} \cap P_{q}$ para algum $p, q \in[1, N]$ com $p \neq q$ e front $(p, q)=$ ' $f^{\prime}$ então $j \in P_{p} \cap P_{q}$;

Então,

$$
\Sigma_{\mathrm{f}} \hat{\mathrm{U}}^{-1} \hat{\mathrm{P}} \Delta_{\mathrm{f}} \Sigma_{1} \hat{\mathrm{L}}^{-1} \Sigma_{\mathrm{f}}=\Sigma_{\mathrm{f}} \hat{\mathrm{U}}^{-1} \Delta_{\mathrm{f}} \Sigma_{\mathrm{l}} \hat{\mathrm{P}} \hat{\mathrm{L}}^{-1} \Sigma_{\mathrm{f}}=\mathrm{MU}^{-1} \mathrm{PL} \mathrm{L}^{-1} \mathrm{M}^{\mathrm{T}}
$$

onde $\Delta_{\mathrm{f}}$ é a matriz diagonal tal que $\Delta_{\mathrm{f}}^{-1} \varepsilon=\Sigma_{\mathrm{f}} \varepsilon$

Os dois resultados dados nos itens b) e c) acima, são casos particulares de (3.28). O primeiro corresponde ao caso onde fronteira $(p, q)=$ ' $\mathrm{l}$ ' para todo $\mathrm{p}$, $\mathrm{q}$ e o segundo corresponde ao caso onde front $(p, q)=$ ' $f$ ' para todo $p, q$.

Observação: Para o pré condicionador $B^{-1}=U^{T} P U$, visto que $\alpha_{k}=\left(r_{k}, g_{k}\right)$ $=\left(r_{k}, B^{-1} r_{k}\right)=\left(\left(U^{-T} r_{k}\right), P\left(U^{-T} r_{k}\right)\right)$, está embutido dentro das comunicações para os nós de interface, a necessidade de atualização de $\alpha_{k}$ com o cálculo de $\mathrm{U}^{-1} \mathrm{y}_{\mathrm{k}}$ onde $y_{k}=P U^{-T} r_{k}$. Isto pode ser obtido dentro da presente estrutura desde que $\left(\hat{r}_{k}, \hat{g}_{k}\right)$ $=\left(\hat{\mathrm{r}}_{\mathrm{k}}, \Sigma_{\mathrm{f}} \hat{\mathrm{U}}^{-1} \hat{\mathrm{P}} \Delta_{\mathrm{f}} \Sigma_{1} \hat{\mathrm{U}}^{-\mathrm{T}} \Sigma_{\mathrm{f}} \hat{\mathrm{r}}_{\mathrm{k}}\right)=\left(\left(\hat{\mathrm{U}}^{-\mathrm{T}} \Sigma_{\mathrm{f}} \hat{\mathrm{r}}_{\mathrm{k}}\right), \hat{\mathrm{P}} \Delta_{\mathrm{f}} \Sigma_{1}\left(\hat{\mathrm{U}}^{-\mathrm{T}} \Sigma_{\mathrm{f}} \hat{\mathrm{r}}_{\mathrm{k}}\right)\right)$

Para concluir as classificações das fronteiras ' $f$ ' e ' $l$ ', serão consideradas agora as definições dadas acima mas, adaptadas aos $\mathrm{p}_{\mathrm{x}} \times \mathrm{p}_{\mathrm{y}}$ processadores na malha, para o domínio $\Omega$. A apresentação será de uma forma que facilite a representação através do exemplo que virá a seguir (Fig.3.14).

Para cada par dos $\mathrm{p}_{\mathrm{x}} \times \mathrm{p}_{\mathrm{y}}$ processadores da malha, que tem uma fronteira em comum, os nós dessa fronteira serão representados em ambos os processadores. Para um processador na posição $\left(i_{p}, j_{p}\right)$ é definido: 


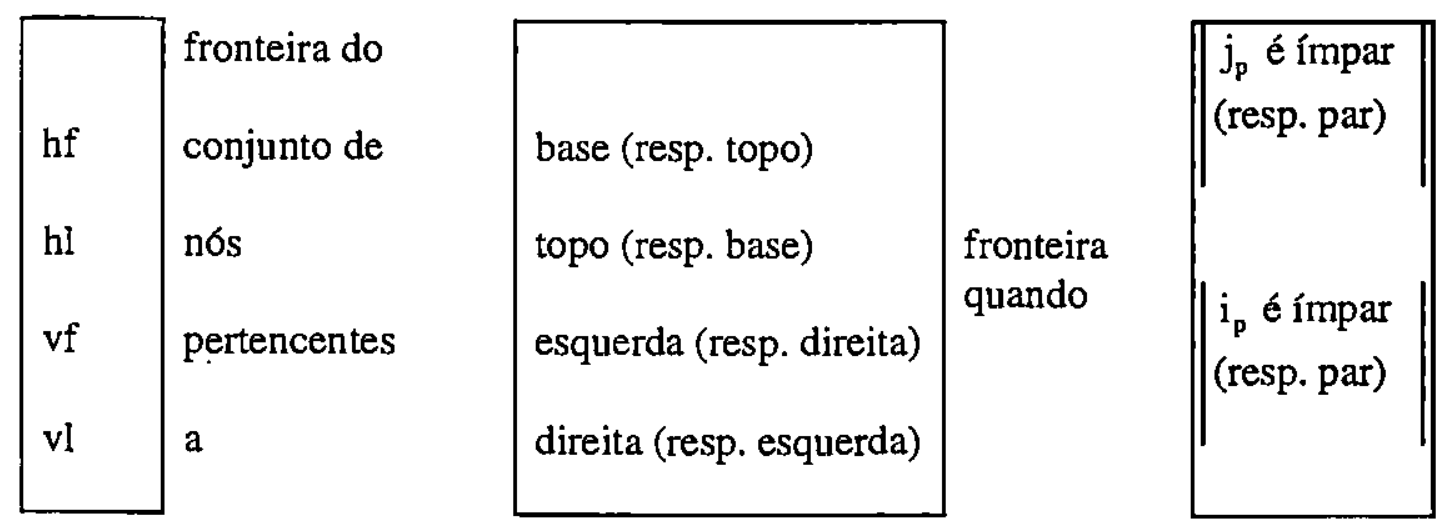

\begin{tabular}{|c|c|c|c|c|c|c|}
\hline$x$ & $x$ & & $x$ & $x$ & $x$ & \\
\hline$x$ & $x$ & $x$ & $x$ & $x$ & $x$ & \\
\hline & $x$ & & $x$ & & $x$ & \\
\hline & & & & & & \\
\hline$x$ & $x$ & $\underline{x}$ & $x$ & $x$ & $x$ & \\
\hline$x$ & $x$ & $x$ & $x$ & $x$ & $x$ & $x$ \\
\hline$x$ & $x$ & $x$ & $x$ & $x$ & $x$ & $x$ \\
\hline$x$ & $x$ & $\bar{x}$ & $x$ & $x$ & $x$ & $\bar{x}$ \\
\hline$x$ & $\bar{x}$ & $\bar{x}$ & $x$ & $x$ & $\bar{x}$ & $x$ \\
\hline
\end{tabular}

\begin{tabular}{|c|c|c|c|c|c|c|c|c|c|c|c|c|}
\hline \multicolumn{5}{|c|}{ hl } & \multicolumn{4}{|c|}{ hl } & & \multicolumn{3}{|c|}{ h] } \\
\hline & 13 & & & & & & & $\begin{array}{l}41 \\
\end{array}$ & & & & 12 \\
\hline & 9 & 10 & 11 & & & 121 & & $0 \mathrm{0s}$ & & \begin{tabular}{|l|}
7 \\
\end{tabular} & 8 & 9 \\
\hline \multirow[t]{5}{*}{$v_{1}$} & 5 & 6 & 7 & & & 8 & & 5 & $\mathrm{ve}$ & 4 & 5 & 6 \\
\hline & 11 & 2 & 3 & & & 4 & 3 & $2[1$ & & 1 & 2 & 3 \\
\hline & & hf & & & & & & & & & hf & \\
\hline & 1 & 2 & 3 & & & 4 & & 21 & & 1 & 2 & 3 \\
\hline & 5 & 6 & 7 & & & 8 & & 515 & & 4 & 5 & 6 \\
\hline \multirow[t]{5}{*}{ vf } & 9 & 10 & 11 & & & 12 & & $\begin{array}{lll}5 & \end{array}$ & $1 \mathrm{vr}$ & 7 & 8 & 9 \\
\hline & 13 & 14| & 15 & & & 16 & & & & 10 & 11 & 12 \\
\hline & & hl & & & & & & & & & $\mathrm{hl}$ & \\
\hline & 13 & 14 & 15 & & & 16 & & \begin{tabular}{l|l}
4 & 1 \\
\end{tabular} & & & 11 & 12 \\
\hline & 9 & 10 & 11 & & & 121 & & 0.5 & & 7 & 8 & 9 \\
\hline \multirow[t]{2}{*}{$\mathbf{v f}$} & 5 & 6 & 7 & & & 8 & & $\begin{array}{lll}5 & 5\end{array}$ & $\mathrm{vr}$ & 4 & 5 & 6 \\
\hline & 1 & 2 & 3 & & & 4 & & 21 & & & 2 & 3 \\
\hline
\end{tabular}

Fig.3.14 Domínio $\Omega$ com noventa nós para nove processadores e as fronteiras ' $f$ ' e 'l'.

Esta classificação (Fig.3.14) é tal que a fronteira comum entre $\left(i_{p}, j_{p}\right)$ e $\left(i_{p}, j_{p}+1\right)$ é uma fronteira 'hf' sobre ambos os processadores $\left(j_{p}\right.$ par) ou uma fronteira 'hl' sobre ambos os processadores ( $\mathrm{j}_{\mathrm{p}}$ ímpar). Portanto, pode-se fixar sem ambigüidade o conjunto:

fronteira $\left(\left(i_{p}, j_{p}\right),\left(i_{p}, j_{p} \pm 1\right)\right)=$ ' $f$ ' se sua fronteira comum é a fronteira 'hf' e fronteira $\left(\left(i_{p}, j_{p}\right),\left(i_{p}, j_{p} \pm 1\right)\right)=$ 'l' se esta mesma fronteira é 'hl'.

Simultaneamente, têm-se:

fronteira $\left(\left(i_{p}, j_{p}\right),\left(i_{p} \pm 1, j_{p}\right)\right)=$ ' $f$ ' se sua fronteira comum é a fronteira ' $v f^{\prime}$ e 
fronteira $\left(\left(i_{p}, j_{p}\right),\left(i_{p} \pm 1, j_{p}\right)\right)=$ 'l' se esta mesma fronteira é 'vl'.

Finalmente, a classificação é completada pelo conjunto:

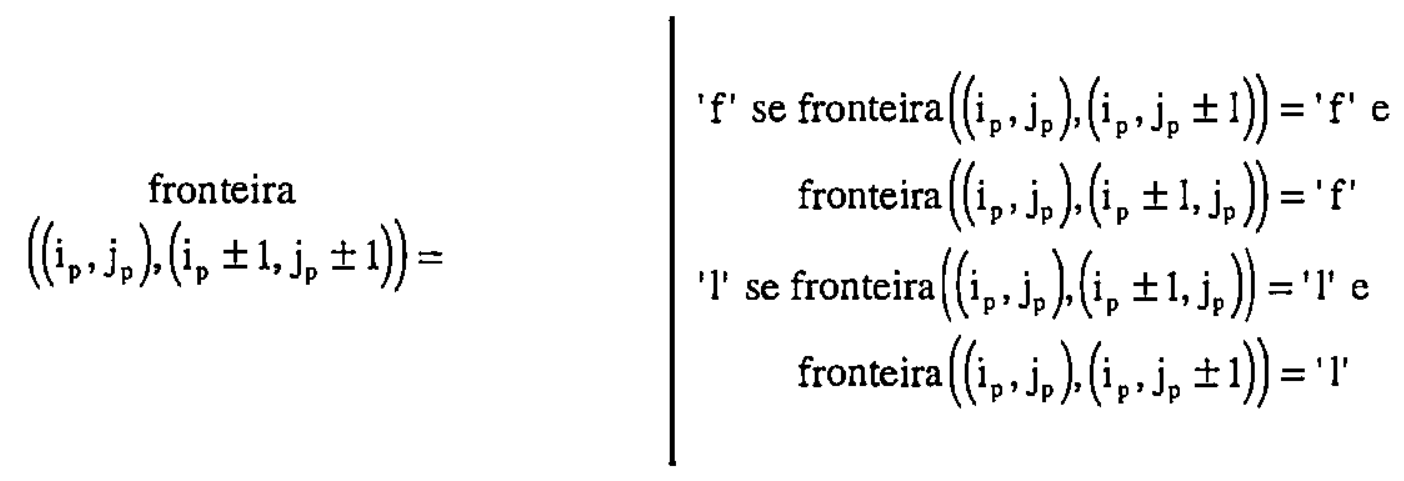

\subsubsection{Método dos gradientes conjugados com pré condicionamento adaptado à nova divisão de domínio}

É apresentado nesta seção, uma versão do método dos gradientes conjugados com pré condicionamento à esquerda $\hat{\mathrm{B}}^{(1)}$, o mesmo pré condicionador apresentado no começo da seção 3.6 .3 (Fig.3.10). O algoritmo apresentado tem a característica de ser executado, independentemente, em cada processador. As comunicações entre os processadores ocorrem apenas no produto interno e no pré condicionamento. $O$ algoritmo a ser executado em cada processador terá como matriz $\mathrm{A}_{\mathrm{p}}$, que é simétrica definida positiva relativo ao bloco particionado do processador de posição $p$, $\mathrm{B}_{\mathrm{p}}=\mathrm{U}_{\mathrm{p}}^{\mathrm{T}} \mathrm{P}_{\mathrm{p}} \mathrm{U}_{\mathrm{p}}$ é o pré condicionador com $\mathrm{U}_{\mathrm{p}}$ matriz triangular superior e $\mathrm{P}_{\mathrm{p}}$ matriz diagonal onde $B_{p}$ também está restrito ao mesmo bloco particionado. Têm-se também $\Delta_{\mathrm{p}}$ sendo a matriz diagonal definida por $\left(\Delta_{\mathrm{p}}\right)_{\mathrm{ii}}=\frac{1}{\mathrm{~m}_{\mathrm{i}}}$ tal que, para todo nó i no processador $p, m_{i}=1+\#\left\{q \neq p \mid\right.$ fronteira $(p, q)={ }^{\prime} f^{\prime}$ ou fronteira $(p, q)={ }^{\prime} l^{\prime}$ e o ponto correspondente a i é também representado em $\mathrm{q}\}$, ou seja, $\mathrm{m}_{\mathrm{i}}$ equivale à quantidade de representações, de um nó na posição $(\mathrm{i}, \mathrm{i})$, nos processadores. 
Então, dado o sistema $A_{p} x_{p}=b_{p}$ e tendo $x_{p}$ como aproximação inicial, considere a notação $u_{p} \leftarrow \sum_{p}(u)$ como sendo a comunicação para o vetor $u_{p}$ do processador $p$ em relação aos outros processadores e $\alpha_{p} \leftarrow \sum_{q=1}^{N}\left(\alpha_{q}\right)$, a comunicação para o produto interno do processador $\mathrm{p}$ em relação a todos os processadores. Têm-se então, o seguinte algoritmo:

$$
\begin{aligned}
& \mathrm{k} \Leftarrow 0 \\
& \mathrm{r}_{\mathrm{p}} \Leftarrow \mathrm{b}_{\mathrm{p}}-\mathrm{A}_{\mathrm{p}} \mathrm{x}_{\mathrm{p}} \quad \text { algoritmo (04) } \\
& * \quad \text { início do pré condicionamento }\left(\mathrm{g}_{\mathrm{p}} \Leftarrow \mathrm{B}_{\mathrm{p}}^{-1} \mathrm{r}_{\mathrm{p}}\right) \\
& \mathrm{g}_{\mathrm{p}} \Leftarrow \mathrm{r}_{\mathrm{p}} \\
& \mathrm{g}_{\mathrm{p}} \leftarrow \sum_{\mathrm{p}}\left(\mathrm{g}_{\mathrm{p}}\right) \\
& \mathrm{g}_{\mathrm{p}} \Leftarrow\left(\mathrm{U}_{\mathrm{p}}^{\mathrm{T}}\right)^{-1} \mathrm{~g}_{\mathrm{p}} \\
& \mathrm{g}_{\mathrm{p}} \leftarrow \sum_{\mathrm{p}}\left(\mathrm{g}_{\mathrm{p}}\right) \\
& \mathrm{g}_{\mathrm{p}} \Leftarrow\left(\mathrm{P}_{\mathrm{p}}^{-1} \mathrm{U}_{\mathrm{p}}\right)^{-1} \Delta_{\mathrm{p}} \mathrm{g}_{\mathrm{p}} \\
& \mathrm{d}_{\mathrm{p}} \leftarrow \sum_{\mathrm{p}}\left(\mathrm{g}_{\mathrm{p}}\right) \\
& * \quad \text { final do pré condicionamento } \\
& \delta_{\text {novo }} \Leftarrow \mathrm{r}_{\mathrm{p}}^{\mathrm{T}} \mathrm{d}_{\mathrm{p}} \\
& \delta_{\text {novo }} \leftarrow \sum_{\mathrm{q}=1}^{\mathrm{N}}\left(\delta_{\mathrm{q}}\right) \\
& \delta_{0} \Leftarrow \delta_{\text {novo }} \\
& \text { Enquanto } \mathrm{k}<\mathrm{k}_{\max } \text { e } \delta_{\text {novo }}>\varepsilon^{2} \delta_{0} \text { faça } \\
& \mathrm{t}_{\mathrm{p}} \Leftarrow \mathrm{A}_{\mathrm{p}} \mathrm{d}_{\mathrm{p}} \\
& \alpha_{\mathrm{p}} \Leftarrow \mathrm{d}_{\mathrm{p}}^{\mathrm{T}} \mathrm{t}_{\mathrm{p}} \\
& \alpha_{\mathrm{p}} \leftarrow \sum_{\mathrm{q}=1}^{\mathrm{N}}\left(\alpha_{\mathrm{q}}\right) \\
& \alpha \Leftarrow \frac{\delta_{\text {novo }}}{\alpha_{\mathrm{p}}} \\
& \mathrm{x}_{\mathrm{p}} \Leftarrow \mathrm{x}_{\mathrm{p}}+\alpha \mathrm{d}_{\mathrm{p}} \\
& \quad \text { Se ké divisivel por } \mathrm{n} \\
& \mathrm{r}_{\mathrm{p}} \Leftarrow \mathrm{b}_{\mathrm{p}}-\mathrm{A}_{\mathrm{p}} \mathrm{x}_{\mathrm{p}}
\end{aligned}
$$




\section{Caso contrário}

Fim se

$$
r_{p} \Leftarrow r_{p}-\alpha t_{p}
$$

* início do pré condicionamento $\left(\mathrm{g}_{\mathrm{p}} \Leftarrow \mathrm{B}_{\mathrm{p}}^{-1} \mathrm{r}_{\mathrm{p}}\right)$

$\mathrm{g}_{\mathrm{p}} \Leftarrow \mathrm{r}_{\mathrm{p}}$

$g_{\mathrm{p}} \leftarrow \sum_{\mathrm{p}}\left(\mathrm{g}_{\mathrm{p}}\right)$

$\mathrm{g}_{\mathrm{p}} \Leftarrow\left(\mathrm{U}_{\mathrm{p}}^{\mathrm{T}}\right)^{-1} \mathrm{~g}_{\mathrm{p}}$

$\mathrm{g}_{\mathrm{p}} \leftarrow \sum_{\mathrm{p}}\left(\mathrm{g}_{\mathrm{p}}\right)$

$\mathrm{g}_{\mathrm{p}} \Leftarrow\left(\mathrm{P}_{\mathrm{p}}^{-1} \mathrm{U}_{\mathrm{p}}\right)^{-1} \Delta_{\mathrm{p}} \mathrm{g}_{\mathrm{p}}$

$\mathrm{g}_{\mathrm{p}} \leftarrow \sum_{\mathrm{p}}\left(\mathrm{g}_{\mathrm{p}}\right)$

* final do pré condicionamento

$\delta_{\text {velho }} \Leftarrow \delta_{\text {novo }}$

$\delta_{\text {novo }} \Leftarrow r_{p}^{T} g_{p}$

$\delta_{\text {novo }} \leftarrow \sum_{q=!}^{N}\left(\delta_{q}\right)$

$\beta \Leftarrow \frac{\delta_{\text {novo }}}{\delta_{\text {velho }}}$

$\mathrm{d}_{\mathrm{p}} \Leftarrow \mathrm{g}_{\mathrm{p}}+\beta \mathrm{d}_{\mathrm{p}}$

$\mathrm{k} \Leftarrow \mathrm{k}+1$

Fim enquanto 


\section{PIM 1.1 (Métodos Iterativos Paralelos para Sistemas de Equações Lineares)}

\subsection{Introdução}

O pacote PIM foi utilizado para efeito de comparaçāo das implementaçōes paralelas.

Para implementar um método iterativo têm-se duas opções: ou faz-se uma implementação totalmente nova, ou procura-se usar um pacote pronto, fazendo-se apenas as adaptações necessárias. No caso da escolha de um pacote pronto, o melhor é usar um que já tenha sua eficiência testada em outras máquinas. Neste trabalho, a opção pelo pacote PIM dá-se por sua robustez e por sua portabilidade. Dentro do PIM, é utilizado o método dos gradientes conjugados, que, pela divisão da malha apresentada no capítulo 3, teve que sofrer algumas modificações. Na sequiência, será dada uma breve apresentação do pacote em questão.

\subsection{Método iterativo dentro do pacote PIM}

A (Fig.4.1) mostra um diagrama para a seleção de um método iterativo dentre todos os oferecidos pelo pacote PIM. 


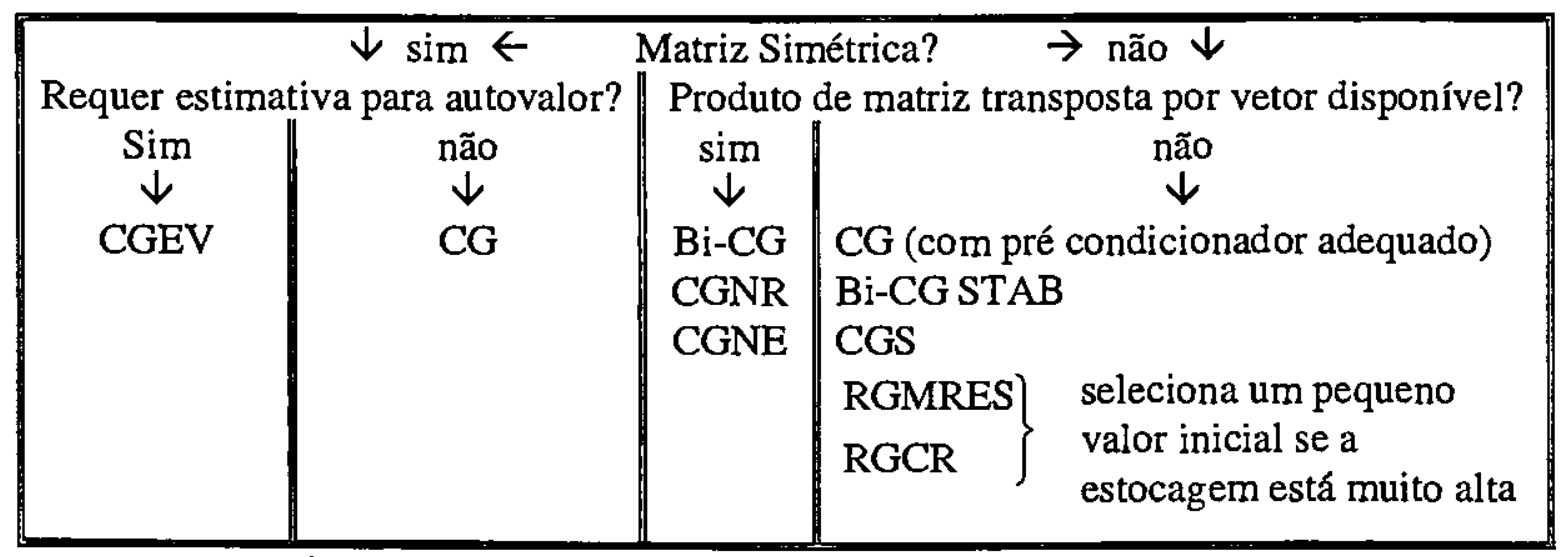

Fig.4.1 Diagrama para selecionar um método iterativo no PIM.

PIM é um conjunto de rotinas, para a linguagem de programação FORTRAN 77, construído para resolver sistemas de equações lineares através de métodos iterativos, usando processamento paralelo. Uma variedade de métodos iterativos para sistemas simétricos e não simétricos é implementado. No PIM, temos o método dos Gradientes Conjugados (CG) que é o método utilizado neste trabalho, Gradiente Bi Conjugado (BiCG), Gradiente Conjugado quadrado (CGS), a versão estabilizada do Gradiente Bi Conjugado (Bi-CGSTAB), resíduo mínimo generalizado (GMRES), resíduo conjugado generalizado (GCR), Gradiente Conjugado para equações normais com minimização por norma residual (CGNR), Gradiente Conjugado para equações normais com minimização por norma de erro (CGNR), e o resíduo quase mínimo sem transposta (TFQMR).

As rotinas do PIM podem ser usadas com o pré condicionador fornecido pelo usuário, esquerda, direita, ou são usados pré condicionamentos simétricos como suporte. Vários critérios de parada podem ser escolhidos pelo usuário.

No manual do PIM é apresentado um breve apanhado geral dos métodos iterativos e algoritmos disponíveis. O uso do PIM é introduzido via exemplos. São também apresentados alguns resultados obtidos com o PIM relativos à seleção do critério de parada e escalonamento paralelo. No guia de usuários do PIM é apresentado um manual de referências com detalhes específicos de rotinas e parâmetros. 
PIM foi desenvolvido com dois objetivos principais:

1. Permitir ao usuário autonomia completa com respeito ao armazenamento da matriz, acesso e partição;

2. Permitir sua utilização em uma variedade de arquiteturas paralelas e ambientes de programação.

Estes objetivos são conseguidos escondendo-se, nas rotinas do PIM, os detalhes específicos derivados do cálculo das três operações de álgebra linear citadas abaixo:

1. Produto de matriz por vetor e produto da matriz transposta por vetor;

2. Passo pré condicionador;

3. Produto interno e norma de vetor.

As rotinas de cálculo dessas operações precisam ser providenciadas pelo usuário. 


\section{Exemplos e Comparações}

\subsection{Introdução}

Serão apresentados alguns exemplos, considerando-se uma malha gerada pela divisão de um domínio retangular. Existem dois testes principais, apresentados neste capítulo. O primeiro teste consiste em avaliar o desempenho comparando a execução do programa sequiencial com a execução do programa paralelo para números variados de processadores. O segundo consiste em avaliar o desempenho do algoritmo paralelo aplicado a uma malha dividida em duas dimensões, que é a proposta de divisão desse trabalho, em comparação com a divisão unidimensional.

\subsection{Exemplos seqüencial e para vários processadores}

Será desenvolvido um exemplo para a equação (1.1) com execução do programa sequiencial e para números variados de processadores com os seguintes dados:

$$
\begin{aligned}
& -\left[\frac{\partial}{\partial x} A(x, y) \frac{\partial}{\partial x} U(x, y)+\frac{\partial}{\partial y} B(x, y) \frac{\partial}{\partial y} U(x, y)\right]+C(x, y) U(x, y)=F(x, y) \\
& A(x, y)=1, \quad B(x, y)=1, \quad C(x, y)=1 \quad \text { e } F(x, y)=x^{2}-y^{2} \quad \text { com erro de }
\end{aligned}
$$

aproximação de $10^{-10}$. Os valores de $U$ nas fronteiras de $\Omega$ são dados a seguir (Fig.5.1):

$$
\begin{array}{ll}
\mathrm{U}\left(\mathrm{x}, \mathrm{y}_{0}\right)=\mathrm{F}_{1}(\mathrm{x})=\mathrm{x}^{2}-4 & \left(\mathrm{y}_{0}=-2\right) \\
\mathrm{U}\left(\mathrm{x}_{0}, \mathrm{y}\right)=\mathrm{F}_{2}(\mathrm{y})=-\mathrm{y}^{2}+1 & \left(\mathrm{x}_{0}=-1\right) \\
\mathrm{U}\left(\mathrm{x}, \mathrm{y}_{1}\right)=\mathrm{F}_{3}(\mathrm{x})=\mathrm{x}^{2}-16 & \left(\mathrm{y}_{1}=4\right)
\end{array}
$$




$$
\mathrm{U}\left(\mathrm{x}_{1}, \mathrm{y}\right)=\mathrm{F}_{4}(\mathrm{y})=-\mathrm{y}^{2}+9 \quad\left(\mathrm{x}_{1}=3\right)
$$

Cuja solução exata é $\mathrm{U}(\mathrm{x}, \mathrm{y})=\mathrm{x}^{2}-\mathrm{y}^{2}$.

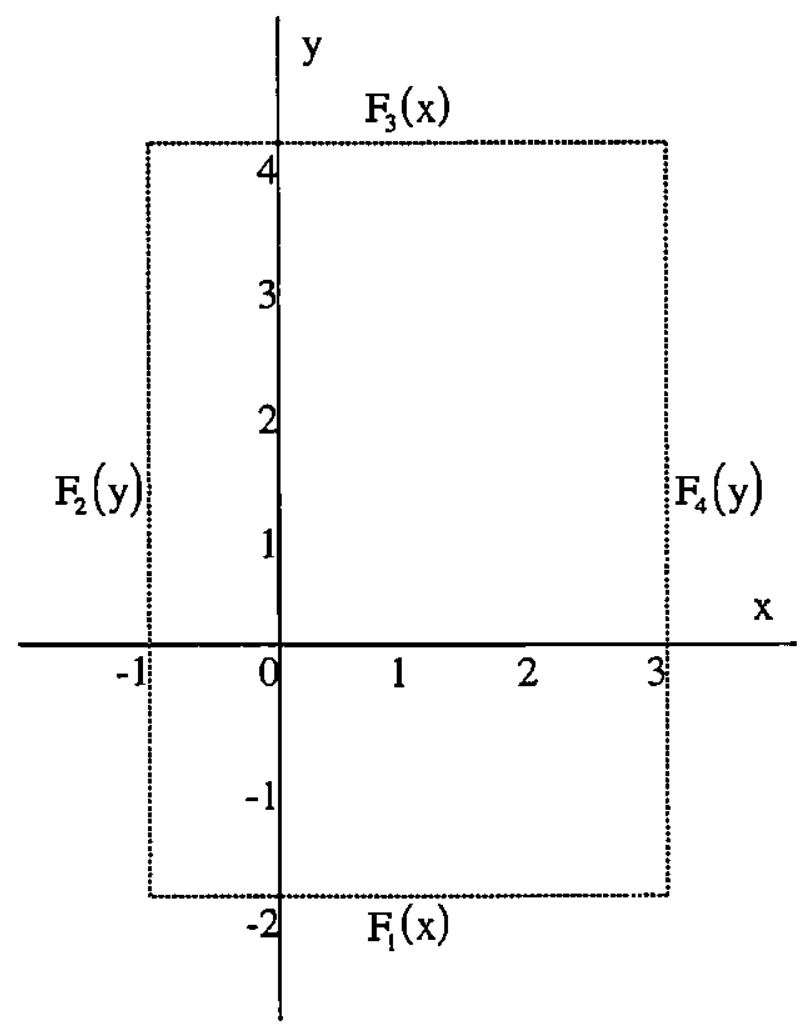

Fig.5.1 Domínio $\Omega$ com a representação das funções $F_{i}$ de fronteira com $i=1, \ldots, 4$

Está representado, na (Fig.5.2), o gráfico da solução $\mathrm{U}(\mathrm{x}, \mathrm{y})$ no domínio $[-1,3] \times[-2,4]$. 


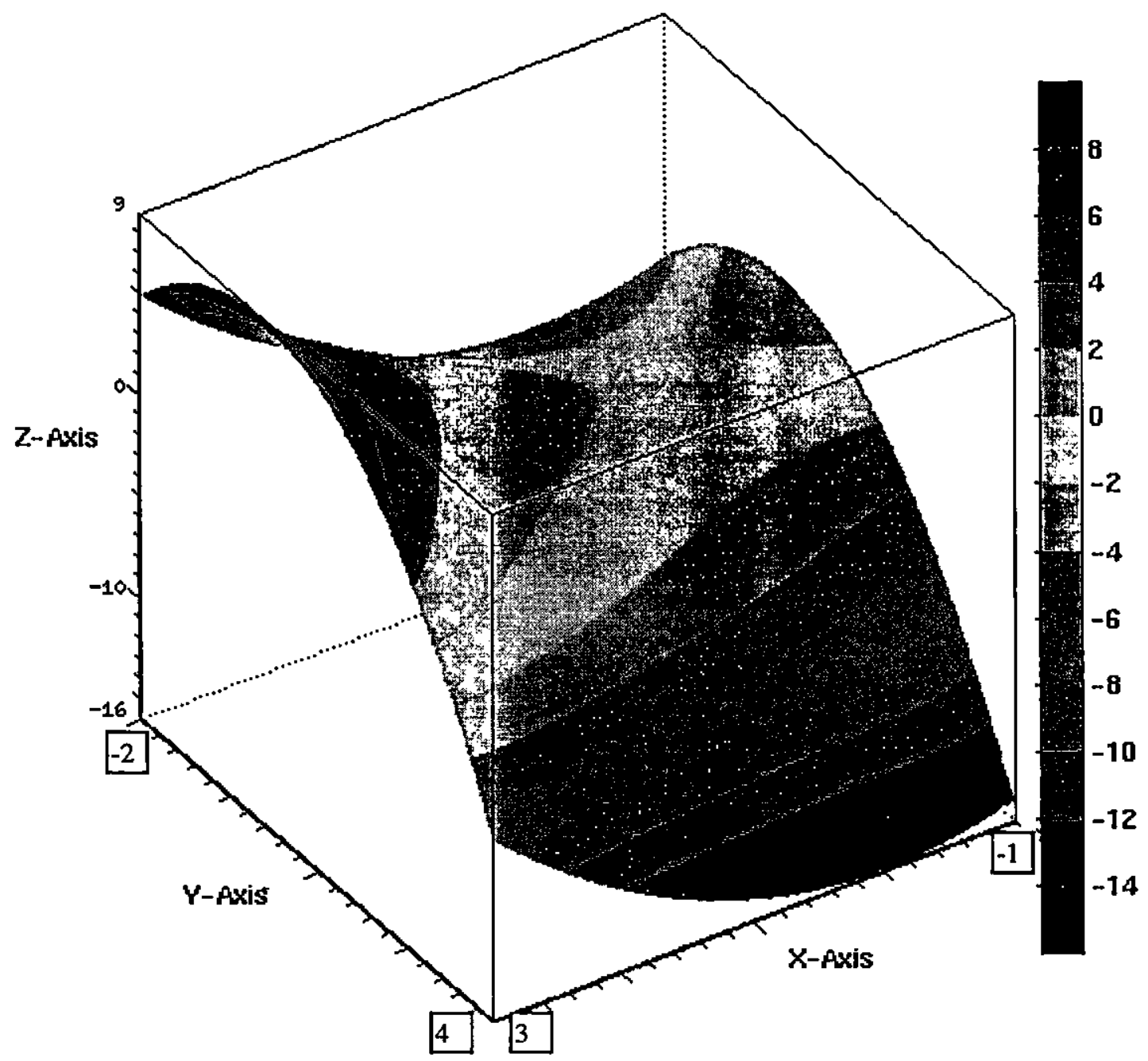

Fig.5.2 Gráfico em 3 dimensöes, relativo aos resultados do exemplo aplicado ao domínio $\Omega$.

\subsubsection{Comparação do desempenho em malhas de tamanhos variados}

A seguir, serão apresentados gráficos de desempenho para alguns dos testes realizados. Após a apresentação dos gráficos, será feito uma análise do desempenho do algoritmo para vários tipos de refinamento da malha relativo ao domínio apresentado na (Fig.5.1) . 


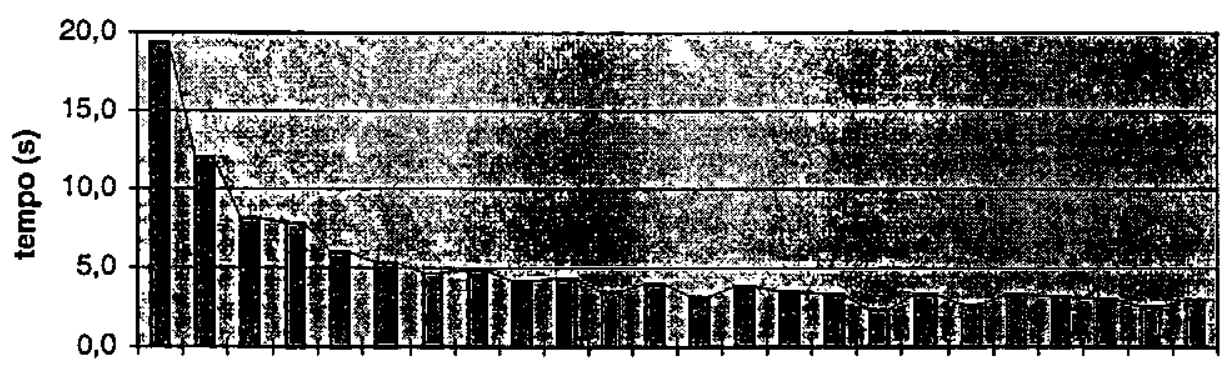

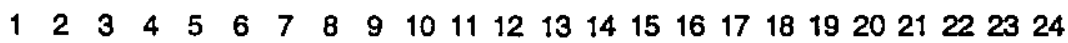

Nro. de processadores

Fig.5.3 Tempo de processamento de 1 a 24 processadores (malha 100 $\times 100$ )

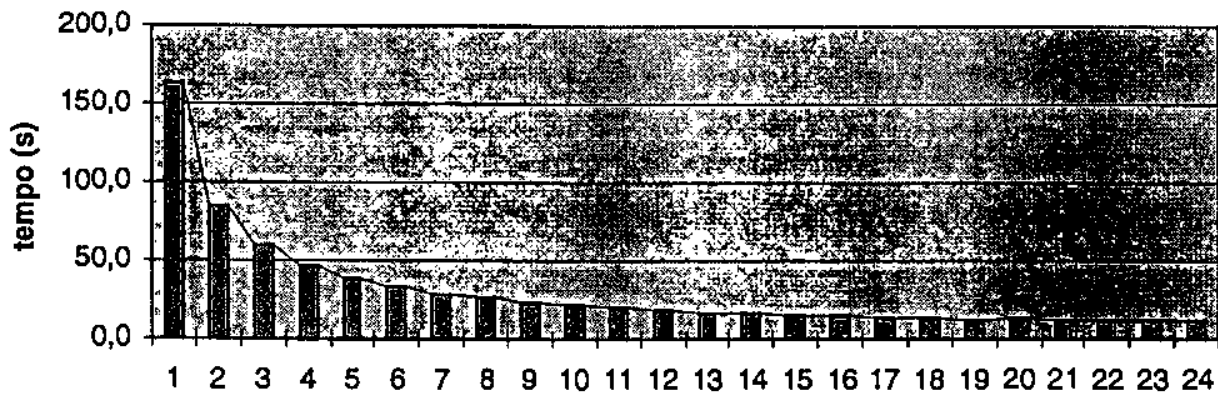

Nro. de processadores

Fig.5.4 Tempo de processamento de 1 a 24 processadores (malha 200×200)

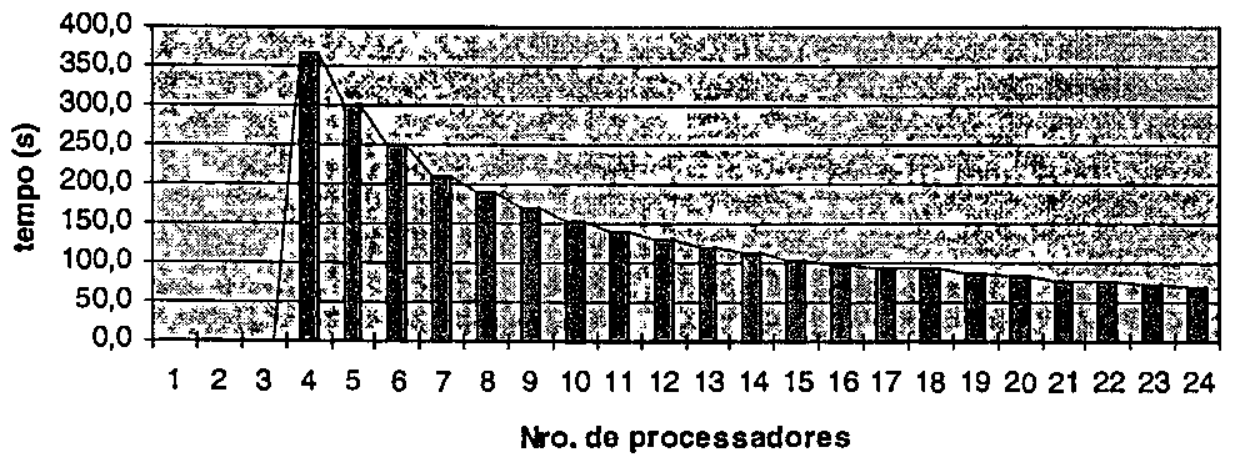

Fig.5.5 Tempo de processamento de 4 a 24 processadores (malha $400 \times 400$ ) 


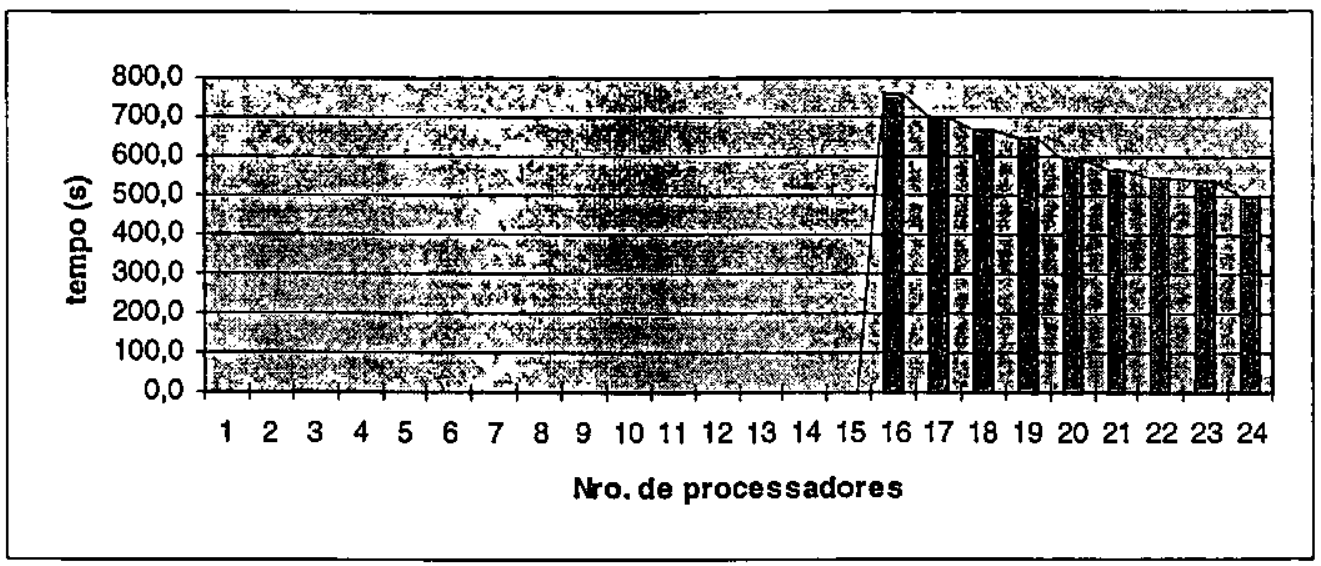

Fig.5.6 Tempo de processamento de 16 a 24 processadores (malha 800 7990 )

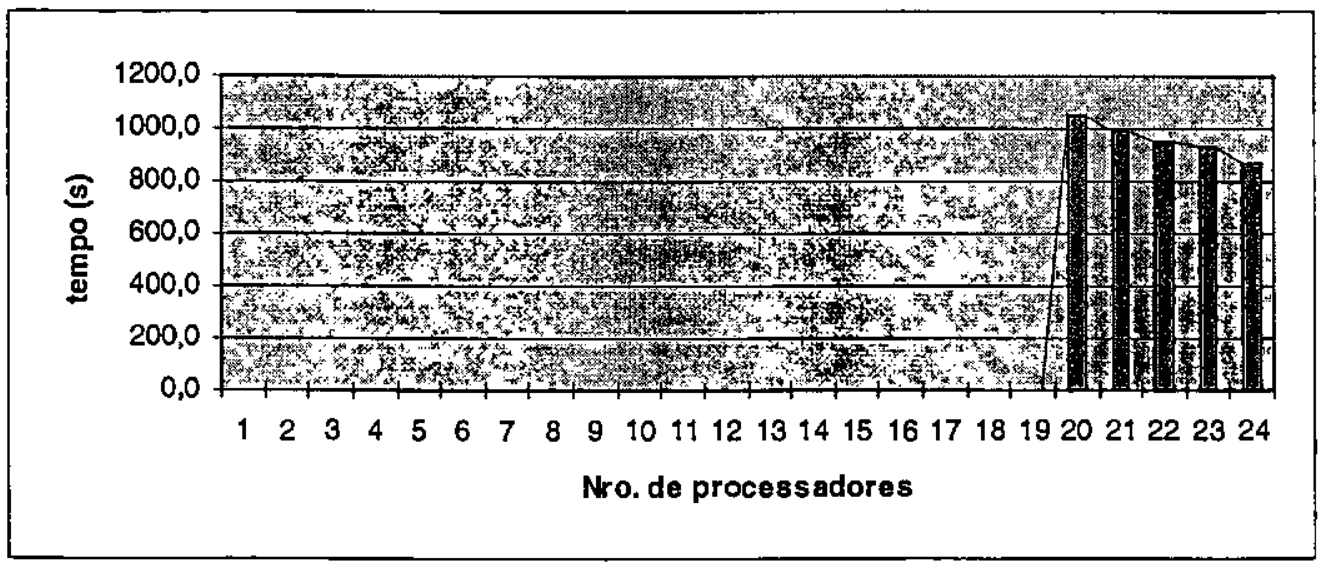

Fig.5.7 Tempo de processamento de 20 a 24 processadores (malha 890×890)

Nem sempre o aumento do número de processadores implica na melhoria do desempenho, de fato, observando as (Fig.5.3) até (Fig.5.7), a partir de um certo número de processadores não existe melhoria significativa e às vezes, até piora o desempenho. Isto deve-se ao fato de que, aumentando o número de processadores, aumenta a comunicação e diminui o processamento. A desvantagem no aumento de processadores ocorre quando o aumento no custo da comunicação iguala ou supera o ganho do custo de processamento. O que leva a concluir que: quanto maior for a malha, maior será o número de subdomínios ótimos para o processamento paralelo, o que determina 0 número ótimo de processadores. 
No processamento paralelo através da rede, cada processador corresponde a um computador que tem sua memória própria. Se o sistema gerado pela discretização for muito grande, para um número pequeno de processadores (computadores), o bloco de processamento destinado a cada processador pode superar a capacidade de sua memória. Aumentando o número de processadores, diminui-se o tamanho de cada bloco de forma a tornar possível o processamento. Nesse caso o aumento do número de processadores se dá em virtude do limite da capacidade de memória em cada computador e não da diminuição do tempo de processamento.

\subsubsection{Avaliação do tipo de divisão sobre a maiha (bidimensional e unidimensional)}

Para avaliar melhor o desempenho na divisão da malha em uma matriz de processadores (método apresentado nesta dissertação), foram executados testes para o mesmo algoritmo com divisão bidimensional e unidimensional. $\mathrm{Na}$ divisão unidimensional, toma-se o número de processadores na direção y igual a 1 .

Será apresentado, a seguir, um gráfico de comparação para três tamanhos diferentes de malhas.

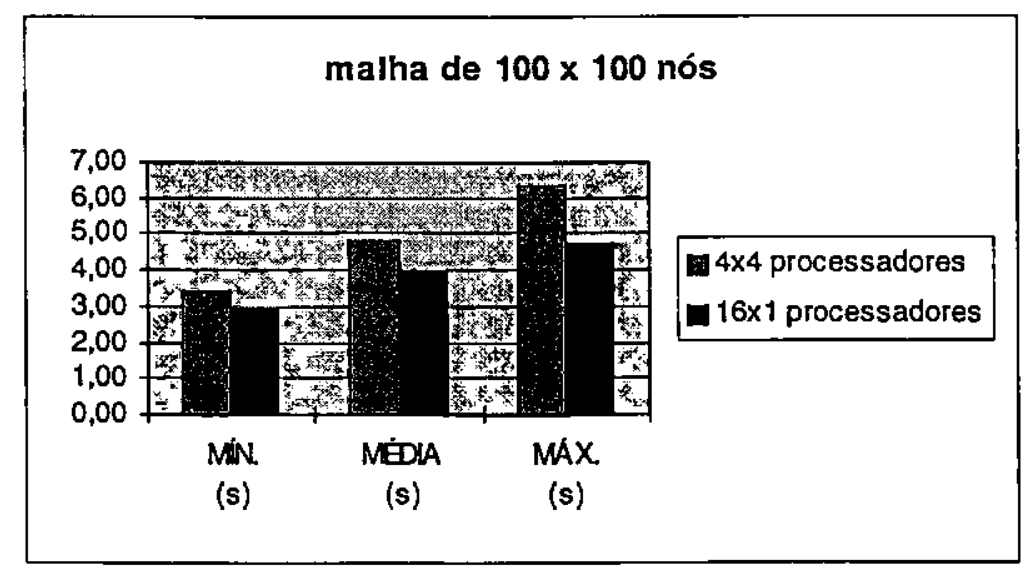

Fig.5.8 Desempenho para uma malha $100 \times 100$, distribuída para 16 processadores. 


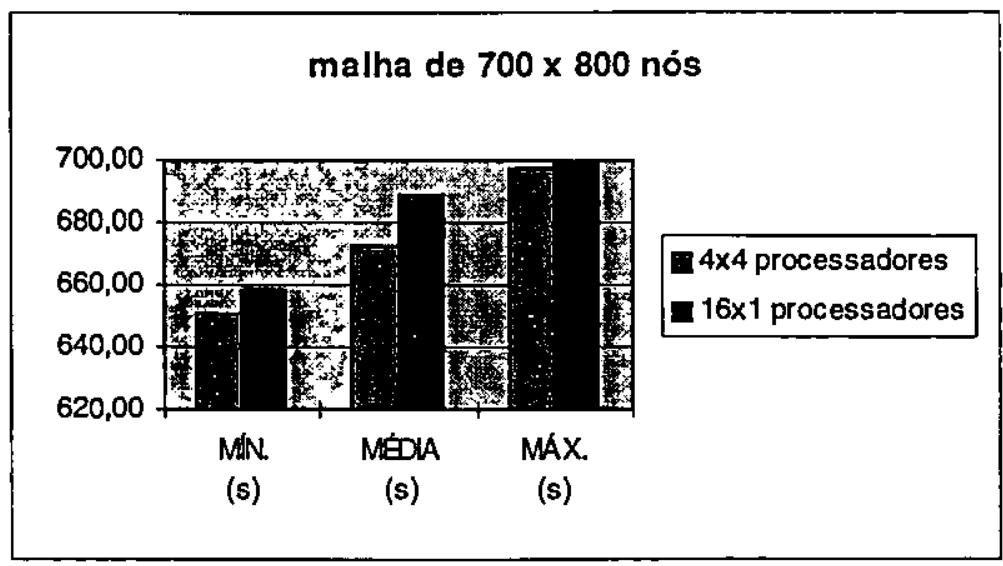

Fig.5.9 Desempenho para uma malha $700 \times 800$, distribuída para 16 processadores.

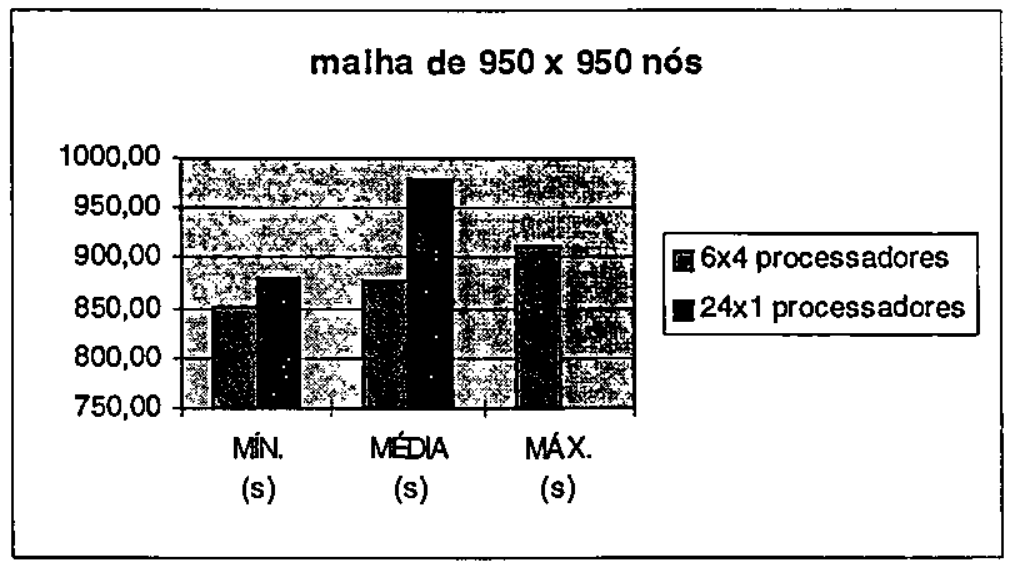

Obs.: O tempo máximo para a divisão $24 \times 1$ é de 2307.21 (s)

Fig.5.10 Desempenho para uma malha 950×950, distribuída para 24 processadores.

Pode ser observado, pela (Fig.5.8), que para uma malha $100 \times 100$, a distribuição bidimensional apresenta um desempenho inferior. Para uma malha 700×800 (Fig.5.9), esta distribuição já apresenta um pequeno ganho. No entanto, numa malha 950×950 (Fig.5.10), o desempenho para a distribuição bidimensional apresentou um ganho considerável. Não foi possível efetuar testes para malhas maiores devido à limitação de capacidade de memória da máquina utilizada. 
Com os resultados acima, observa-se que o método de distribuição proposto neste trabalho é mais adequado para malhas grandes.

\subsection{Comparação com o PIM em uma malha de 129×129 nós}

Para essa malha pequena, o desempenho do algoritmo apresentado neste trabalho não foi melhor em relação ao PIM. Segue abaixo um gráfico mostrando o desempenho do programa em questão, executado de 1 a 24 processadores, e o PIM executado de 2 a 8 processadores, sob as mesmas condiçōes.

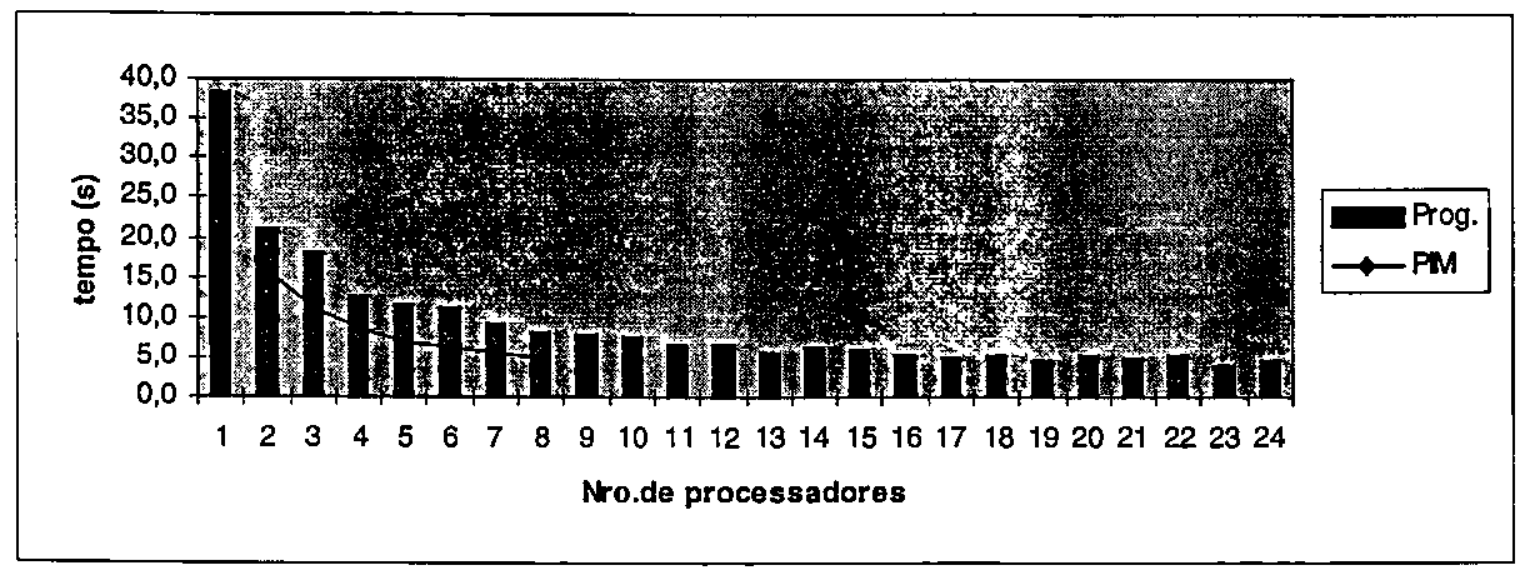

Fig.5.11 Tempo de processamento de 1 a 24 processadores (PIM: 2 a 8 proc.) (malha 129x129) 


\section{Conclusões e Propostas Futuras}

\subsection{Conclusões}

Nos testes realizados, o algoritmo implementado teve desempenho um pouco inferior ao PIM. Esta simulação foi feita, usando apenas um computador, utilizando processamento concorrente. Nas comunicações desse tipo, os dados enviados são transferidos rapidamente, o que faz com que o tempo gasto dependa mais do número de comunicação do que da quantidade de dados enviados. A implementação utilizada neste trabalho, que distribui a malha para os processadores de forma bidimensional, resulta numa menor quantidade de dados para serem comunicados. Assim, seria natural esperar que o desempenho fosse melhor. Porém, nesta implementação, apesar de ter havido uma diminuição na quantidade de dados a serem transferidos, o aumento na quantidade de comunicação não compensou para esse tipo de processamento.

Como mostra a (Fig.6.1), no algoritmo implementado, a ordem da matriz do sistema cresce de acordo com o aumento do número de processadores. Já, no PIM, a ordem da matriz é constante. Na simulação, a troca de dados ocorre dentro do mesmo computador, onde a comunicação é rápida. Nesse caso, compensa mais uma implementação que mantenha fixa a ordem da matriz do sistema, do que uma que diminui a quantidade de dados à serem comunicados com o preço do aumento no sistema. 


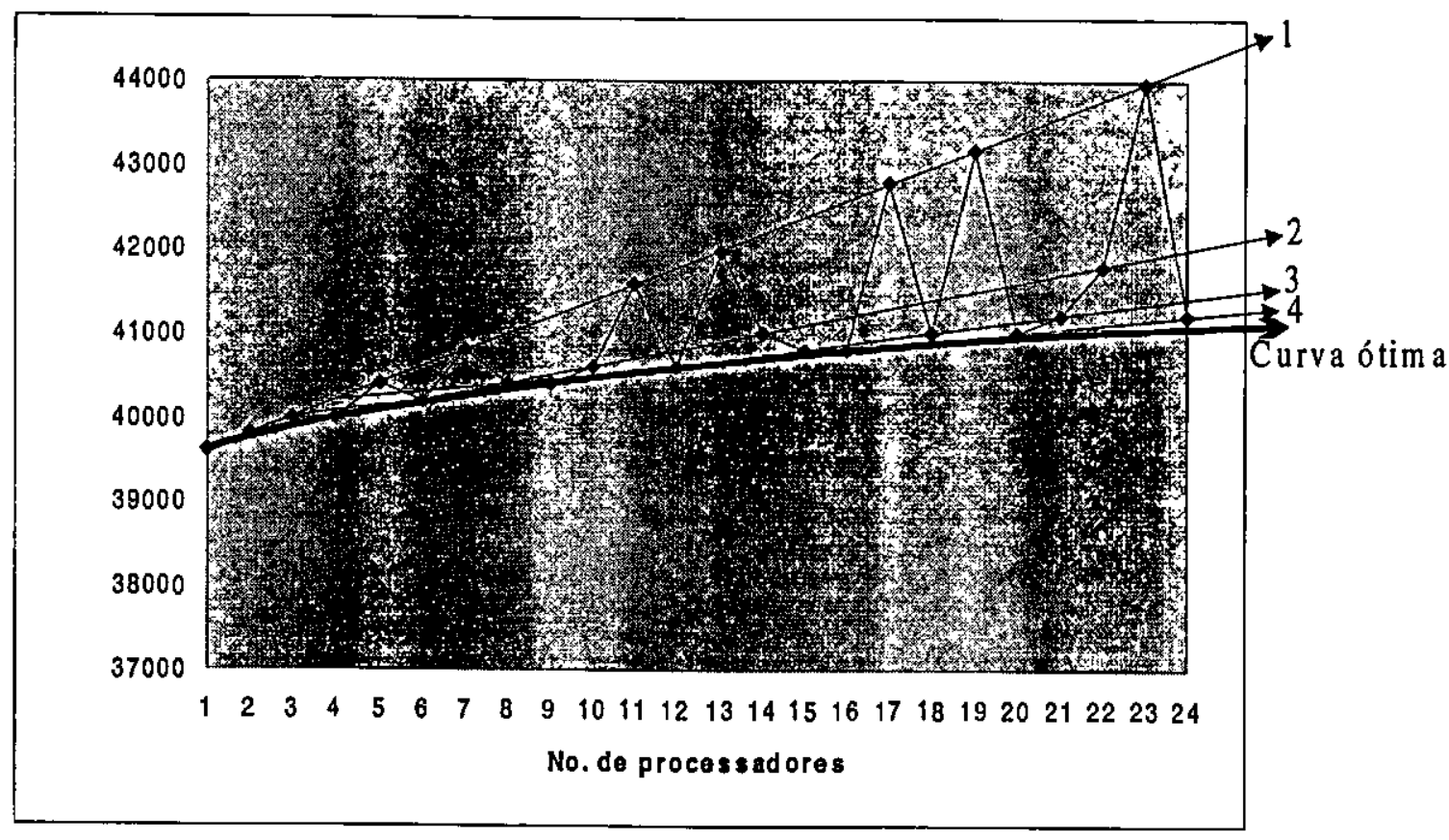

Fig.6.1 Crescimento da ordem da matriz numa malha de $200 \times 200$

$\mathrm{Na}$ (Fig.6.1), a $1^{2}$. semi-reta corresponde a um número primo de processadores, logo a malha será dividida em colunas verticais, isto é, uma divisão unidimensional. A $2^{\text {a }}$. semi-reta corresponde ao arranjo em que obtém-se duas linhas de processadores, a $3^{\text {a }}$. corresponde à três linhas, etc. Cada bloco de divisão, em relação ao número de linhas de processadores, produz um crescimento linear da ordem da matriz. O coeficiente angular das retas $1,2,3, \ldots$ decresce rapidamente na direção daquele da curva ótima. Esse fato é explicado pela diminuição da quantidade de nós compartilhados à medida que mais divisões verticais são inseridas e consequente desaceleração do crescimento da ordem da matriz $\hat{A}$. A linha ótima indicada na (Fig.6.1), representa a situação em que o crescimento da ordem da matriz, relativo ao número de processadores, é o menor possível. Observe que, para o gráfico acima, o número de divisões ótimo é atingido nos casos de 1, 4, 9 e 16 processadores, situação na qual os subdomínios são quadriláteros.

Esse tipo de comportamento ocorre também em relação a quantidade de dados a serem comunicados. Quanto mais próximo da divisão em quadriláteros, menor será a quantidade de nós compartilhados nos processadores. Observe no exemplo prático 
abaixo, a divisão de domínio para nove processadores comparando o arranjo unidimensional e bidimensional.
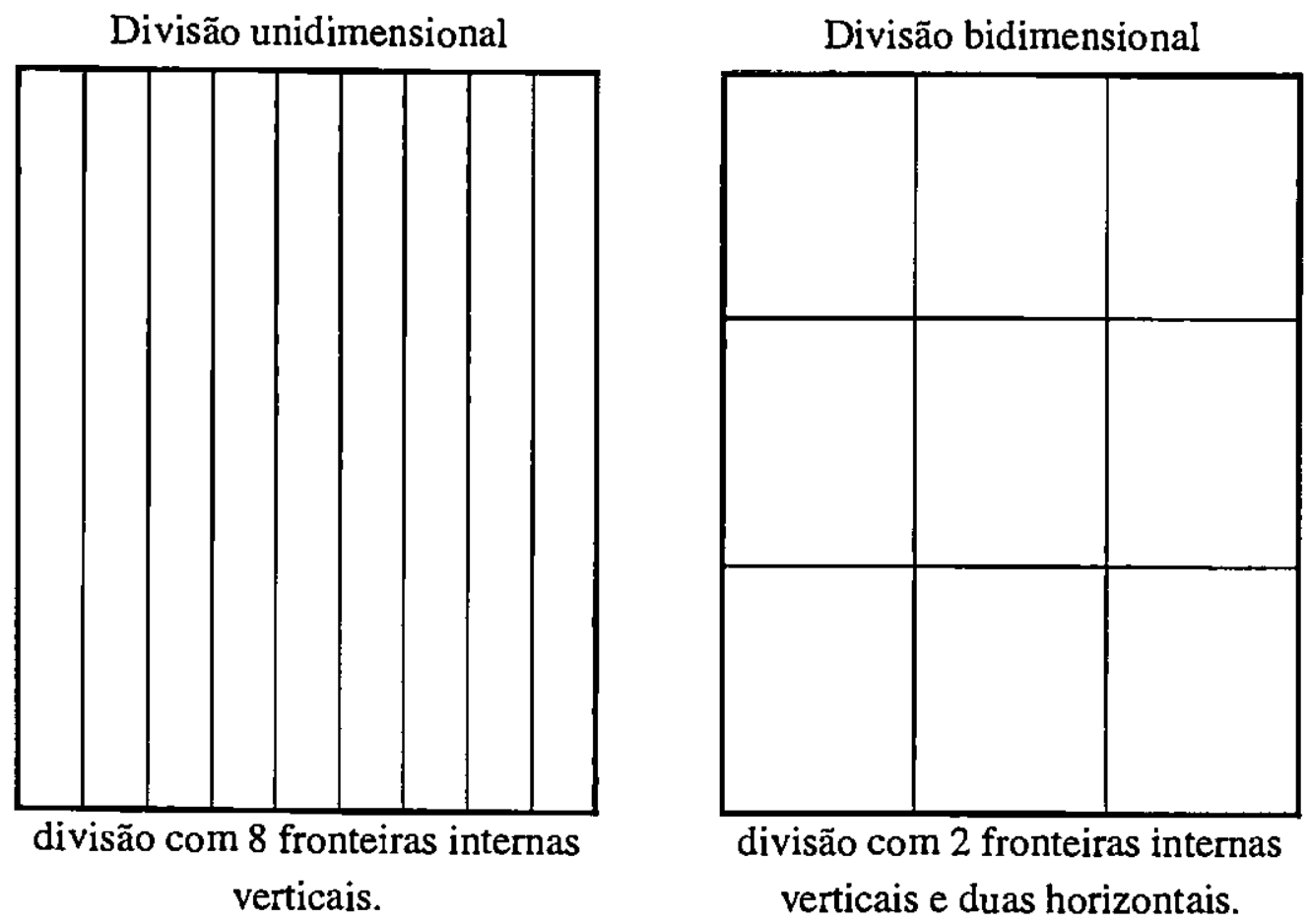

Fig.6.2 Fronteiras em uma malha, com divisões uni e bidimensionais, para nove processadores.

Se for considerado uma malha de $200 \times 200$ dividida para 9 processadores, como no exemplo da (Fig.6.2), a quantidade de nós comunicados para a divisão unidimensional será de 1592 , enquanto que, para a divisão bidimensional será de 796 , e portanto a metade.

Portanto, uma divisão ideal seria aquela em que, o número de processadores nos sentidos horizontal e vertical na malha, é próximo, seja em termos da ordem da matriz, ou da quantidade de dados a serem comunicados.

Em geral, para uma malha de grande porte, o aumento percentual, para o método utilizado, passa à ser insignificante. No caso de uma malha de $100 \times 100$ nós, o aumento na ordem da matriz para 24 processadores foi de $8 \%$ em relação ao processamento sequencial. Já, para uma malha de $200 \times 200$ nós (Fig.6.1), o aumento foi apenas de $4 \%$. 
Esta implementação tem como objetivo, resolver problemas de grande porte, utilizando o paralelismo através da rede. Neste tipo de paralelismo, existe mais disponibilidade de memória uma vez que, cada computador (processador) tem sua própria memória. Também não há grande limitação na quantidade de processadores. Devido ao custo benefício, em relação aos computadores com múltiplos processadores, o paralelismo através da rede está sendo cada vez mais utilizado. O problema deste tipo de paralelismo, é que o tempo de transferência de dados é maior, além disso, não depende muito da quantidade de comunicação logo, uma implementação melhor, seria aquela que tem menor quantidade de dados a serem comunicados. O algoritmo implementado aumenta a quantidade de comunicação, mas o total de dados comunicados são menores, o que na rede, pode tornar um ganho significativo de desempenho.

\subsection{Propostas Futuras}

Os testes apresentados na seção 5.2.2, comprovam a superioridade da divisão bidimensional sobre a unidimensional, implementado para o mesmo algoritmo sobre uma malha de grande porte. Uma das possíveis propostas futuras, seria a implementação da divisão bidimensional para um domínio irregular. Neste caso espera-se que, mesmo em malhas pequenas o desempenho seja superior à divisão unidimensional, pois, a bidimensional pode balancear cargas nos processadores de forma a atenuar grandes irregularidades que podem surgir em subdomínios que contenham partes da fronteira. $\mathrm{A}$ figura seguinte ilustra esta situação. 

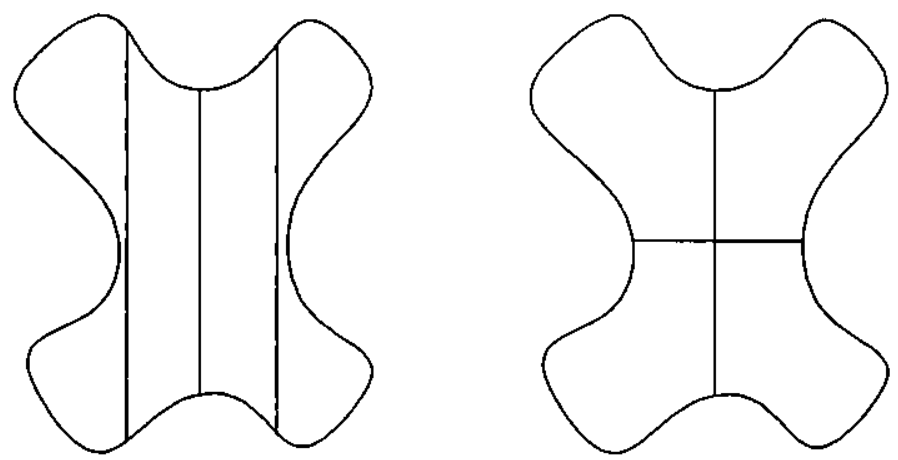

Fig.6.3 Domínio irregular dividido para quatro processadores.

Para a (Fig.6.3), têm-se o mesmo domínio com a divisão unidimensional à esquerda e bidimensional à direita. O domínio à esquerda apresenta dois subdomínios com alguma irregularidade, o que gera um aumento no custo de processamento desses subdomínios, que prejudica o desempenho do paralelismo. No domínio à direita estas irregularidades são amenizadas, pois, possui uma distribuição melhor da malha nos processadores. Isto pode garantir um melhor balanceamento de carga.

Uma outra proposta, seria a implementação bidimensional no PIM para reduziu a quantidade de dados a serem comunicados. Com isso, espera-se uma melhoria no desempenho objetivando o trabalho em malhas de grande porte.

Existem muitas pesquisas alternativas nesta área. Estas e outras propostas estimulam o desenvolvimento, contribuindo para o aperfeiçoamento dos métodos e descoberta de novas técnicas. 


\section{Bibliografia}

[01] CUMINATO, J.A.; MENEGUETTE $\mathrm{J}^{\mathrm{r}}$., M. - Discretização de Equações Diferenciais Parciais: Técnicas de Diferenças Finitas, XIX CNMAC, Goiânia, 1996.

[02] CUNHA, R.D.; HOPKINS, T.; PIM 1.1 The Parallel Iterative Methods package for Systems of Linear Equations User's Guide (Fortran 77 version), Computing Laboratoty University of Kent at Canterbury United Kingdom.

[03] DONGARRA, J.J.; DUFF, I.S.; SORENSEN, D.C.; VORST, H.A. - Solving Linear Systems on Vector and Shared Memory Computers, Society for Industrial and Applied Mathematics, Philadelphia, 1991.

[04] FREEMAN, T.L.; PHILLIPS,C. - Parallel Numerical Algorithms, Prentice Hall International series in computer science, 1996.

[05] FRITZSCHE, H. - Programação Não Linear, Edgard Blücher Ltda: Ed. da Universidade de São Paulo, São Paulo, 1978.

[06] GALlIVAN, K.A.; HEATH, M.T. - ParalleI Algorethms for Matrix Computations, University City Science Center, Philadelphia, 1994.

[07] GOLUB, G.H.; VAN LOAN, C.F. - Matrix Computations Second Edition, John Hopkins University Press, 1993.

[08] JEAN, P.A. - Approximation of Elliptic Boundary-Value Problems, John Wiley \& Sons Ltda., 1972.

[09] HOLTER, W.H.; NAVON, I.M.; OPPE, T.C. - Parallelizable preconditioned Conjugate Gradient methods for the Cray Y-MP and the TMC CM-2, Technical report, Supercomputer Computations Research Institute, Florida State University, 1991.

[10] LUENBERGER, D.G. - Linear and Nonlinear Programming Second Edition, Addison, Wesley, 1984.

[11] MITCHELL, A.R. - Computational Methods in Partial Differential Equations, John Wiley \& Sons Ltda., 1969. 
[12] NOTAY, Y. - An efficient parallel discrete PDE solver, Parallel Computing 21 (1995) $1725-1748$.

[13] NOTAY,Y. - Parallel implementation of preconditioned iterative schemes by means of overlapping decomposition, submitted for publication, 1995.

[14] SHEWCHUK, J.R. - An Introduction to the Conjugate Gradient Method Without the Agonizing Pain, School of Computer Science Carnegie Mellon University Pittsburgh, 1994.

[15] SMTTH, G.D. - Numerical Solution of Partial Defferential Equations: Finite Difference Methods, $2^{\mathrm{a}}$. ed., Oxford University Press, 1978. 